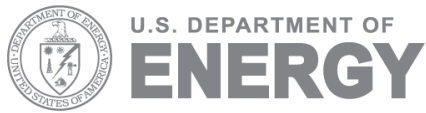

Prepared for the U.S. Department of Energy under Contract DE-AC05-76RL01830

\title{
Analysis of the Hydrologic Response Associated With Shutdown and Restart of the 200- ZP-1 WMA T Tank Farm Pump-and- Treat System
}

\author{
F. A. Spane
}

August 2008

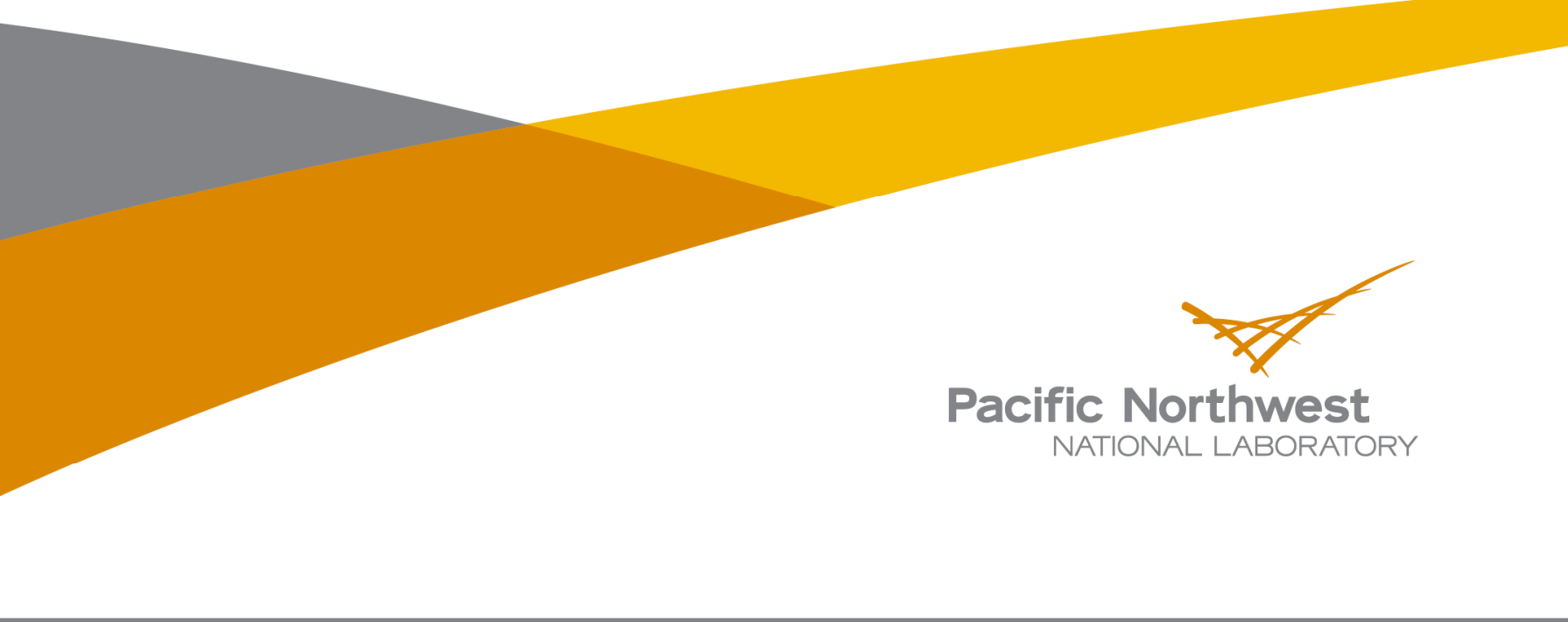




\title{
DISCLAIMER
}

This report was prepared as an account of work sponsored by an agency of the United States Government. Neither the United States Government nor any agency thereof, nor Battelle Memorial Institute, nor any of their employees, makes any warranty, express or implied, or assumes any legal liability or responsibility for the accuracy, completeness, or usefulness of any information, apparatus, product, or process disclosed, or represents that its use would not infringe privately owned rights. Reference herein to any specific commercial product, process, or service by trade name, trademark, manufacturer, or otherwise does not necessarily constitute or imply its endorsement, recommendation, or favoring by the United States Government or any agency thereof, or Battelle Memorial Institute. The views and opinions of authors expressed herein do not necessarily state or reflect those of the United States Government or any agency thereof.

\author{
PACIFIC NORTHWEST NATIONAL LABORATORY \\ operated by \\ BATTELLE \\ for the \\ UNITED STATES DEPARTMENT OF ENERGY \\ under Contract DE-ACO5-76RL01830
}

Printed in the United States of America
Available to DOE and DOE contractors from the
Office of Scientific and Technical Information,
P.O. Box 62, Oak Ridge, TN 37831-0062;
ph: (865) 576-8401
fax: (865) 5765728
email: reports@adonis.osti.gov

\author{
Available to the public from the National Technical Information Service, \\ U.S. Department of Commerce, 5285 Port Royal Rd., Springfield, VA 22161 \\ ph: (800) 553-6847 \\ fax: (703) 605-6900 \\ email: orders@nits.fedworld.gov \\ online ordering: http://www.ntis.gov/ordering.htm
}




\section{Analysis of the Hydrologic Response Associated With Shutdown and Restart of the 200-ZP-1 WMA T Tank Farm Pump-and-Treat System}

FA Spane

August 2008

Prepared for

the U.S. Department of Energy

under Contract DE-AC05-76RL01830

Pacific Northwest National Laboratory

Richland, Washington 99352 


\section{Abstract}

A number of programs have been implemented on the Hanford Site that use the pumping and treatment of contaminated groundwater as part of their remediation strategy. The implementation of remedial pump-and-treat systems results in hydraulic pressure responses both areally and vertically (i.e., with depth) within the pumped aquifer. The area within the aquifer affected by the pump-and-treat system (i.e., radius of influence) is commonly estimated based on detecting associated water-level responses within surrounding monitor wells. Natural external stresses, such as barometric pressure fluctuations, however, can have a discernible impact on well water-level measurements. These temporal barometric effects may significantly mask water-level responses within more distant wells that are only slightly affected $(\leq 0.10 \mathrm{~m})$ by the treatment system. External stress effects, therefore, can lead to erroneous indications of the radius of influence of the imposed pump-and-treat remediation activities and can greatly diminish the ability to analyze the associated well responses for hydraulic property characterization. When these extraneous influences are significant, adjustments or removal of the barometric effects from the test-response record may be required for quantitative hydrologic assessment.

This report examines possible hydrologic effects of pump-and-treat remediation actions and provides a detailed analysis of water-level measurements for selected 200-ZP-1 T Tank Farm pump-and-treat system monitor wells during a recent shutdown (May 1, 2008) and restart activity (June 4, 2008) involving extraction well 299-W11-46. Specifically, this report 1) applies to recently developed methods for removing barometric pressure fluctuations from well water-level measurements to enhance the detection of pump-and-treat system effects at selected monitor wells, 2) analyzes the barometric-corrected well water-level responses to determine large-scale hydraulic properties, and 3) assesses characteristics and conditions that influence hydrologic responses (both laterally and vertically) associated with pumpand-treat systems. In all, the $10 \mathrm{~T}$ Tank Farm wells monitored during this investigation provided results for six composite and individual interwell tests for unconfined aquifer characterization. These large-scale aquifer characterization results will be utilized for optimization and site selection of additional extraction wells within the WMA T Tank Farm pump-and-treat system. 



\section{Summary}

As noted in a previous study by Spane and Thorne (2000), remedial pump-and-treat systems impose variable hydrologic pressure responses both areally and vertically (i.e., with depth) within the affected aquifer. The area within the aquifer influenced by the pump-and-treat system (i.e., radius of influence) is commonly determined by detecting associated water-level responses within surrounding monitor wells. These discernible hydrologic responses can also be analyzed, under favorable conditions, to provide estimates of aquifer hydraulic properties. The characterization of hydraulic properties is important for evaluating groundwater-flow and transport characteristics of the aquifer system. An inherent assumption in the hydraulic test analysis process, however, is that the well water-level responses analyzed are due solely to the imposed hydrologic stress. Natural external stresses, such as barometric pressure fluctuations, can have a discernible impact on well water-level measurements. These temporal barometric effects may significantly mask water-level responses within more distant wells that are only slightly affected $(\leq 0.10 \mathrm{~m})$ by the pump-and-treat system. External stress effects, therefore, can greatly diminish the ability to analyze the associated well responses for hydraulic property characterization and possibly lead to erroneous indications of the radius of influence of the imposed pump-and-treat system. If they are significant, the barometric effects from the test-response record may then need to be removed from the test-response record to quantify hydraulic properties and assess the area of influence of the pump-andtreat system.

Previous studies by Rasmussen and Crawford (1997) and Spane $(1999,2002)$ have demonstrated that barometric pressure fluctuations can be effectively removed with a multiple-regression deconvolution technique, which significantly improves the detection and analysis of hydrologic stresses imposed by pumping wells that are observed at surrounding monitor-well locations. This method was successfully applied in removing the obscuring effects of barometric pressure fluctuations from water-level responses observed at nine monitor well locations associated with the shut-down and re-start of Waste Management Area (WMA) T Tank Farm well 299-W11-46 that occurred on May 1 and June 4, 2008, respectively. The barometrically corrected well responses clearly indicate that the hydrologic radius-of-influence of WMA T Tank Farm extraction well 299-W11-46 extends beyond the most distant surrounding monitor well included in this study (i.e., $100.4 \mathrm{~m}$; well 299-W11-23). The barometric correction of well water-level responses also facilitated hydrologic property characterization, which would not have been possible using uncorrected, observed well responses.

The analysis of individual barometrically corrected well responses associated with the WMA T Tank Farm well 299-W11-46 restart period (i.e., June 4 to July 7, 2008) provided results for six composite and individual interwell tests for unconfined aquifer characterization. These large-scale aquifer characterization results will be utilized for optimization and site selection of additional extraction wells within the WMA T Tank Farm pump-and-treat system. Inter-well hydraulic property estimates for transmissivity ranged from 300 to $475 \mathrm{~m}^{2}$ /day, and hydraulic conductivity ranged from 6.11 to $9.69 \mathrm{~m} / \mathrm{d}$ (geometric mean $8.01 \mathrm{~m} / \mathrm{d}$ ). The calculated geometric mean value from the large-scale re-start analysis is slightly higher than the geometric mean value of $5.22 \mathrm{~m} /$ day (range: 1.24 and $28.1 \mathrm{~m} /$ day) obtained from single-well slug test characterizations performed for 12 WMA T Tank Farm wells, as reported in Spane 
and Newcomer (2008) and Spane (2008). Estimates obtained for vertical anisotropy $\left(\mathrm{K}_{\mathrm{D}}=\mathrm{K}_{\mathrm{v}} / \mathrm{K}_{\mathrm{h}}\right)$ ranged from 0.02 to 0.09 . These values are within the anticipated range for layered sedimentary units like the Ringold Formation Unit E, which the pump-and-treat and monitor well system has completed. No quantitative estimates for horizontal anisotropy were possible from the inter-well tests. This was due to the generally restricted azimuth deployment (i.e., north-south) of the WMA T Tank Farm monitor well locations. The relative correspondence of hydraulic property results for composite and individual interwell tests, however, suggests that there is little large-scale horizontal anisotropy within the unconfined aquifer system at this location.

Estimates for storativity ranged from $1.8 \mathrm{E}-3$ to $1.9 \mathrm{E}-2$. This yields an equivalent specific storage value range of 3.7E-5 to 3.9E-4 m $\mathrm{m}^{-1}$, based on an average aquifer thickness of $49 \mathrm{~m}$. Estimates obtained for specific yield ranged from $\geq 0.01$ to $\geq 0.03$ and represent lower bounding values for this hydrologic parameter. The lower bounding values are lower than expected (i.e., between 0.05 and 0.15 ) for this hydrogeologic unit. The reason for this apparent discrepancy is related to the dependence of this hydrologic parameter on late-time test data, which are highly impacted by water-level trends (which are difficult to resolve with high degree of certainty within a dynamically perturbed hydrologic system). Additionally, the partial aquifer penetration aspect of the WMA T Tank Farm well completions greatly extends the time requirement for fully resolving specific yield for hydrologic test conditions. For these reasons, estimates for specific yield obtained from the restart analyses are considered to be less reliable in comparison to estimates derived for transmissivity and hydraulic conductivity.

Operation of the pump-and-treat system induces both horizontal and vertical groundwater-flow components within the aquifer. Based on the investigation performed, it is likely that the pump-and-treat system imposes a discernible hydrologic response over a significant area surrounding the remediation facility (i.e., $>300 \mathrm{~m}$ for pumping durations of a month or more). The distance, or radius of influence, is a function of a number of physical factors and characteristics of test-facility operations. Important physical factors include aquifer properties (i.e., hydraulic conductivity, vertical anisotropy, specific yield, aquifer thickness) and well/aquifer completion relationships (i.e., partial penetration aspect). Characteristics of test-facility operations include the location, duration, magnitude, and variability of groundwater extraction within the aquifer.

\section{Summary References}

Rasmussen TC and LA Crawford. 1997. "Identifying and removing barometric pressure effects in confined and unconfined aquifers." Ground Water 35(3):502-511.

Spane FA, Jr. 1999. Effects of barometric fluctuations on well water-level measurements and aquifer test data. PNNL-13078, Pacific Northwest National Laboratory, Richland, Washington.

Spane FA, Jr. 2002. "Considering barometric pressure in groundwater flow investigations." Water Resources Research 38(6), 14:1-18. 
Spane FA. 2008. Aquifer testing recommendations for supporting phase II of the T-Area technetium-99 data objectives process - letter report. PNNL-17433, Pacific Northwest National Laboratory, Richland, Washington.

Spane FA., Jr., and DR Newcomer. 2008. Results of detailed hydrologic characterization tests - fiscal and calendar year 2005. PNNL-17348, Pacific Northwest National Laboratory, Richland, Washington.

Spane FA and PD Thorne. 2000. Analysis of the hydrologic response associated with shutdown and restart of the 200-ZP-1 pump-and-treat system. PNNL-13342, Pacific Northwest National Laboratory, Richland, Washington. 



\section{Acknowledgments}

Several Pacific Northwest National Laboratory (PNNL) staff members provided contributions to this report's preparation. Technical peer review and editorial comments were provided by P.D. Thorne and Wayne Cosby, respectively. D. R. Newcomer and R. E. Clayton provided field support for water-level responses from selected monitoring wells during this investigation.

A number of people in addition to PNNL staff also provided significant contributions for well data and processing that were used in the development of this report. In particular, the author is indebted to the efforts of R. S. Edrington of Fluor Hanford, Inc. (FH) for his efforts in this regard. In addition, M. E. Byrnes, L. C. Swanson, and S. C. Adams of FH, and M. Tonkin of S. S. Papadopulos and Associates, Inc. also provided technical peer review comments. 



\section{Acronyms}

$\begin{array}{ll}\text { EPA } & \text { U.S. Environmental Protection Agency } \\ \text { LED } & \text { light-emitting diode } \\ \text { MSL } & \text { mean sea level } \\ \text { OU } & \text { operable unit } \\ \text { PNNL } & \text { Pacific Northwest National Laboratory } \\ \text { ROD } & \text { Record of Decision } \\ \text { UHF } & \text { ultra-high frequency } \\ \text { USB } & \text { universal serial bus } \\ \text { WMA } & \text { Waste Management Unit }\end{array}$





\title{
Nomenclature
}

\author{
$\mathrm{b}=$ aquifer thickness; $\mathrm{L}$ \\ $D_{a}=$ vertical pneumatic diffusivity of the vadose zone; $L^{2} / T$ \\ $\mathrm{K}_{\mathrm{D}}=$ vertical anisotropy $\left(\mathrm{K}_{\mathrm{v}} / \mathrm{K}_{\mathrm{h}}\right)$; dimensionless \\ $\mathrm{K}_{\mathrm{h}}=$ hydraulic conductivity in the horizontal direction; $\mathrm{L} / \mathrm{T}$ \\ $\mathrm{K}_{\mathrm{v}}=$ hydraulic conductivity in the vertical direction; $\mathrm{L} / \mathrm{T}$ \\ $\mathrm{Q}=$ pumping rate; $\mathrm{L}^{3} / \mathrm{T}$ \\ $r_{c}=$ radius of well casing; $L$ \\ $\mathrm{r}_{\mathrm{o}}=$ radial distance from pumped well to monitor well location; $\mathrm{L}$ \\ $\mathrm{r}_{\mathrm{w}}=$ radius of well; $\mathrm{L}$ \\ $\mathrm{s}=$ drawdown; $\mathrm{L}$ \\ $\mathrm{S}=$ storativity; dimensionless \\ $\mathrm{S}_{\mathrm{y}}=$ specific yield; dimensionless \\ $\mathrm{T}=$ transmissivity; $\mathrm{L}^{2} / \mathrm{T}$ \\ $\sigma=$ dimensionless unconfined aquifer parameter, equal to $\mathrm{S} / \mathrm{S}_{\mathrm{y}}$
}





\section{Contents}

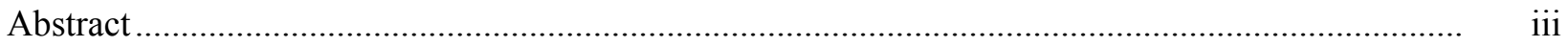

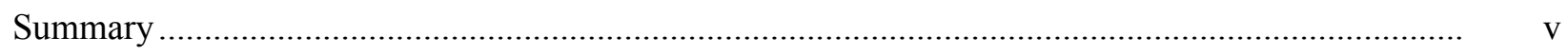

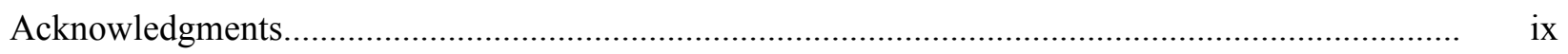

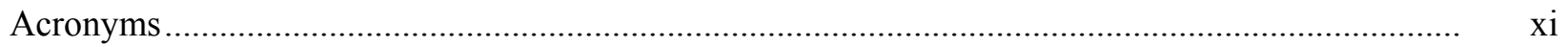

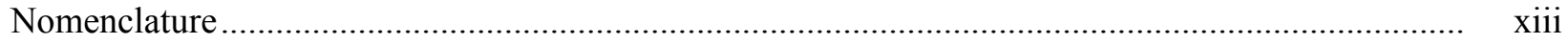

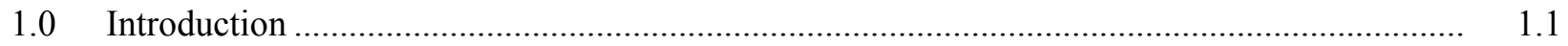

$2.0 \quad$ 200-ZP-1 WMA T Tank Farm Pump-and-Treat System.................................................... 2.1

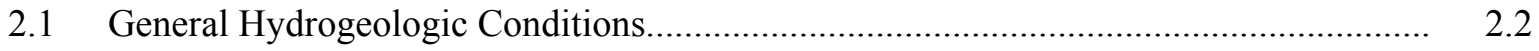

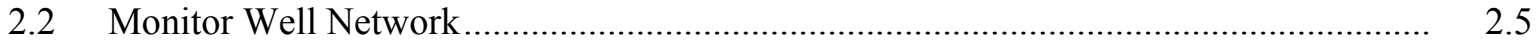

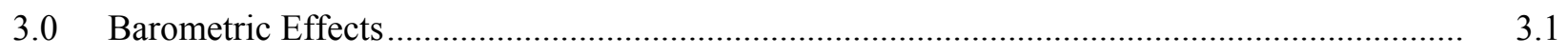

3.1 Baseline Well Water-Level Response ................................................................... 3.4

3.2 Multiple-Regression Removal Method ................................................................... 3.6

3.3 Corrected Baseline Well Water-Level Response ......................................................... $\quad 3.7$

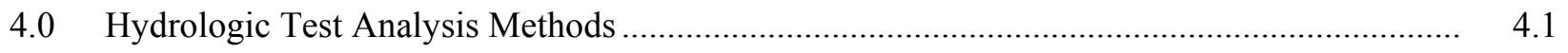

4.1 Diagnostic Analysis and Derivative Plots .................................................................. 4.1

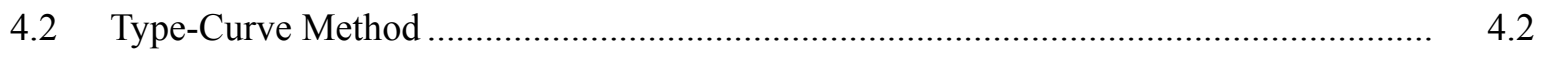

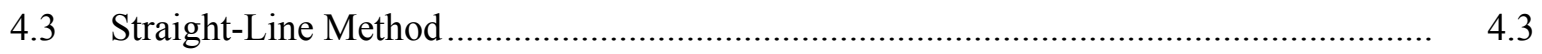

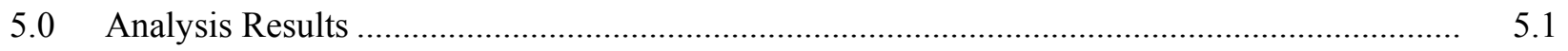

$5.1 \quad$ Near Well Field Analysis .......................................................................................... 5.1

5.1.1 Composite Analysis: Wells 299-W11-46 and 299-W11-39 …....................... 5.2

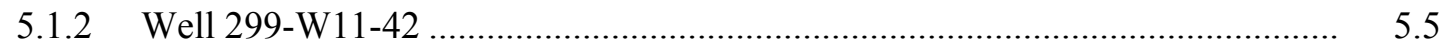

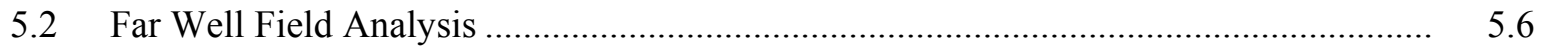

5.2.1 Composite Analysis: Wells 299-W10-23 and 299-W10-24 _.......................... 5.6

5.2.2 Composite Analysis: Wells 299-W11-40 and 299-W11-41 ........................... 5.7

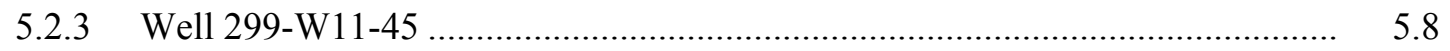

5.2.4 Well 299-W11-47 _............................................................................ 5.9

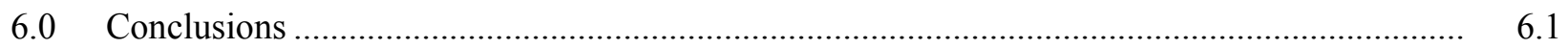

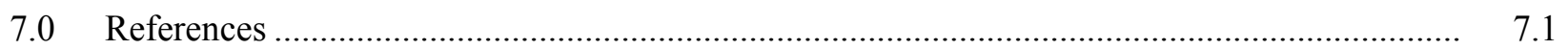


Appendix A: Daily Groundwater Pumping Rate Data for WMA T Tank Farm Extraction Wells: 299-W11-45 and 299-W11-46.

Appendix B: Observed Baseline Well Water-Level Response Plots

Appendix C: Barometric-Corrected Baseline Well Water-Level Response Plots

\section{Figures}

2.1. Location Map Showing T Tank Farm Well Sites

2.2. Generalized North-South Geologic Cross Section along the Eastern Boundary of WMA

T Tank Farm

2.3. Long-Term Well Water-Level Elevation Decline Monitored at Selected WMA T Tank Farm Monitor Wells

3.1. Well Barometric Pressure-Response Models

3.2. Diagnostic Composite Barometric Response Model for Wellbore-Storage/Unconfined Aquifer System.

3.3. Comparison of Predicted Well Water-Level Elevation Versus Aquifer Water-Table Elevation and Hydraulic Head Response, Based on Observed Atmospheric Pressure Measurements.

3.4. Observed Baseline Well Water-Level Response: Well 299-W10-24.

3.5. Water-Level Barometric Response Patterns for Selected WMA T Tank Farm Monitor Wells

3.6. Observed and Corrected Baseline Well Water-Level Response: Well 299-W10-24 .....

4.1. Characteristic Log-Log Drawdown and Drawdown Derivative Plots for Various Hydrogeologic Formation and Boundary Conditions.

5.1. Comparison of Observed and Corrected Drawdown Response: Well 299-W10-24 ....

5.2. Comparison of Corrected Drawdown and Corrected Recovery Response:

Well 299-W10-24

5.3. Composite Multi-Well Corrected Drawdown Analysis: Wells 299-W11-39 and 299-W11-46.. 
5.4. Combined Type-Curve and Derivative Plot Analysis of Corrected Drawdown Test Data: Well 299-W11-42.....

5.5. Composite Multi-Well Corrected Drawdown Analysis: Wells 299-W10-23 and 299-W10-24.

5.6. Composite Multi-Well Corrected Drawdown Analysis: Wells 299-W11-40 and 299-W11-41

5.7. Combined Type-Curve and Derivative Plot Analysis of Corrected Drawdown Test Data: Well 299-W11-45

5.8. Combined Type-Curve and Derivative Plot Analysis of Corrected Drawdown Test Data: Well 299-W11-47

5.9. Combined Type-Curve and Derivative Plot Analysis of Corrected Drawdown Test Data: Well 299-W11-48

\section{Tables}

2.1. Pertinent Survey, Completion, and Distance Information for T Tank Farm Wells .................. 2.7

5.1. Test Analysis Summary: Near Well Field .......................................................................

5.2. Test Analysis Summary: Far Well Field .......................................................................... 


\subsection{Introduction}

A number of programs have been implemented on the Hanford Site that use the pumping and treatment of contaminated groundwater as part of their remediation strategy (e.g., DOE/RL 2000). The implementation of remedial pump-and-treat systems results in hydraulic pressure responses both areally and vertically (i.e., with depth) within the pumped aquifer system. The area within the aquifer affected by the pump-and-treat system (i.e., radius of influence) is commonly estimated based on detecting associated water-level responses within surrounding monitor well locations. Discernible hydrologic responses can also be analyzed, under favorable conditions, to provide estimates of aquifer hydraulic properties. The hydraulic response caused by a pump-and-treat system provides a large-scale aquifer test over a longer duration than is practical for standard hydrologic tests. Analyzing large-scale, hydrologic test responses can result in improved estimates of hydraulic properties and provide better estimates for optimum design and operation of a remediation facility.

An inherent assumption in hydraulic test analysis is that the well water-level responses analyzed are caused solely by the imposed hydrologic stress. Natural external stresses such as barometric pressure fluctuations, however, can have a discernible impact on well water-level measurements. These temporal barometric effects may significantly mask water-level responses within more distant wells that are only slightly affected $(\leq 0.10 \mathrm{~m})$ by the pump-and-treat system. External stress effects, therefore, can greatly diminish the ability to analyze the associated well responses for hydraulic property characterization. External stresses can also lead to erroneous indications of the radius of influence (i.e., under-estimate) of the imposed pump-and-treat system remediation activities. When these extraneous influences are significant, adjustments or removal of the barometric effects from the test-response record may be required for quantitative hydraulic property determination and area-of-influence assessment.

This report examines the hydrologic effects of Waste Management Area (WMA) T Tank Farm pumpand-treat remediation activities within the underlying unconfined aquifer system and analyzes water-level measurements for selected 200 West Area monitor wells during a recent shutdown and restart of the pump-and-treat extraction well system. Specifically, this investigation provides the results for six composite and individual interwell tests for unconfined aquifer characterization. These large-scale aquifer characterization results will be utilized for optimization and site selection of additional extraction wells within the WMA T Tank Farm pump-and-treat system. Section 2.0 of this report describes general aspects of the WMA T Tank Farm pump-and-treat system and monitor wells used in assessing the hydrologic responses imposed by the remediation system. Section 3.0 discusses the relative effects of barometric-pressure fluctuations and their removal from monitor well water levels. Results of the hydrologic test analyses are given in Section 4.0. Conclusions are given in Section 5.0, followed by the references cited in the text in Section 6.0. Appendices of additional information are also provided (Aextraction well daily pumping data; $\mathrm{B}$ - baseline well water-level response plots; $\mathrm{C}$ - barometriccorrected baseline well water-level response plots; and D-observed and barometric-corrected drawdown well plots). Also, a list of the scientific nomenclature used throughout this report is provided on page ix. 


\subsection{0-ZP-1 WMA T Tank Farm Pump-and-Treat System}

The 200-ZP-1 WMA T Tank Farm pump-and-treat system was put into operation in September 2007 as part of a designed interim remediation activity to treat technetium-99 $\left({ }^{99} \mathrm{Tc}\right)$ contamination, specifically within and east of the 241-T Tank Farm area. The interim remediation activity was implemented as part of the general remedial guidance for this Hanford Site Operable Unit (OU) as initially provided in U.S. Environmental Protection Agency (EPA) et al. (1995) and specifically identified within the Data Quality Objectives process, as outlined in WMP-28389 (2007). The pump-and-treat system currently consists of two extraction wells (wells 299-W11-45 and 299-W11-46) that dispose of the pumped groundwater to the 200 Area Effluent Treatment Facility via a direct discharge-line connection. Figure 2.1 shows the locations of the two extraction wells and surrounding monitor wells used in the WMA T Tank Farm pump-and-treat system.

As noted in Spane (2008) and DOE (2008), Fluor Hanford, Inc. is currently assessing aquifer characterization needs to optimize pump-and-treat remedial strategies in the 200-ZP-1 OU, specifically for the immediate area of the 241-T Tank Farm. In addition, Fluor Hanford is focusing on identifying the optimum location for planned characterization well T- 6 that will be used to further refine the 3-dimensional distribution of ${ }^{99} \mathrm{Tc}$ within the area and will potentially be used as an additional pump-andtreat extraction well location.

Based on results of an aquifer characterization review and assessment for this immediate WMA area, Spane (2008) identified six hydrologic test methods as having the potential for providing additional hydrologic characterization information to improve the design and operation of the 241-T Tank Farm pump-and-treat system. These identified test characterization methods include:

- Multi-well, forced-gradient tracer test

- Multi-well, convergent (pump-and-treat) tracer test

- Supplemental slug tests within completed monitor wells

- Dynamic electromagnetic flowmeter surveys within completed monitor well locations

- Detailed test/depth interval slug test characterization during the drilling of new wells

- Large-scale hydrologic test characterization using the water-level response analysis following 241-T Tank Farm extraction well shutdown/recovery and restart/drawdown activities.

Of these test methods, the analysis of large-scale water-level recovery after temporarily terminating pumping at the pump-and-treat extraction wells, and subsequent drawdown following restart of pumping was identified as providing the most important hydrologic information for improving the design of the remediation system. The information provided would be particularly useful for siting additional pumpand-treat system extraction wells. The analysis of areal recovery and drawdown water-level responses provides an opportunity for obtaining detailed, large-scale information for a wide range of hydrologic 
properties (i.e., transmissivity, hydraulic conductivity, vertical and horizontal anisotropy, storativity, and specific yield). Many of these properties cannot be reliably estimated using standard single-well tests or hydrologic tests of short duration.

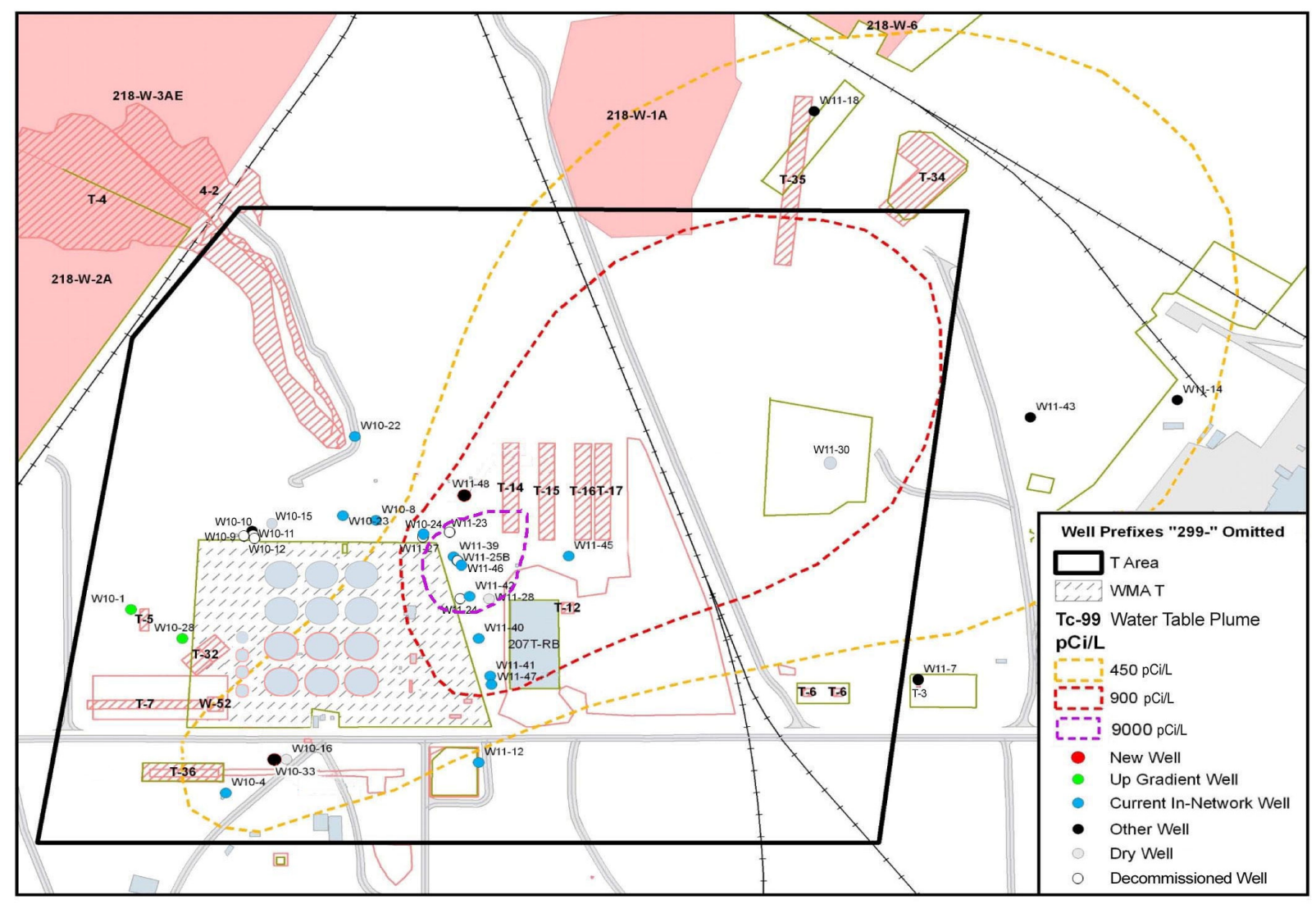

Figure 2.1. Location Map Showing T Tank Farm Well Sites

A general discussion of these six identified characterization methods for possible subsequent characterization within the 241-T Tank Farm area, together with a detailed discussion for implementing the large-scale recovery (shutdown) and drawdown (restart) test through altering pumping at the 241-Tank Farm extraction well locations is presented in Spane (2008). This report provides a general discussion of the analysis of well water-level recovery responses monitored following shutdown of the WMA T Tank Farm extraction well system on May 1, 2008, and areal drawdown responses produced by restart of extraction well pumping on June 4, 2008.

\subsection{General Hydrogeologic Conditions}

Figure 2.2 shows the generalized north-south geologic cross section of sediments oriented along the eastern boundary of the WMA T Tank Farm (see Figure 2.1 for well locations). As noted in Spane and Thorne (2000), the aquifer in this general 200 West Area is unconfined and lies within Ringold Unit E. This hydrogeologic unit is reported by Lindsey (1995) to be composed of gravel, with a fine-sand matrix 


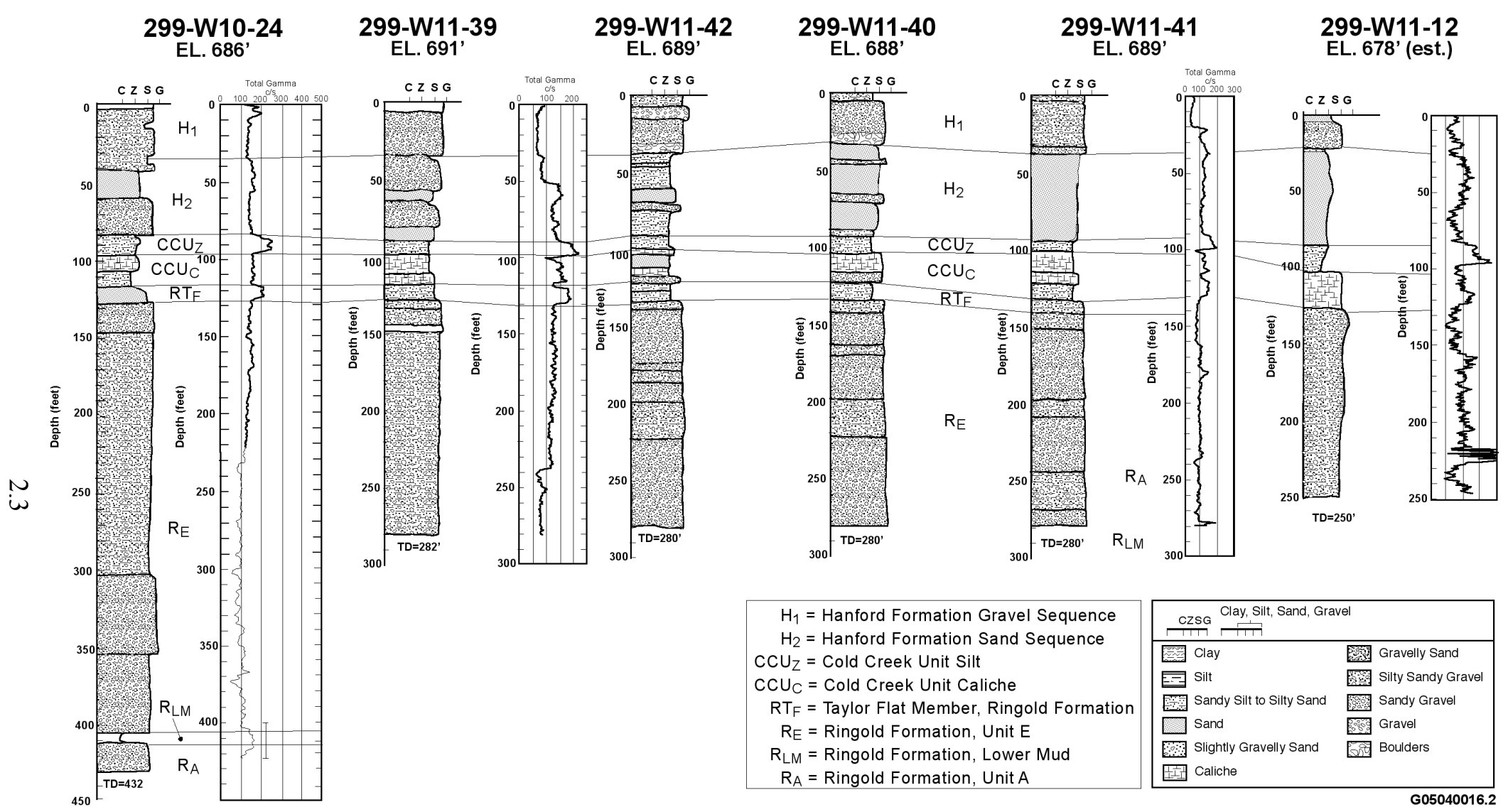

Figure 2.2. Generalized North-South Geologic Cross Section along the Eastern Boundary of WMA T Tank Farm (Horton 2006) 
and contains local sand and silt beds. These sediments are partially to well-indurated and have variable amounts of secondary mineralization. The uppermost aquifer is underlain by a lacustrine mud unit referred to as the Ringold Lower Mud. This mud unit separates the uppermost aquifer from a locally confined aquifer within the underlying Ringold Unit A gravel (basal Ringold), which lies above the basalt bedrock. Other confined aquifers are present within the deeper basalt formations. The mud unit that separates the uppermost unconfined aquifer from the underlying Ringold Unit A gravel is continuous over most of the Hanford Site, but is missing just north of the 200-West Area, and in a small area to the east of the WMA T Tank Farm, near the 200-West Area.

Figure 2.3 indicates that monitor well water levels within the general surrounding region of the WMA $\mathrm{T}$ Tank Farm area exhibited a consistent decline pattern of $\sim 0.35 \mathrm{~m} /$ year for approximately 9 years before starting the pump-and-treat system in September 2007. The overall decline in the unconfined aquifer water-table elevation is consistent with the decrease and cessation of wastewater disposal activities during this period within the 200-West Area.

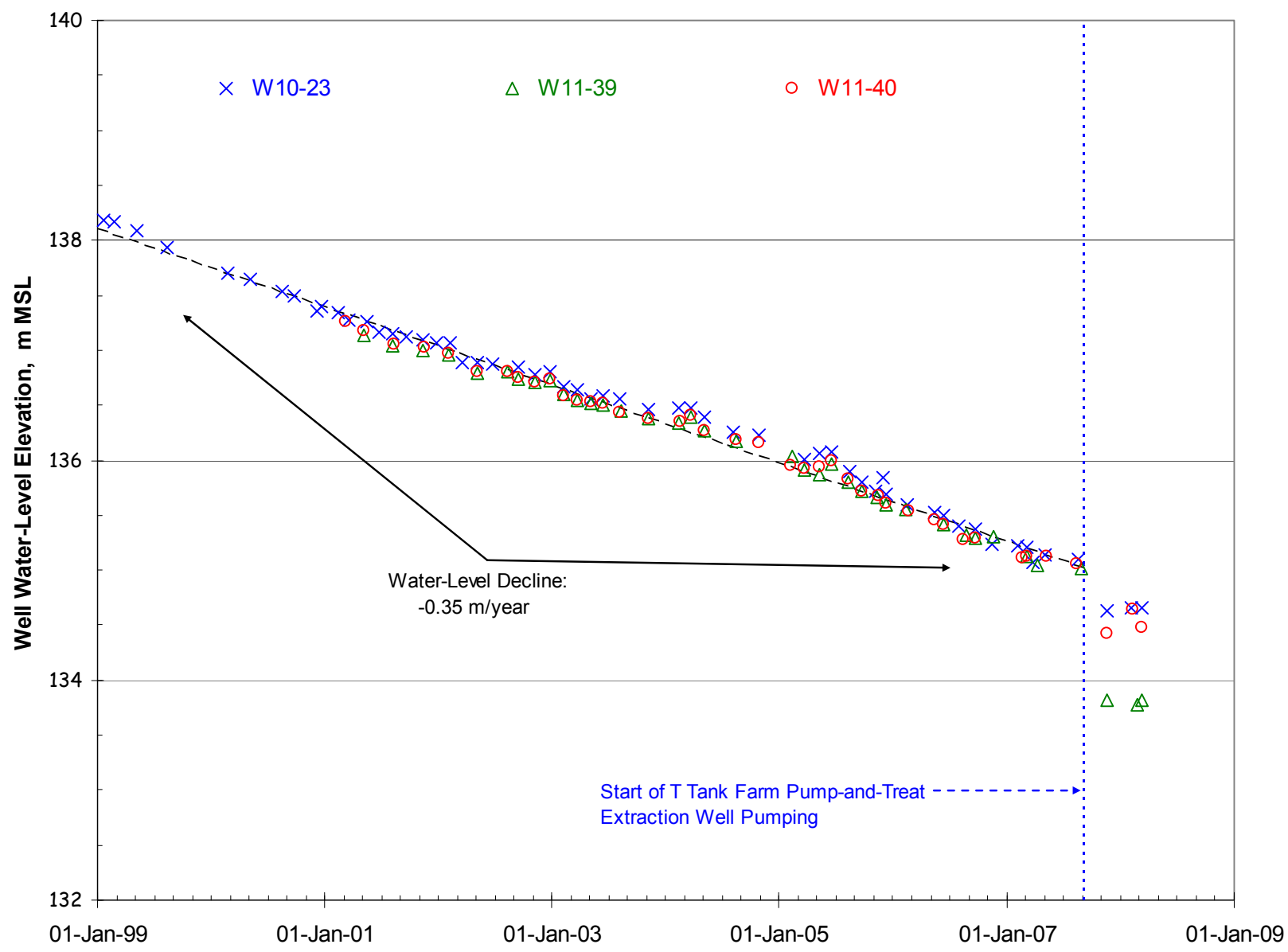

Figure 2.3. Long-Term Well Water-Level Elevation Decline Monitored at Selected WMA T Tank Farm Monitor Wells 


\subsection{Monitor Well Network}

To facilitate the analysis of areal hydrologic response of shutdown and restart of the pump-and-treat system, a group of surrounding wells was selected from the existing Hanford Site network for monitoring. Pressure transducers, with automated datalogger systems and modems for direct transmittal of well water level measurements, were installed between February 14 and 15, 2008, in five existing Hanford Site wells to establish baseline well water-level response measurements before and during shutdown and restart of the pump-and-treat system. These initially selected wells for baseline monitoring included 299-W10-24, 299-W11-39, 299-W11-40, 299-W11-42, and 299-W11-48. All water-level data obtained from these wells were collected and maintained by the Fluor Hanford Soil and Groundwater Remediation Geosciences Group during the period of investigation. Water-level responses in these wells were measured at regular intervals (e.g., frequency $=10$ minutes) using an automated measurement station that records the pressure of the overlying well water column above a submerged, in-well, pressure transducer, which is connected to a surface datalogger. The pressure transducers are vented to the atmosphere, which is used as a reference for calculating a differential pressure that is reflective of only changes in the well fluid-column height above the submerged, in-well transducer. The in-well fluid-column height measurements were converted to water-level elevations, expressed in meters above mean sea level (MSL), using the reference surface well control elevation datum and the measured pressure depth setting. Manual depth-to-water measurements were taken periodically as a field check of the well water-level measurements and pressure transducer performance. Specific pressure recording and transmittal equipment utilized in these wells included:

- Drück PDCR 1830-8388 submersible vented pressure transducer; 5 or 10 psi range

- Campbell Scientific Inc. CR800 series datalogger

- Radio frequency modem and ultra-high frequency (UHF) transceiver and omni-directional antenna.

In addition to these initial five baseline monitor wells, three additional wells (299-W10-23, 299-W1141, and 299-W11-47) were added to the monitor well network starting on March 28, 2008. These wells were maintained by the Pacific Northwest National Laboratory (PNNL) Field Hydrology and Chemistry Group. Well water-level pressures recorded in these wells were monitored and stored with similar equipment. Data for these wells were not automatically transmitted and required manual download of datalogger systems at each well site. Specific pressure recording and datalogger equipment used at these three baseline monitor well sites included:

- Drück PDCR 1830-8388 submersible vented pressure transducer; 10 or 50 psi range

- Campbell Scientific Inc. CR10X series datalogger.

It should be noted that the well water-level data monitored by PNNL were collected in accordance to procedures listed in PNL-MA-567 (1993) and the quality assurance management plan, as specified in Fix (2008).

Onsite barometric pressures were also monitored during the course of the investigation at both well 299-W11-41 and 299-W11-47. These site barometric pressure measurements were the basis for removing the adverse impact of barometric pressure fluctuations on well water-level measurements (Section 3). 
The barometric pressures were measured with a Vaisala barometric pressure transducer (Model \# PTB101B) and recorded on the same datalogger system.

Pressure readings within the extraction wells 299-W11-45 and 299-W11-46 are maintained and recorded at the well site locations by the 200-ZP-1 Pump-and-Treat Operations Group. These wells are not part of the site-wide monitor well network and were designed to monitor operational performance of the pump-and-treat extraction wells. The pressure transducers installed at these two well sites are connected to the pump/flow control panel at each well head. The control panel has a visual readout display (light-emitting diode [LED]) on top of the panel and is wired with dual universal serial bus (USB) dataloggers connected within the panel. The pressure transducer readings are expressed as a fluid-column height above the pressure transducer setting. These pressure readings were not converted to a water-level elevation because of uncertainties in the actual pressured transducer depth setting below the reference surface-elevation datum. The wiring at well 299-W11-45 is not connected properly with the surface datalogger system. As a result, water levels within this well during the investigation are based on manually recorded discrete measurements observed from the surface LED well monitor. Well 299-W1146 is wired correctly, and the USB dataloggers collected data at set intervals, which can be manually downloaded from the site acquisition system.

Cumulative in-line flow meters record the total volume of groundwater pumped at each extraction well. Daily pumping rates at both extraction wells are monitored and recorded manually twice daily (once in the morning and the afternoon period). The daily pumping-rate measurements recorded during calendar year 2008 for each pump-and-treat extraction well are provided in Appendix A. As shown in Appendix A, a number of short-duration, non-pumping periods were recorded at each of the extraction wells before the dedicated system shutdown (May 1, 2008) and restart (June 4, 2008). These temporary periods of shutdown occurred for a variety of maintenance and operational activities. Extraction well 299-W11-45 was shut down for a designed, prolonged period (March 6 through July 7, 2008) to facilitate the hydrologic analysis of the shutdown and restart of extraction well 299-W11-46. Extraction well 299W11-45 is relatively far removed from the nearest WMA T Tank Farm monitor well (i.e., $\geq 80 \mathrm{~m}$ ), and the pumping rates significantly less in comparison to extraction well 299-W11-46 (see Appendix A).

Pertinent monitor well information concerning well-screen completion and the distance relationship to extraction well 299-W11-46 are presented in Table 2.1. 
Table 2.1. Pertinent Survey, Completion, and Distance Information for T Tank Farm Wells (adapted from Spane 2008)

\begin{tabular}{|c|c|c|c|c|c|}
\hline \multirow[b]{2}{*}{$\begin{array}{c}\text { T Tank } \\
\text { Farm Wells }\end{array}$} & \multicolumn{2}{|c|}{$\begin{array}{c}\text { NAD83 (91) } \\
\text { Horizontal Coordinate } \\
\text { Survey } \\
\end{array}$} & \multirow{2}{*}{$\begin{array}{c}\text { NAVD(89) } \\
\text { Elevation } \\
\text { Survey } \\
\text { Brass Cap, } \\
\text { m MSL } \\
\end{array}$} & \multirow{2}{*}{$\begin{array}{c}\text { Well-Screen } \\
\text { Elevation, } \mathbf{m} \\
\text { MSL } \\
\text { (Top - Bottom) }\end{array}$} & \multirow{2}{*}{$\begin{array}{c}\text { Radial Distance from } \\
\text { Well 299-W11-46, } \\
\text { m }\end{array}$} \\
\hline & $\begin{array}{c}\text { North, } \\
\text { m }\end{array}$ & $\begin{array}{c}\text { East, } \\
\text { m }\end{array}$ & & & \\
\hline $2-W 10-23$ & 136815.34 & 566823.73 & 206.69 & $137.87-127.17$ & 100.37 \\
\hline $2-W 10-24$ & 136798.78 & 566885.43 & 208.98 & $137.98-127.28$ & 38.95 \\
\hline 2-W11-39 & 136779.92 & 566908.38 & 209.89 & $137.16-126.48$ & 9.28 \\
\hline $2-W 11-40$ & 136709.67 & 566926.84 & 209.70 & $137.13-126.45$ & 64.72 \\
\hline 2-W11-41 & 136677.78 & 566935.51 & 209.67 & $137.52-126.86$ & 97.70 \\
\hline $2-W 11-42$ & 136745.67 & 566920.44 & 210.18 & $138.02-127.34$ & 28.16 \\
\hline $2-W 11-45$ & 136775.64 & 566992.84 & 212.88 & $127.15-122.70$ & 78.02 \\
\hline $2-W 11-46$ & 136773.27 & 566914.86 & 210.12 & $129.84-123.74$ & 0.00 \\
\hline $2-W 11-47$ & 136680.70 & 566933.82 & 209.66 & $126.07-116.76$ & 94.49 \\
\hline $2-W 11-48$ & 136846.18 & 566881.97 & 208.90 & $124.33-96.88$ & 79.99 \\
\hline
\end{tabular}




\subsection{Barometric Effects}

The following discussion of barometric effects on well water-level measurements is taken primarily from Spane (1999, 2002). Briefly stated, however, well water-level elevations and hydraulic head conditions within aquifers commonly respond to variations in atmospheric pressure. Barometric fluctuations represent an areal, blanket stress applied directly at land surface and to the open well waterlevel surface. The manner in which a well/aquifer system responds to changes in atmospheric pressure, however, is variable and directly related to the degree of aquifer confinement and hydraulic/storage characteristics of the well/aquifer system. Rasmussen and Crawford (1997) identified three conceptual models that describe well water-level measurement response associated with barometric pressure change. These include an instantaneous, uniform well response for non-leaky confined aquifers, a delayed well response within unconfined aquifers (due to delayed transmission of barometric pressure through the vadose zone), and a delayed well response associated with well/aquifer characteristics (i.e., wellborestorage). Spane $(1999,2002)$ subsequently improved upon the barometric response model for wellborestorage (and added the effects of well-skin) and developed composite wellbore-storage/aquifer response models for unconfined and confined aquifer systems. Additionally, Spane (1999, 2002) developed separate barometric response models for aquifer hydraulic head-based measurements.

Figure 3.1 shows examples of diagnostic barometric response plots for the three well water-level response models originally identified by Rasmussen and Crawford (1997). The plots show the time-lag dependence of each barometric response model associated with a unit step change in atmospheric pressure. As shown in the figure, each barometric response model has a distinguishing shape pattern that can be used diagnostically to identify the responsive aquifer model. For composite systems, Spane (1999, 2002 ) indicated that the delaying impact caused by wellbore-storage conditions was largely diminished for aquifers exhibiting transmissivity conditions of $\geq 1 \mathrm{~m}^{2} /$ day for frequency of field measurements commonly used in field investigations (e.g., every 30 to 60 minutes). The presence of a low-permeability well skin (i.e., positive skin) can also enhance the delaying or transitional early response period until representative aquifer response conditions are established. Detailed examples for a variety of composite systems of wellbore-storage and skin, in combination with unconfined and confined aquifers, are presented in Spane $(1999,2002)$. Figure 3.2 shows an example of composite model behavior for an unconfined aquifer with wellbore storage $($ skin $=0$ ) for the given test conditions.

It is important to reiterate that the model patterns indicated in Figure 3.1 and Figure 3.2 are specifically for "well water-level response" associated with stresses imposed by barometric pressure fluctuations. As has been discussed by others (including Rasmussen and Crawford 1997; Spane 1999, 2002), temporal well water-level elevation measurements are not equivalent to the surrounding watertable elevation or hydraulic head condition within the surrounding unconfined aquifer. This is due primarily to the transient imbalance of barometric pressure that is applied instantaneously to the fluidcolumn within an open well and the delayed, counter-balancing transmission of the barometric pressure through the vadose zone to the water-table surface. Figure 3.3 shows a comparison plot that illustrates the relative difference between water-level elevation, hydraulic head, and water-table conditions as presented in Spane (2002). The water-level response was generated based on the observed hourly Hanford Site Meteorological Station atmospheric pressure record and using the vadose zone barometric pressure model 
originally described in Weeks (1979) and the listed pneumatic diffusivity, $\mathrm{D}_{\mathrm{a}}$, value. This pneumatic diffusivity value is within the range commonly exhibited within the 200-West Area, as reported in Spane and Thorne (2000). As shown in Figure 3.3, the observed barometric pressure fluctuations cause the predicted well water-levels to vary inversely with barometric pressure, which contrasts significantly with the existing static water-table elevation condition. The calculated hydraulic head exhibits less variability and is expressed as the static water-table elevation and the component of barometric pressure reaching the water-table surface (located at a depth of $60 \mathrm{~m}$ below land surface) that is greater or less than the reported Hanford Site long-term average barometric pressure value (i.e., $10.087 \mathrm{~m}$ ). As might be expected, the hydraulic head is more variable during the late fall through early spring seasons, when more intense storm activity passes through the Pacific Northwest region.

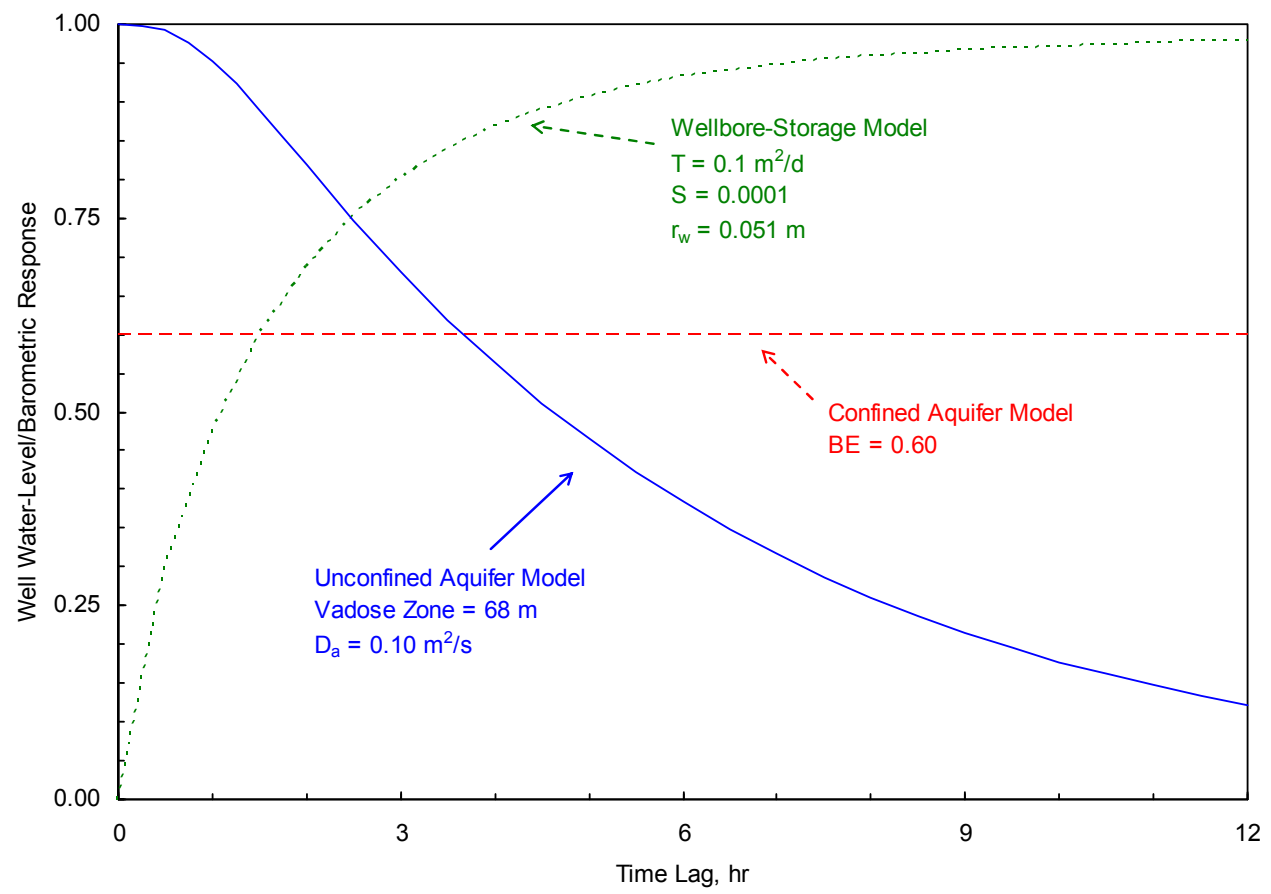

Figure 3.1. Well Barometric Pressure-Response Models (adapted from Spane 2002)

Because of this demonstrated adverse impact, it is important to remove the temporal impact of barometric pressure fluctuations from well water-level measurements for quantitative hydrologic test analysis (e.g., drawdown associated with long-duration pumping tests) or for detailed groundwater-flow characterization investigations, particularly within low-hydraulic gradient areas (e.g., 200-East Area). Generally, stresses imposed by hydrologic tests commonly exceed those imposed by barometric pressure fluctuations on the well/aquifer system. Removing barometric effects, however, is more important for hydrologic tests of long duration (e.g., pump-and-treat system pumping cycles) when imposed hydrologic responses have quasi-stabilized and/or for monitor wells located at a moderate distance from pumping well locations. This is because of the low-magnitude changes in hydraulic head that occur at late pumping times and/or for distant observation-well locations. It was important to remove barometric effects for both these reasons to analyze the WMA T Tank pump-and-treat response. 


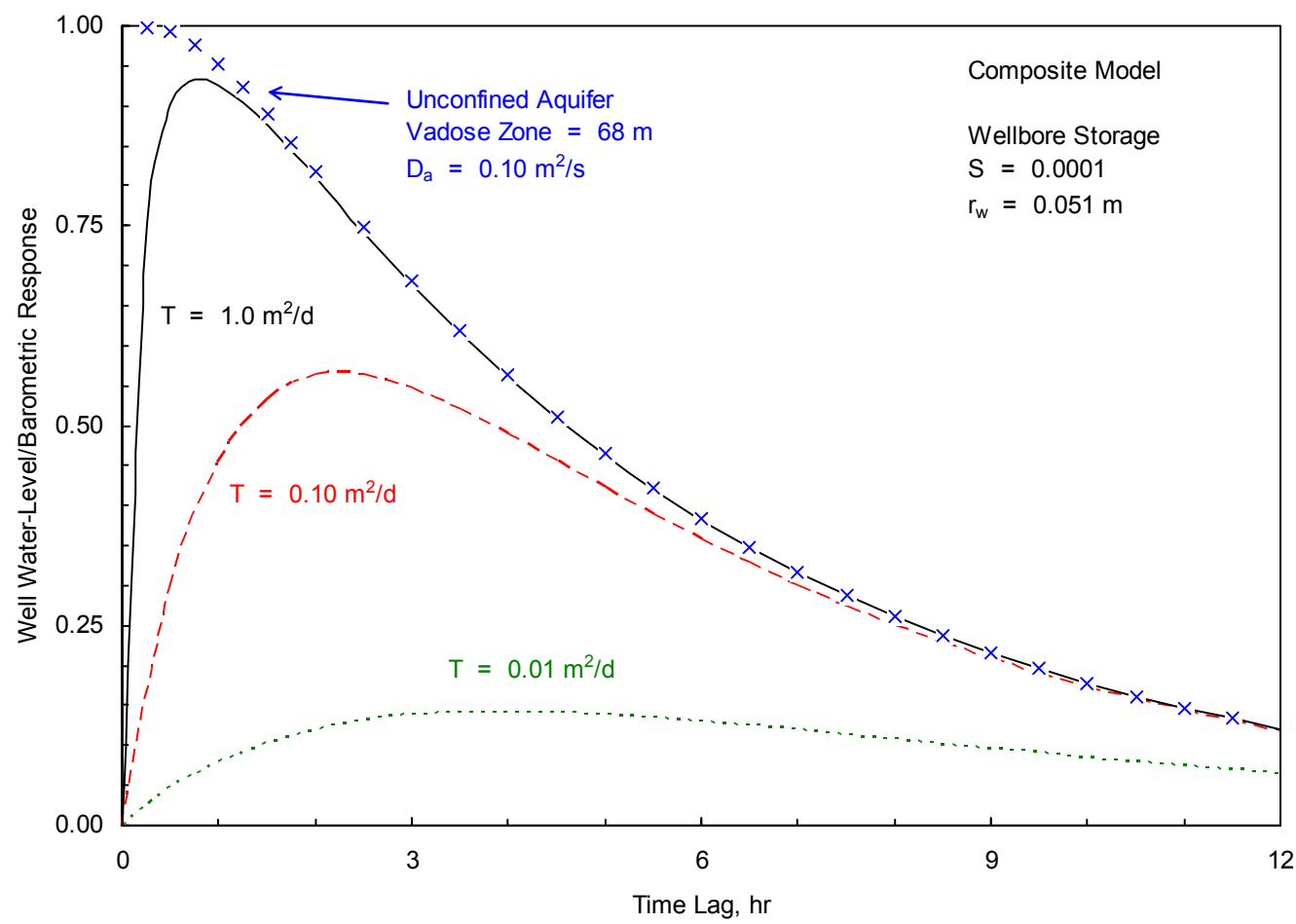

Figure 3.2. Diagnostic Composite Barometric Response Model for Wellbore-Storage/Unconfined Aquifer System (adapted from Spane 2002)

The barometric correction of well water-level measurements provides a measurement of the watertable elevation in the vicinity of the monitor well. Removing barometric effects depends on the diagnostic response model exhibited by the well/aquifer system with different removal methods recommended for confined and unconfined aquifers, as well as for those exhibiting composite modelresponse behavior. As noted in Spane (1999), removing barometric fluctuations from hydrologic test data requires the following steps:

1. Collect test site atmospheric pressure values and associated aquifer formation pressure values for a pre- or post-test baseline period, during which no other extraneous stresses are imposed on the well/aquifer system.

2. Perform diagnostic barometric response analysis of the baseline well data record using the multiple-regression convolution method described by Rasmussen and Crawford (1997) to distinguish between aquifer or composite well-/aquifer-model behavior.

3. Remove barometric induced changes from the test data record using the multiple-regression deconvolution technique.

It should be noted that pump-and-treat system operation represents a dynamic, extraneous stress, which conflicts with the Step 1 requirement. However, during the late stages of a prolonged pumping or recovery cycle, the pump-and-treat system likely impose minimum extraneous stresses and likely has no 
significant adverse impact on data collected for use in the barometric pressure removal process. This assumption is supported by a similar successful hydrologic analysis performed at a neighboring 200-West Area pump-and-treat system, as reported in Spane and Thorne (2000).

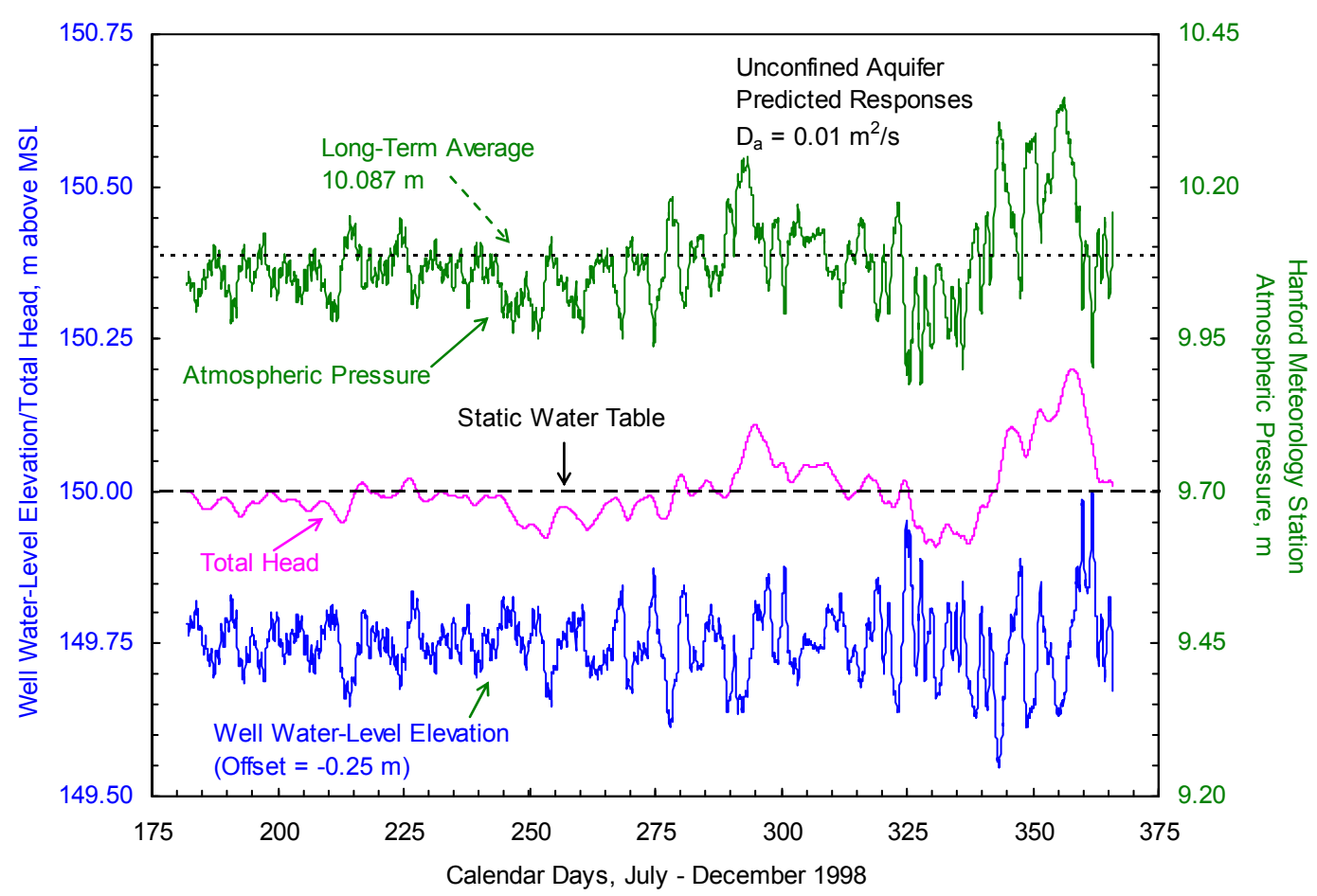

Figure 3.3. Comparison of Predicted Well Water-Level Elevation Versus Aquifer Water-Table Elevation and Hydraulic Head Response, Based on Observed Atmospheric Pressure Measurements (adapted from Spane 2002)

\subsection{Baseline Well Water-Level Response}

Baseline water-level measurements were recorded at each well to facilitate the removal of barometric pressure fluctuations from surrounding well water-level responses from monitor wells used to assess the areal hydrologic impact imposed by shutdown and restart of the WMA T Tank Farm extraction wells. The baseline measurement frequencies used at the well sites were reflective of observations reported in Spane (1999) and specified in Spane (2008). As noted in Spane (1999), test data having recording frequencies from 10 to 60 min during baseline collection periods produce consistent barometric removal results for Hanford Site conditions (i.e., vadose zone thickness $=25$ to $75 \mathrm{~m}$, pneumatic diffusivities $\left(\mathrm{D}_{\mathrm{a}}\right)$ $=0.01$ to $0.1 \mathrm{~m}^{2} / \mathrm{s}$ ).

Figure 3.4 shows the baseline comparison of observed hourly well water-level and barometric pressure response for well 299-W10-24, which is located at a distance of $38.95 \mathrm{~m}$ from extraction well 299-W11-46. The barometric pressure shown was measured at the WMA T Tank Farm site only between calendar days 88 through 193 (March 28 through July 11, 2008). The barometric pressure record was extended back to calendar day 45 (February 14, 2008) through correlation with nearby, hourly Hanford 
Site Meteorological Station readings. Also shown are superimposed shutdown and restart of pumping for extraction well 299-W11-46. Of particular note are the designed long-duration shutdown (on May 1; calendar day 122) and restart pumping (on June 4, 2008, calendar day 156) that occurred for extraction well 299-W11-46. These designed shutdown and restart periods represent the recovery and drawdown phases, which were analyzed as an areal response characterization. As shown in the figure, the shutdown and restart of pumping at extraction well 299-W11-46 produced a recognizable response within the observed well water-level record. Barometric pressure fluctuations, however, produce obvious masking of the underlying hydrologic test-response signal, which would adversely impact any efforts to quantitatively analyze the observed water-level response for quantitative hydrologic property characterization.

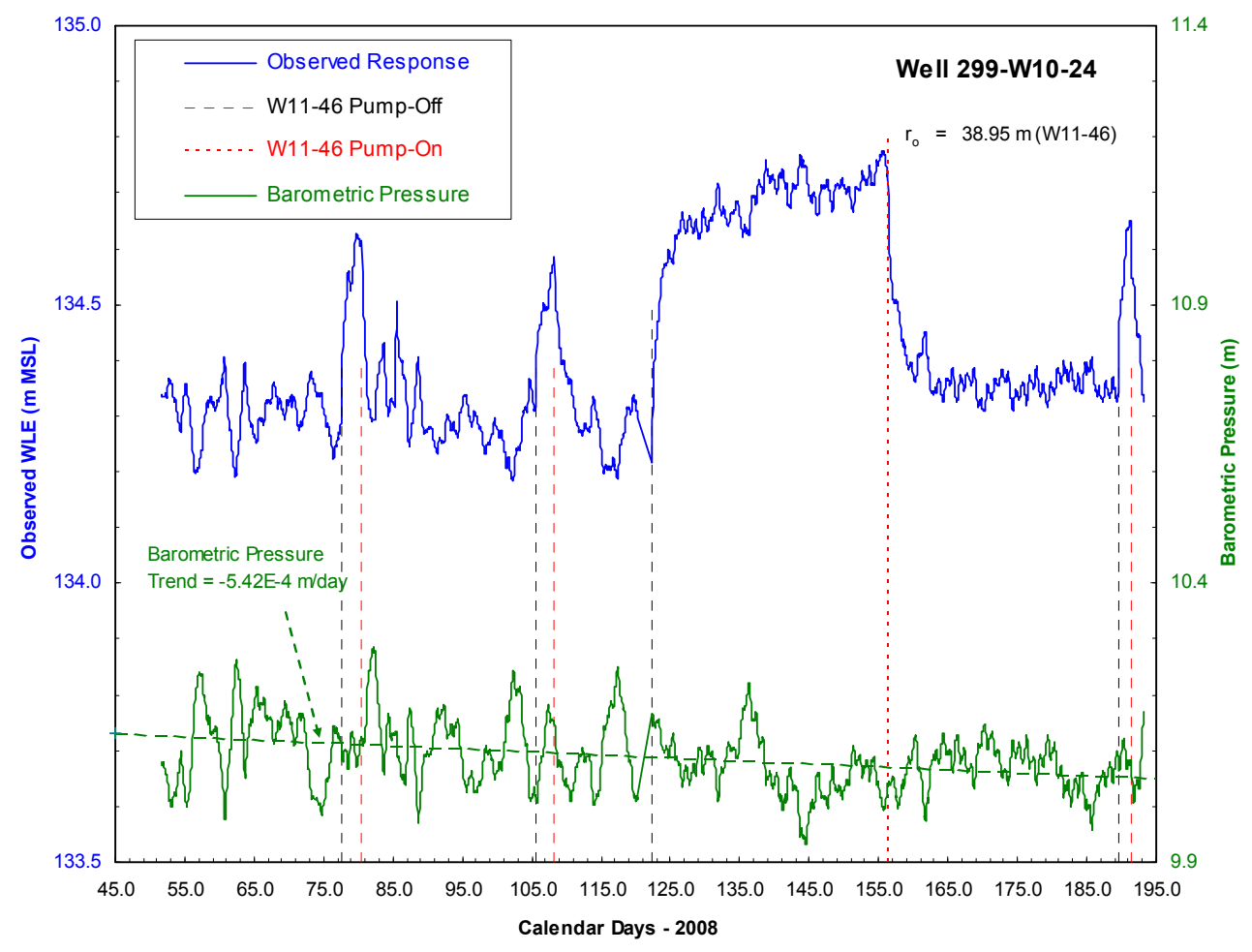

Figure 3.4. Observed Baseline Well Water-Level Response: Well 299-W10-24

Of additional interest is the negative linear barometric pressure trend over the period of record (i.e., -5.42E-4 m/day) indicated in Figure 3.4. This is a common observation for long baseline barometric pressure periods approaching summer months and is attributable to warming of the overlying surface atmosphere. This atmospheric warming lowers the blanketing gas density and gas partial pressures acting on land surface and vadose zone. The negative barometric pressure trend exhibited would impose an associated positive well water-level trend that would be influenced by the individual well/aquifer barometric response characteristics. Baseline comparisons of observed hourly well water-level and barometric pressure response are presented in Appendix B for other WMA T Tank Farm wells monitored as part of this investigation. As noted in Section 2.2, no baseline information was available for extraction well 299-W11-45 because of a lack of automated data-acquisition capability for this well site. 


\subsection{Multiple-Regression Removal Method}

A number of methods are available (i.e., time and frequency-domain) that have been shown to be effective in removing the effects of barometric pressure fluctuations from well water-level measurements. A comparison and discussion of a number of these removal methods is presented in Spane $(1999,2002)$. Because of the relative-ease and dependable removal capability, the multiple-regression deconvolution technique was selected for use in removing barometric pressure effects from the WMA T Tank Farm monitor-well measurements. Multiple-regression deconvolution techniques have been shown by Rasmussen and Crawford (1997) and Spane (1999) to be effective in removing barometric effects from hydrologic test data that exhibit either aquifer or composite wellbore-storage/aquifer-response characteristics. To implement the removal procedure, 20-day barometric response analysis data sets were selected for both the shutdown/recovery and restart/drawdown time periods. The data analysis sets were selected during the last 20 days of each test element phase (i.e., recovery analysis period $=136-156$ calendar days; drawdown analysis period $=169-189$ calendar days).

The 20-day baseline water-level response records for WMA T Tank Farm monitor wells were analyzed using the multiple-regression convolution technique described in Rasmussen and Crawford (1997) and Spane (1999). Figure 3.5 shows the well water-level/barometric response patterns obtained from the multiple-regression analysis for each well. Generally, the barometric response patterns obtained for the shutdown and restart data sets were nearly identical for each individual monitor well location. The drawdown response patterns, however, exhibited slightly less variability than their recovery counterparts. For this reason, the drawdown response characteristics were used to deconvolute the well water-level response in most cases and to remove the effects of barometric pressure fluctuation. It should be noted that the barometric response pattern exhibited for well 299-W11-48 displays a significantly different pattern that the other WMA T Tank Farm monitor wells and appears to be more similar to hydraulic head/barometric response patterns that are discussed in Spane (2002). The difference in behavior exhibited by well 299-W11-48 may be attributed to either: 1) a blockage of the reference vent tube for the pressure transducer readings within this well or 2) inclusion of atmospheric pressure change values in the in-well pressure transducer readings. Either of these two mechanisms would produce a hydraulic head measurement rather than a well water-level measurement and be consistent with the apparent hydraulic-head response pattern exhibited for this well. Whatever the cause, this appears to have occurred on or about calendar day 102 (April 11,2008) because visual examination of baseline data exhibited for this well in Appendix B and $\mathrm{C}$ exhibit a distinctly different pattern following this date.

All other WMA T Tank Farm monitor wells shown in Figure 3.5 exhibit very similar barometric response characteristics. These wells generally exhibit a barometric time-lag dependence ranging from 92 to 134 hours. This relatively large barometric time-lag dependence is attributed to the presence of lower permeability sedimentary units within the vadose zone (e.g., Cold Creek Unit) that retard the vertical transmission of barometric pressure fluctuations from ground level to the water-table surface. These time-lags are similar to other well response characteristics previously examined at other neighboring 200-West Area locations. 


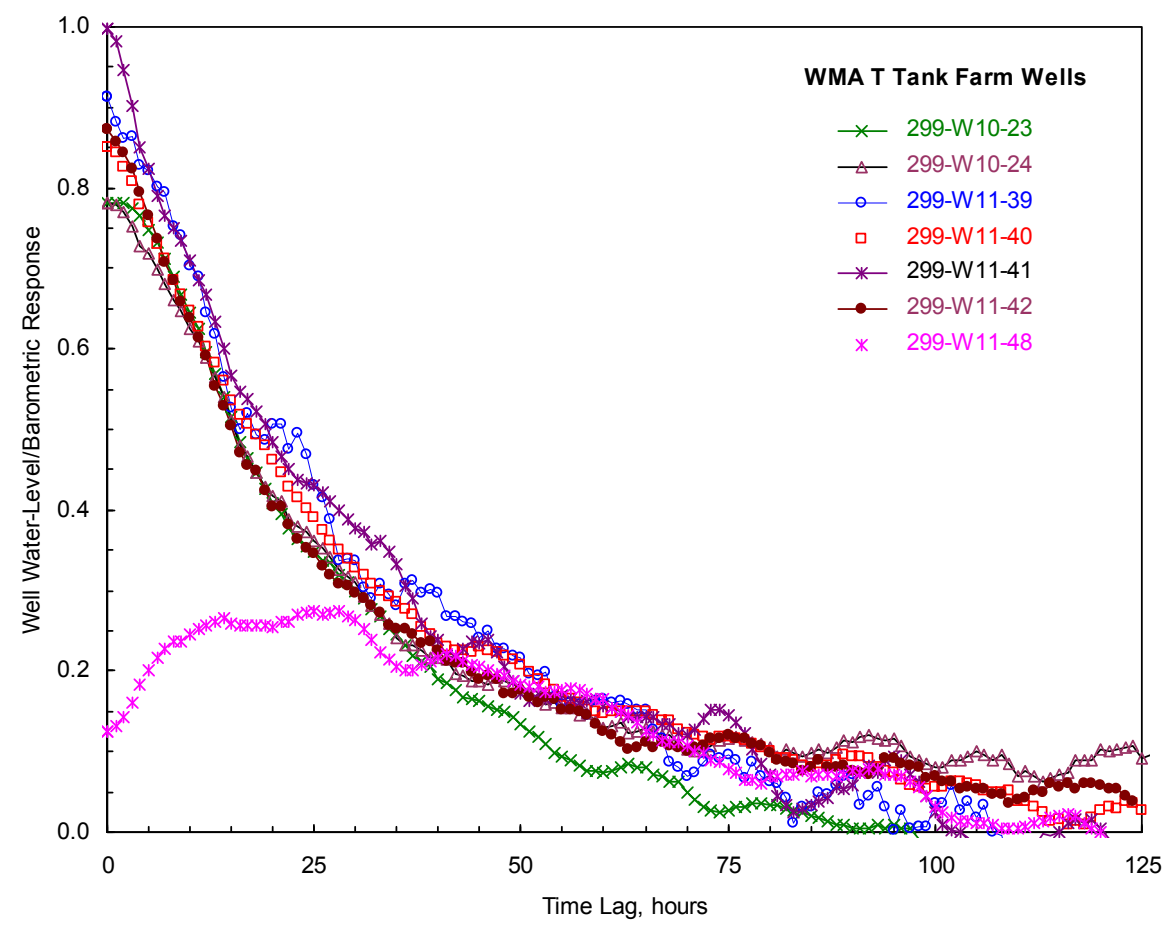

Figure 3.5. Water-Level Barometric Response Patterns for Selected WMA T Tank Farm Monitor Wells

\subsection{Corrected Baseline Well Water-Level Response}

To demonstrate the multiple-regression deconvolution method for barometric pressure removal, Figure 3.6 shows the hourly observed and corrected well water-level responses for well 299-W10-24 during the baseline period of calendar days 88 to 193 (March 28 to July 11, 2008). The baseline period reflects the time period for site barometric pressure readings. As shown in the figure, barometric pressure fluctuations were effectively corrected and removed from the observed well water-level measurements. As indicated in the figure, the correction procedure appears to be applicable even for wells with data records that have short-term data gaps (note the missing data gap for this well occurring between calendar days 120 and 122). The corrected response was developed using a linear water-level trend of $+8.2 \mathrm{E}-5$ $\mathrm{m} /$ day. This trend value was used for most WMA T Tank Farm monitor well locations. For "near" wells located in proximity to extraction well 299-W11-46 (e.g., 299-W11-39, 299-W11-42), the linear trends determined from the drawdown data-set analysis appeared to provide better visual corrected responses during the shutdown and restart periods. A comparison of the observed and corrected baseline hourly well water-level response is presented in Appendix C for other WMA T Tank Farm wells monitored as part of this investigation. As noted previously in Section 3.1, no baseline information was available for extraction well 299-W11-45 because of a lack of automated data-acquisition capability for this well site. 


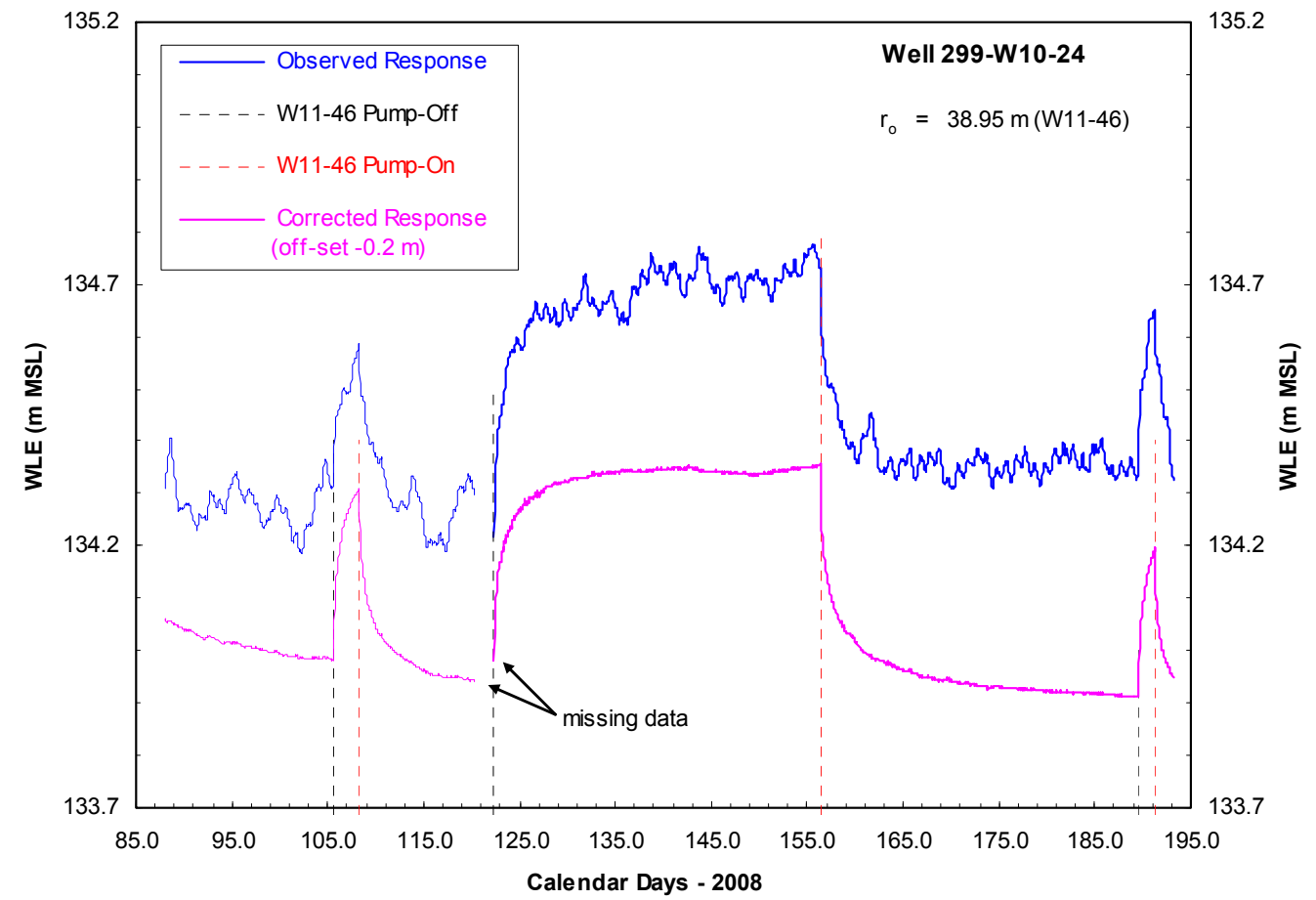

Figure 3.6. Observed and Corrected Baseline Well Water-Level Response: Well 299-W10-24 


\subsection{Hydrologic Test Analysis Methods}

All WMA T Tank Farm monitor well water-level data were corrected for barometric pressure fluctuations using the multiple-regression deconvolution technique described in Section 3. The corrected response removed water-level variations exhibited in the observed water-level measurements, which enabled successful diagnostic and analytical methods to be applied for areal hydrologic test analysis of the shutdown and restart periods. The standard hydrologic methods used to analyze the barometriccorrected well water-level responses assume homogeneous/anisotropic conditions and account for wellbore storage and well/aquifer partial penetration relationships. The following discussion pertaining to hydrologic test analysis methods (Sections 4.1 to 4.3) is taken primarily from Spane and Thorne (2000).

\subsection{Diagnostic Analysis and Derivative Plots}

Log-log plots of water level versus time have traditionally been used for diagnostic purposes and, more recently, the derivative of the water level or pressure has also been used (e.g., Bourdet et al. 1989; Spane 1993) as an enhanced diagnostic tool. The derivative of the corrected water level with respect to the natural logarithm of time (i.e., essentially the slope of the semi-log plot) was calculated and plotted on the log-log plots of drawdown versus time. The use of derivatives has been shown to significantly improve the diagnostic and quantitative analysis of various hydrologic test methods (Bourdet et al. 1989; Spane and Wurstner 1993). The improvement in test analysis is attributed to the sensitivity of pressure derivatives to various test/formation conditions. Specific applications for which derivatives are particularly useful include the following:

- determining formation-response characteristics (confined or unconfined aquifer) and boundary conditions (impermeable or constant head) that are evident within the test data

- assisting in the selection of the appropriate type-curve solution through combined typecurve/derivative plot matching

- determining when infinite-acting, radial flow conditions are established and, therefore, when straight-line analysis methods are applicable.

Figure 4.1 shows log-log drawdown and derivative responses for pumping tests that are characteristic of some commonly encountered formation conditions. The early-time data, when wellbore storage is dominant, produce a steep, upward-trending derivative. The derivative normally decreases during transition from wellbore storage to radial flow and stabilizes at a constant value when infinite-acting, radial flow conditions are established. The stable derivative reflects the straight line on the semi-log plot for infinite-acting radial flow. Unconfined and double-porosity aquifers may show two stable derivative sections at the same vertical position, separated by a "valley" representing the transition from an initial elastic storage response to a total test system storativity condition. Diagnostic derivative plots are also useful in identifying boundary effects. A linear, no-flow boundary will result in a doubling of the magnitude of the derivative. If radial flow is established before the influence of the boundary is seen, a stable derivative will occur for a time followed by an upward shift to twice the original value. Constant-head boundaries display a downward trend in the derivative, which may be preceded by a stable derivative if radial flow conditions occur before the boundary effect becomes 
dominant. For the diagnostic and test analysis aspects of this report, derivative responses were calculated using the DERIV program, which is described in Spane and Wurstner (1993).

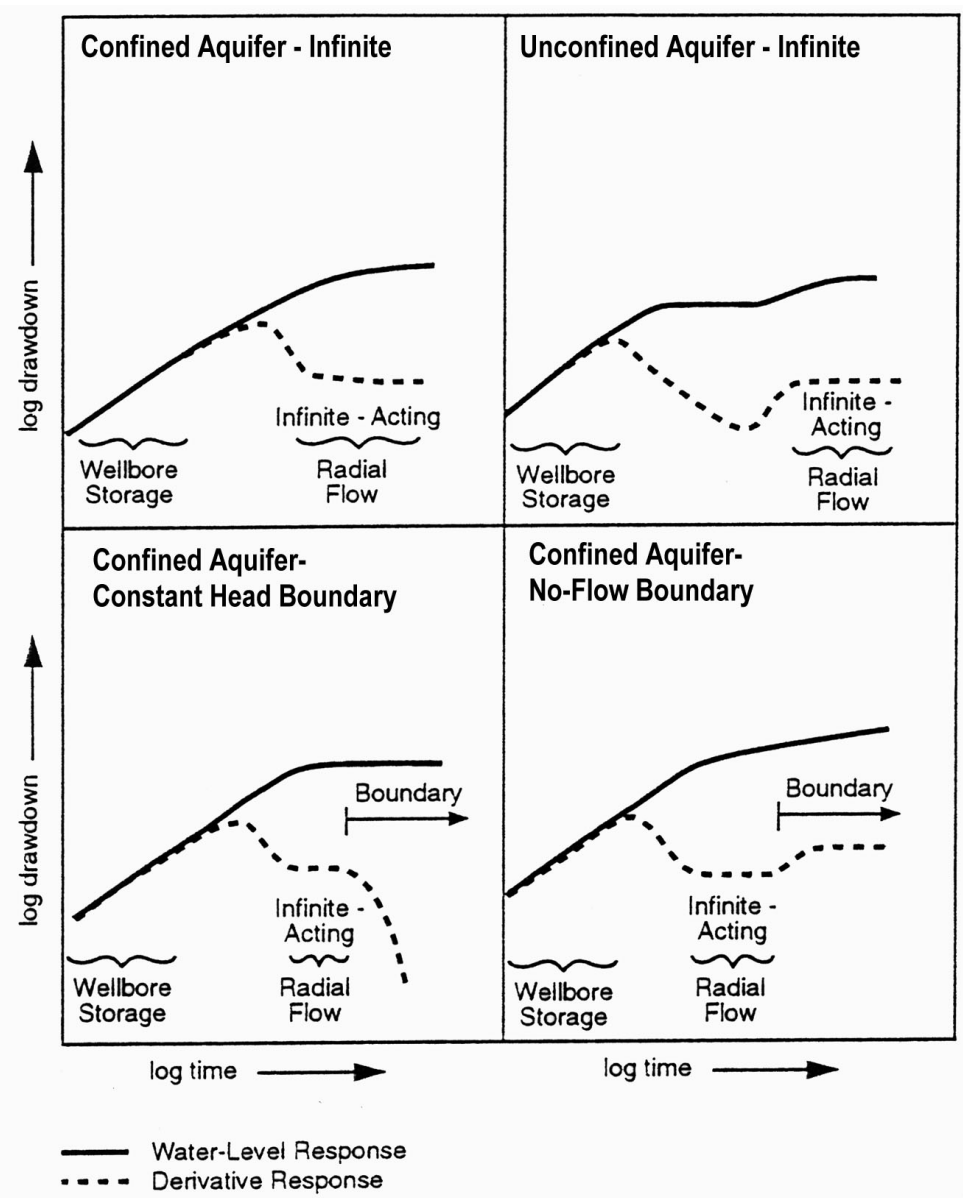

Figure 4.1. Characteristic Log-Log Drawdown and Drawdown Derivative Plots for Various Hydrogeologic Formation and Boundary Conditions (adapted from Spane and Wurstner, 1993)

\subsection{Type-Curve Method}

Type-curve matching methods (Theis 1935; Hantush 1964; Neuman 1972, 1974, 1975) are commonly used to analyze pumping test responses. To support this analysis aspect, type curves were generated using the WTAQ3 computer program described by Moench (1997). WTAQ3 can be used to generate pumping test-type curves that represent a wide range of test and aquifer conditions, including partially penetrating wells, confined or unconfined aquifer models, and wellbore storage at both the stress (pump) and observation (monitor) well locations. The type-curve generation program also allows for non-instantaneous release (drainage-delay factor) of water from the unsaturated zone. However, this was found to not be a significant factor in analyzing the selected WMA T Tank Farm monitor well 
response; therefore, the type curves used in the analyses for this report all reflect an instantaneous release of water, which is the approach used by Neuman $(1972,1974,1975)$.

The shape of the unconfined aquifer pumping test-type curves used in the individual well response analysis are sensitive to a number of hydrologic parameters, including radial distance from the pumping well location, $r_{o}$, vertical anisotropy, $K_{D}$ ( i.e., $\left.K_{v} / K_{h}\right)$, and the storativity/specific yield ratio $\left(\sigma=S / S_{y}\right)$. To facilitate the type-curve matching process, an automated analytical type-curve program ISOAQX (HydraLogic 1989) was used as an initial screening tool. The ISOAQX program does not account for wellbore storage effects, which is an important consideration for matching early-time type-curve response both in the pumped well and monitor well locations. The preliminary screening value for $\mathrm{S}$ was modified based on an estimated $\mathrm{S}_{\mathrm{s}}$ value of $2 \mathrm{E}-5 \mathrm{~m}^{-1}$. This estimate is representative of average values reported by Shestakov (2002) for sandy alluvial sediments at these depths. The input parameter values for $\mathrm{K}_{\mathrm{D}}, \mathrm{S}$, and $\sigma$ were then adjusted to match the general shape of the corrected water-level response. Following obtaining an acceptable shape match, $\mathrm{K}_{\mathrm{h}}$ was adjusted for final matching of the type curve to the corrected well water-level response. A uniform aquifer thickness, $\mathrm{b}$, of $49 \mathrm{~m}$ was used for all analyses and is reflective of the depth to the Ringold Lower Mud contact in the vicinity of extraction well 299-W11-46, and a water-table elevation of $\sim 135 \mathrm{~m} \mathrm{MSL}$, which was observed for the general area surrounding the extraction well before starting the pump-and-treat investigation in late 2007.

\subsection{Straight-Line Method}

For straight-line analysis methods, the rate of change of water levels within the well during drawdown and/or recovery is analyzed to estimate hydraulic properties. Because well effects are constant with time during constant-rate tests, straight-line methods can be used to quantitatively analyze water-level response at both pumping and observation wells. The semi-log, straight-line analysis techniques commonly used are based on either the Cooper and Jacob (1946) method (for drawdown analysis) or the Theis (1935) recovery method (for recovery analysis). These methods are theoretically restricted to analyzing test responses from wells that fully penetrate non-leaky, homogeneous, isotropic, confined aquifers. Straight-line methods, however, may be applied under non-ideal well and aquifer conditions if infiniteacting, radial flow conditions exist. Infinite-acting, radial flow conditions are indicated during testing when the change in pressure, at the point of observation, increase in proportion to the logarithm of time. As discussed above, the use of diagnostic derivative methods (Bourdet et al. 1989) makes it easier to identify the portions within the test data where straight-line analysis is appropriate. As was determined during the course of the investigation, derivative analysis of the corrected test responses indicated that radial flow conditions were not established at any of the selected monitor well locations during either the shutdown/recovery or restart/drawdown phases. Using straight-line analysis methods, therefore, was not appropriate for the corrected test data obtained for the selected WMA T Tank Farm wells monitored during this investigation. The use of straight-line analysis methods is mentioned in this report, however, because of their common use to analyze pumping test results and their particular historical use for pumping tests conducted on the Hanford Site. 


\subsection{Analysis Results}

Based on examination of the individual barometric-corrected well water-level response plots shown in Appendix C, it is apparent that for some well sites, slightly more variability was exhibited for corrected shutdown /recovery in comparison to the corrected restart/drawdown phase. For this reason, the corrected drawdown was selected as the primary data set for comparing hydrologic test analysis results for the respective WMA T Tank Farm monitor wells. Figure 5.1 shows a comparison of the observed and corrected drawdown for well 299-W10-24, which is located $38.95 \mathrm{~m}$ from extraction well 299-W11-46. As indicated, removing barometric effects greatly reduces the apparent "noise fluctuations" exhibited in the observed drawdown response and facilitates the test analysis process. Appendix D presents a comparison of the observed and corrected drawdown data for all WMA T Tank Farm wells examined in this investigation. Figure 5.2 also shows a comparison of the corrected drawdown and corrected shutdown/recovery for this well site. As indicated, the corrected recovery compares favorably to the corrected drawdown, although some departure is indicated during late-recovery time.

An average pumping rate of 37.95 gpm was calculated for extraction well 299-W11-46 during the 33-day restart pumping period (calendar days: 156 to 189; June 4 to July 7, 2008). Although some slight variability in pumping rate was noted in the daily-discharge-rate information listed for this well in Appendix A, this was considered not to be significant and variable-rate pumping test analysis was not warranted.

Three approaches were adopted for analyzing the corrected drawdown data. The first was to group and analyze the wells by proximity to extraction well 299-W11-46. The second was to attempt composite multi-well drawdown analysis for those wells completed at similar aquifer depths and azimuth directions from the extraction well location. Composite multi-well analysis provides a more powerful analytical tool for hydraulic characterization over inter-well regions because of the integration of different areas impacting hydrologic responses of the wells analyzed. Examples of composite multi-well analysis within unconfined aquifer systems are provided in Neuman (1975) and Moench (1994). A third approach that employed individual well analysis was used for those wells not meeting the composite multi-well criteria. Table 5.1 and Table 5.2 list hydrologic test results for these various approaches.

\subsection{Near Well Field Analysis}

The proximity of wells 299-W11-39 and 299-W11-42 to the extraction well location provides the opportunity of analyzing these two monitor wells and the extraction well compositely. While the two monitor wells are completed similarly within the upper $\sim 9 \mathrm{~m}$ of the aquifer and overlap with the deeper aquifer completion of the extraction well (see Table 2.1), the two monitor wells are separated by a wide azimuth angle (i.e., $\sim 155^{\circ}$ ) from the central extraction well location. Additionally, Spane (2008) indicates that previous single-well testing at the two monitor well locations exhibited significant local hydraulic conductivity, $K_{h}$, differences for these two well locations (well 299-W11-39, $K_{h}=1.69 \mathrm{ft} /$ day; well 299$\mathrm{W} 11-42, \mathrm{~K}_{\mathrm{h}}=28.1 \mathrm{~m} /$ day). Given this significant difference in local hydraulic conductivity conditions, it would be unlikely that a composite inter-well analysis would be successful that included these two monitor well locations. Based on this initial assessment, a composite interwell analysis was performed 
for monitor well 299-W11-39 and extraction well 299-W11-46, and an individual well drawdown analysis was conducted for monitor well 299-W11-42.

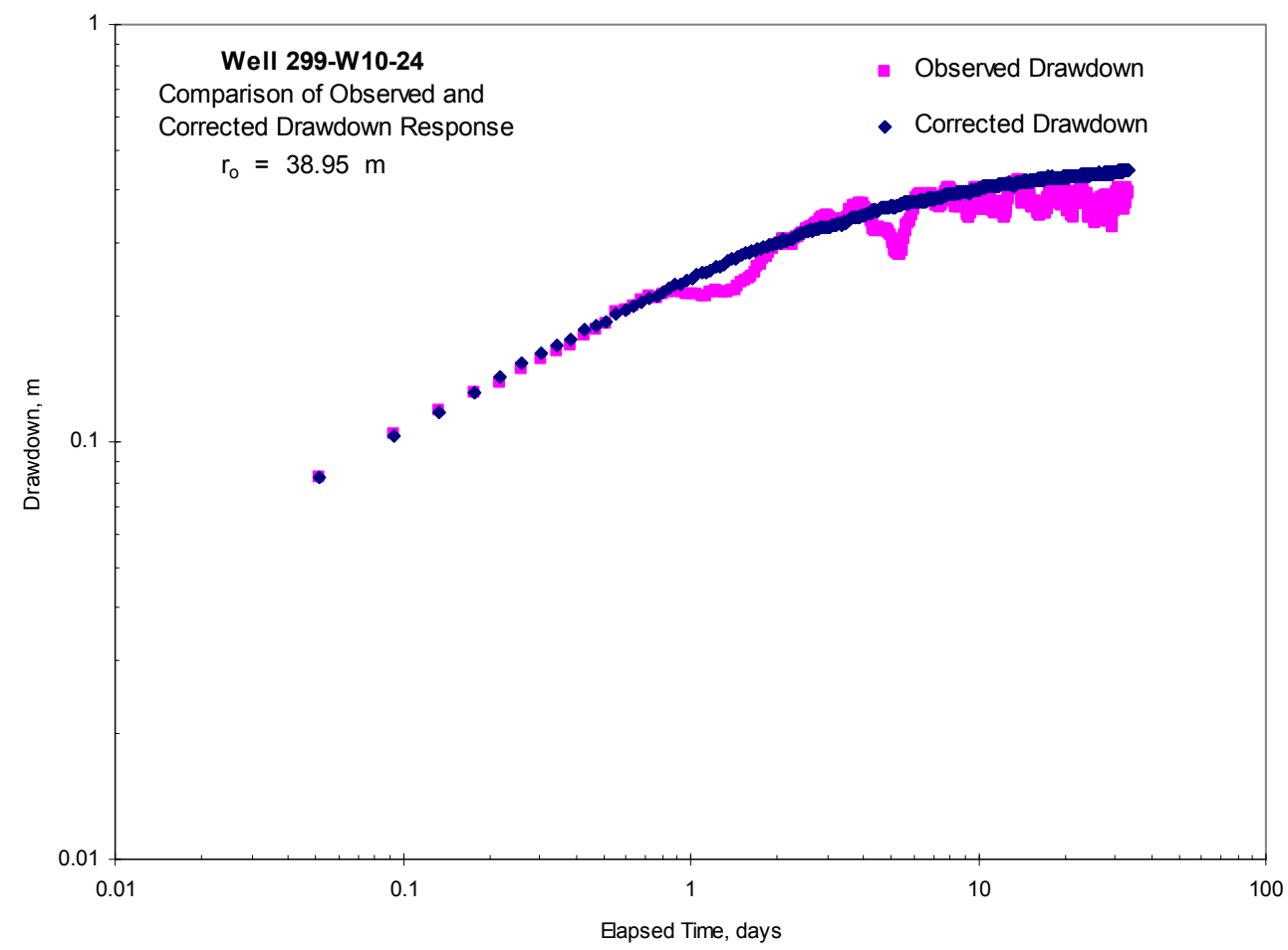

Figure 5.1. Comparison of Observed and Corrected Drawdown Response: Well 299-W10-24

\subsubsection{Composite Analysis: Wells 299-W11-46 and 299-W11-39}

A composite multi-well analysis of monitor well 299-W11-39 and extraction well 299-W11-46 was performed to provide interwell characterization information in the extraction well vicinity. Monitor well 299-W11-39 is located $9.28 \mathrm{~m}$ in a northwest direction $\left(\sim 130^{\circ}\right)$ from the extraction well. Table 2.1 presents details pertaining to the monitoring well's completion, particularly as it relates to the extraction well completion relationship.

Figure 5.3 shows a log-log plot of the corrected drawdown data for both wells. It should be noted that the Jacob (1963), the correction for unconfined aquifer dewatering was applied to the extraction well's corrected drawdown. The corrected drawdown, s', which accounts for aquifer dewatering, can be calculated using the following relationship:

$$
s^{\prime}=s-\left(s^{2} / 2 \mathrm{~b}\right)
$$

where $\mathrm{s}$ is the observed drawdown, and $\mathrm{b}$ is the initial saturated aquifer thickness. 


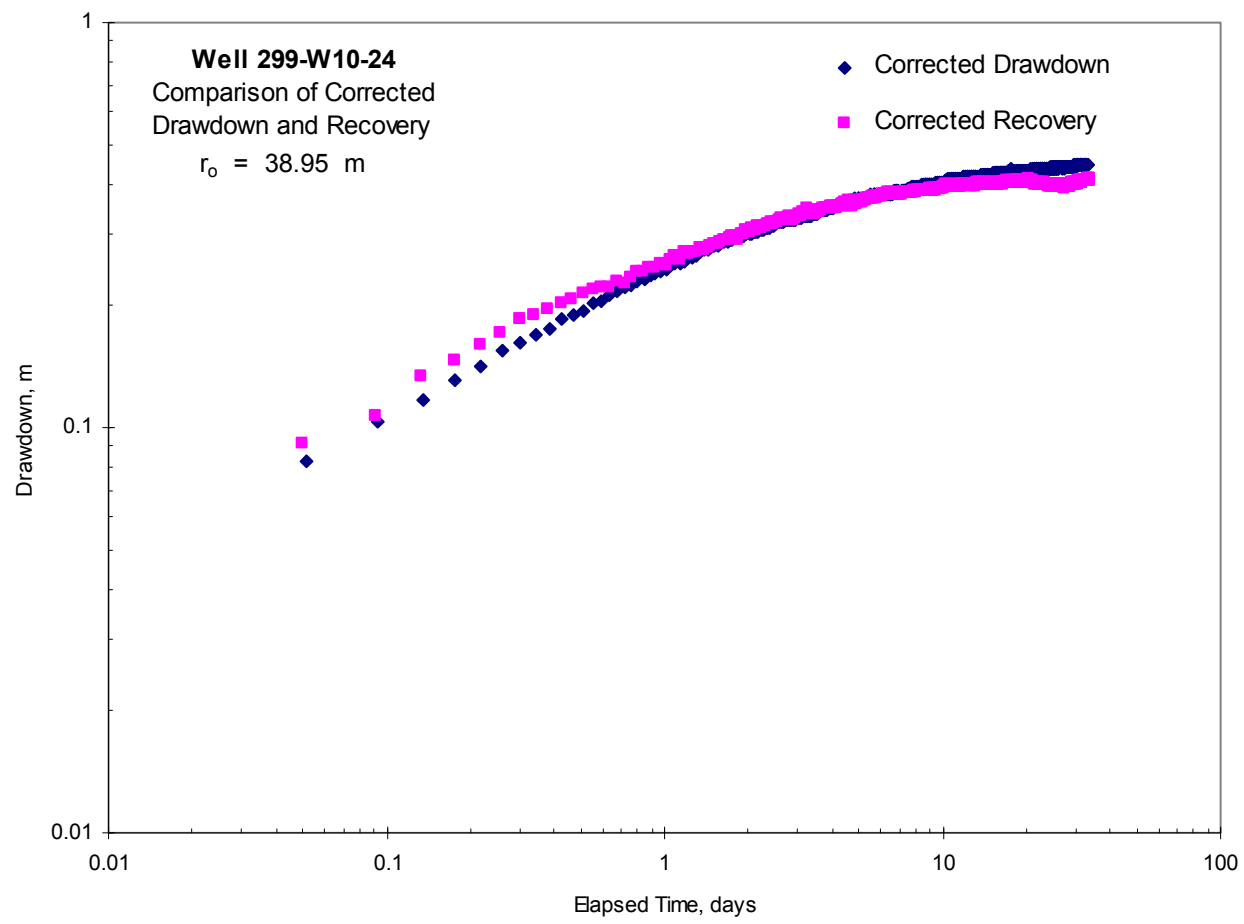

Figure 5.2. Comparison of Corrected Drawdown and Corrected Recovery Response: Well 299-W10-24

Table 5.1. Test Analysis Summary: Near Well Field

\begin{tabular}{|c|c|c|c|c|c|}
\hline \multirow[b]{2}{*}{$\begin{array}{l}\text { Monitor } \\
\text { Well(s) }\end{array}$} & \multicolumn{5}{|c|}{ Hydrologic Property Estimates } \\
\hline & $\begin{array}{c}\mathbf{T}, \\
\mathbf{m}^{2} / \mathbf{d}\end{array}$ & $\begin{array}{c}\mathbf{K}_{\mathbf{h}}^{(\mathbf{a})}, \\
\mathbf{m} / \mathbf{d}\end{array}$ & $\mathbf{K}_{\mathbf{D}}$ & $\mathbf{S}$ & $\mathbf{S}_{\mathbf{y}}^{(\mathbf{b})}$ \\
\hline $\begin{array}{c}\text { Composite } \\
\text { Analysis: } \\
\text { 299-W11-37 } \\
\text { 299-W11-46 }\end{array}$ & 299.4 & 6.11 & 0.05 & $1.9 \mathrm{E}-02$ & $\geq 0.014$ \\
\hline 299-W1-42 & 420.0 & 8.57 & 0.05 & $1.2 \mathrm{E}-02$ & $\geq 0.030$ \\
\hline \multicolumn{6}{|c|}{$\begin{array}{l}\text { (a) } \mathrm{K}_{\mathrm{h}}=\mathrm{T} / \mathrm{b} \text {; where } \mathrm{b}=49.0 \mathrm{~m} \text {. } \\
\text { (b) } \mathrm{S}_{\mathrm{v}} \text { estimate is highly uncertain. }\end{array}$} \\
\hline
\end{tabular}


Table 5.2. Test Analysis Summary: Far Well Field

\begin{tabular}{|c|c|c|c|c|c|}
\hline \multirow[b]{2}{*}{$\begin{array}{l}\text { Monitor } \\
\text { Well(s) }\end{array}$} & \multicolumn{5}{|c|}{ Hydrologic Property Estimates } \\
\hline & $\begin{array}{c}\mathbf{T}, \\
\mathbf{m}^{2} / \mathbf{d}\end{array}$ & $\begin{array}{l}\mathbf{K}_{\mathbf{h}}^{(\mathbf{a})}, \\
\mathbf{m} / \mathbf{d}\end{array}$ & $\mathbf{K}_{\mathbf{D}}$ & $\mathbf{S}$ & $\mathbf{S}_{\mathbf{y}}^{(\mathbf{b})}$ \\
\hline $\begin{array}{c}\text { Composite } \\
\text { Analysis } \\
299-W 10-23 \\
299-W 10-24\end{array}$ & 425 & 8.67 & 0.03 & $9.0 \mathrm{E}-03$ & $\geq 0.015$ \\
\hline $\begin{array}{c}\text { Composite } \\
\text { Analysis: } \\
\text { 299-W11-40 } \\
\text { 299-W11-41 }\end{array}$ & 475 & 9.69 & 0.02 & $2.4 \mathrm{E}-03$ & $\geq 0.013$ \\
\hline 299-W11-45 & 375 & 7.65 & 0.03 & $2.4 \mathrm{E}-3$ & $\geq 0.03$ \\
\hline 299-W11-47 & 425 & 8.67 & 0.04 & $1.8 \mathrm{E}-3$ & $\geq 0.01$ \\
\hline 299-W11-48 & 355 & 7.24 & 0.09 & $1.9 \mathrm{E}-2$ & $\geq 0.01$ \\
\hline $\begin{array}{l}\text { (a) } \mathrm{K}_{\mathrm{h}}=\mathrm{T} / \\
\text { (b) } \mathrm{S}_{\mathrm{y}} \text { estim }\end{array}$ & $=4$ & & & & \\
\hline
\end{tabular}

This drawdown correction was relatively small for the extraction well and largely inconsequential (i.e., $<0.01 \mathrm{~m}$ ) at monitor well 299-W11-39. For this reason, no dewatering corrections were applied for either well 299-W11-39 or at other, more distant monitor well locations.

Figure 5.3 shows the best-fit, type-curve match for the multi-well combination. As shown, the predicted type-curve analytical solution provides a visually good match to the corrected drawdown data. The best-fit type curve solution was obtained using the following hydrologic properties: $\mathrm{T}=299.4 \mathrm{~m}^{2} / \mathrm{d}$, $\mathrm{K}_{\mathrm{h}}=6.11 \mathrm{~m} /$ day, $\mathrm{K}_{\mathrm{D}}=0.05, \mathrm{~S}=0.019$, and $\mathrm{S}_{\mathrm{y}} \geq 0.014$. The calculated value for $\mathrm{S}$ is approximately an order-of-magnitude (or more) greater than anticipated. This higher-than-expected estimate for $\mathrm{S}$, however, may be attributable to the entrainment of gas within the upper-section of the unconfined aquifer because of repeated lowering and rebounding of the water table in the vicinity of the extraction well location. The incorporation of atmospheric/vadose zone gas within the upper-section of the unconfined aquifer greatly increases the composite fluid compressibility and associated storativity (S) of the aquifer in proximity to the extraction well location. Similar behavior has been noted by Yager and Fountain (2001) in the vicinity of confined aquifer pumping wells where the lowering of well water levels can produce exsolution of dissolved gas. This phenomenon, while not the same physical process, produces the same effect of increasing the presence of gas bubbles within the aquifer surrounding the pumping well and produces an increase in aquifer storativity. 


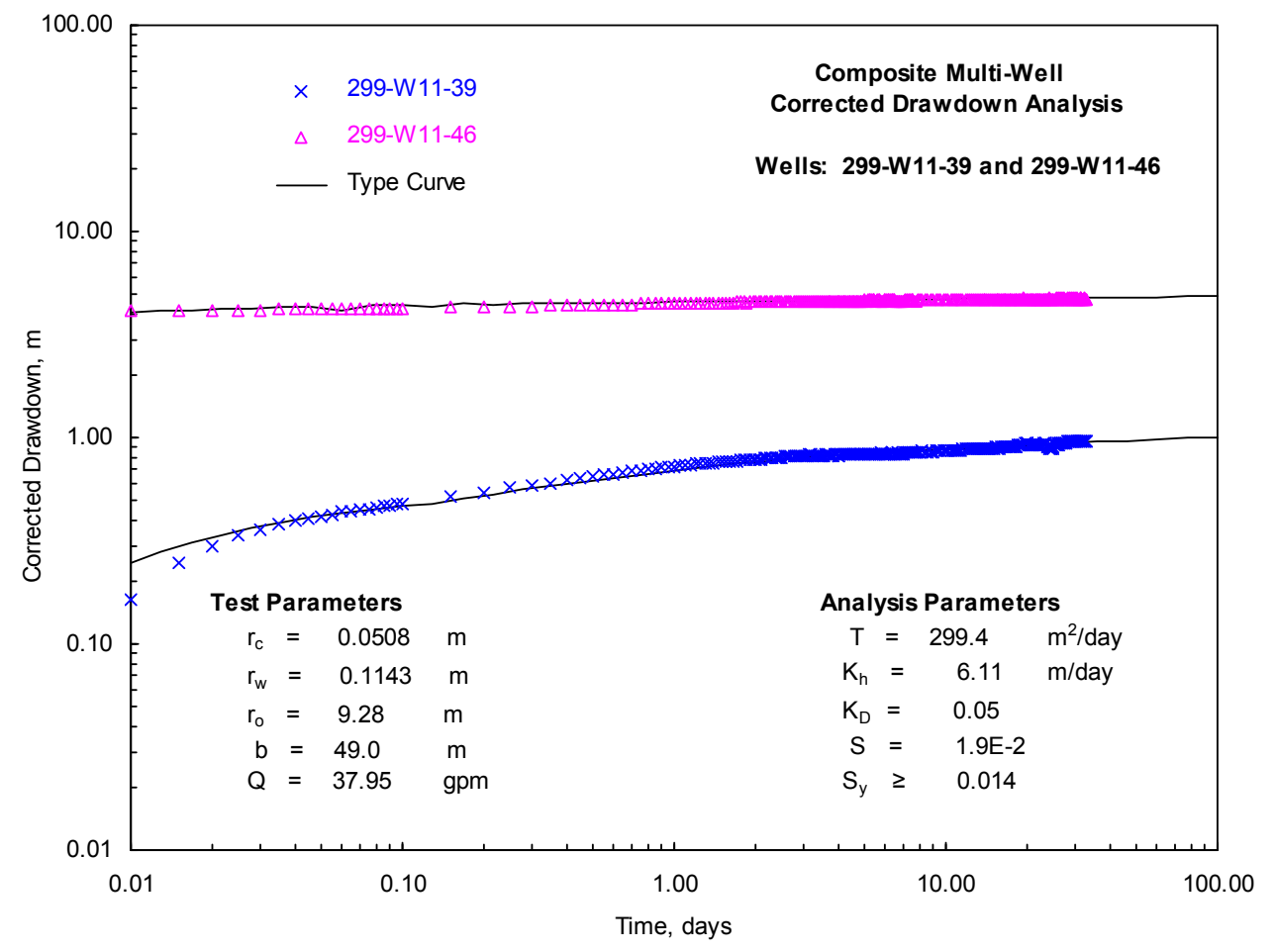

Figure 5.3. Composite Multi-Well Corrected Drawdown Analysis: Wells 299-W11-39 and 299-W11-46

The estimated value for $S_{y}$ represents only a lower bounding value for the well couplet. This parameter is highly dependent on long duration tests that have attained infinite-acting radial flow conditions to resolve with any degree of certainty. However, as noted in Neuman (1974), the effect of wells that only partially penetrate an unconfined aquifer greatly extends the time to establish infiniteacting radial flow conditions within the unconfined aquifer system.

\subsubsection{Well 299-W11-42}

Monitor well 299-W11-42 is located at a distance of $28.16 \mathrm{~m}$ to the south-southeast $\left(\sim 285^{\circ}\right)$ from the extraction well. Table 2.1 presents details pertaining to the well's completion relationship as it relates to extraction well 299-W11-46. Figure 5.4 shows the best-fit, combined type-curve and derivative plot match for the individual well analysis. As shown, the predicted type-curve analytical solution provides a consistent fit for the corrected drawdown data and data derivative for all but the early-time data (i.e., $<0.05$ days). Efforts to improve the early-time fit by adjusting the various hydrologic parameters were largely unsuccessful. The lack of a complete corrected drawdown analysis match may be attributed to the significant differences in local hydraulic properties (horizontal anisotropy) near this well in comparison to the other two nearby wells, as discussed in Section 5.1. The best-fit analysis results shown are considered to provide representative, integrated results for the inter-well distances in this azimuth direction from the extraction well location. As shown in Figure 5.4, the best-fit type curve solution was obtained using the following hydrologic properties: $\mathrm{T}=420.0 \mathrm{~m}^{2} / \mathrm{d}, \mathrm{K}_{\mathrm{h}}=8.57 \mathrm{~m} /$ day, $\mathrm{K}_{\mathrm{D}}=0.05, \mathrm{~S}=0.012$, and $\mathrm{S}_{\mathrm{y}} \geq 0.030$. 


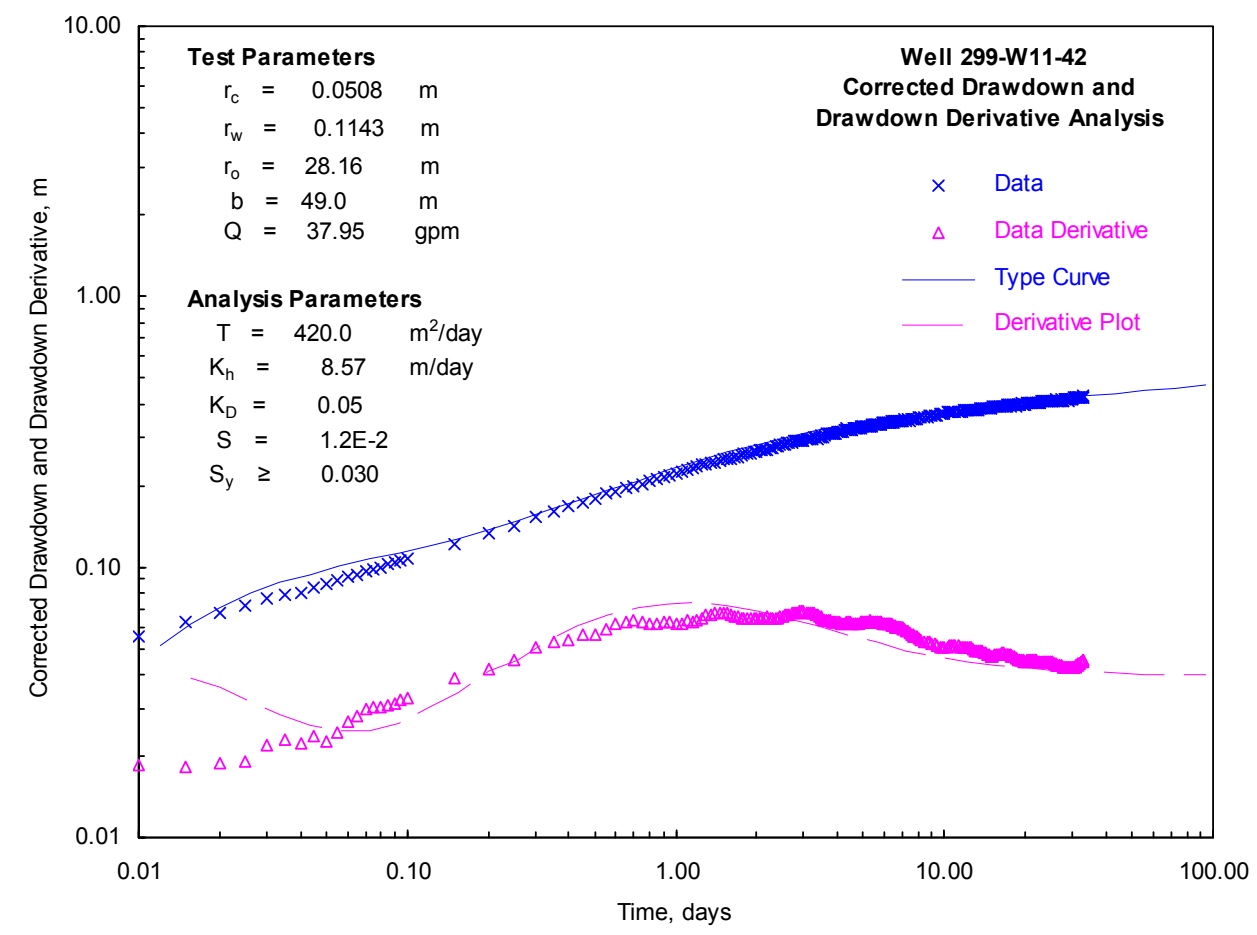

Figure 5.4. Combined Type-Curve and Derivative Plot Analysis of Corrected Drawdown Test Data: Well 299-W11-42

\subsection{Far Well Field Analysis}

Seven of the WMA T Tank Farm wells monitored during this investigation are located at radial distances ranging from 38.95 to $100.37 \mathrm{~m}$ from extraction well 299-W11-46. These more distantly located monitor wells comprise the "Far Well Field" analysis group. Four of the wells (299-W10-23, 299-W10-24, 299-W11-40, and 299-W11-41) are screened within the upper 8 to $9 \mathrm{~m}$ of the unconfined aquifer, while the other three wells in the far well field grouping are completed below the water table at different aquifer depth intervals (see Table 2.1). Two well couplets are present within the far well field group that present opportunities for composite multi-well analysis in northwest and south-southeast azimuth directions from the extraction well location. Wells 299-W10-23 and 299-W10-24 are located to the northwest, and wells 299-W11-40 and 299-W11-41 are situated south-southeast of the extraction well. The three remaining monitor wells in the far well field group are located either in different azimuth directions or completed at different aquifer depths. Consequently, these three wells were analyzed individually.

\subsubsection{Composite Analysis: Wells 299-W10-23 and 299-W10-24}

A composite multi-well analysis of monitor wells 299-W10-23 and 299-W10-24 was performed to provide directional interwell characterization information between the extraction well and monitor well locations. Monitor wells 299-W10-23 and 299-W10-24 are located in a northwesterly azimuth direction $\left(\sim 130^{\circ}\right)$ from the extraction well at radial distances of 100.37 and $38.95 \mathrm{~m}$, respectively. Both wells are 
screened within the upper $\sim 8 \mathrm{~m}$ of the unconfined aquifer. Table 2.1 presents specific details pertaining to the two monitor wells completion relationships.

Figure 5.5 shows a log-log plot of the corrected drawdown data for both monitor wells. As shown, the predicted composite type-curve analytical solution provides a good match to the corrected drawdown data for all but the early-time data (i.e., $<0.1$ days). Efforts to improve the early-time fit were made for individual monitor wells by adjusting S; however, a composite early-time match at both wells could not be realized. The lack of a complete corrected drawdown analysis match may be attributed to slight variations in elastic storage properties $(\mathrm{S})$ of the unconfined aquifer over the monitoring well distance. The best-fit analysis results shown are considered to provide representative, integrated results for the inter-well distances in this azimuth direction from the extraction well location. The best-fit type curve solution was obtained using the following hydrologic properties: $\mathrm{T}=425.0 \mathrm{~m}^{2} / \mathrm{d}, \mathrm{K}_{\mathrm{h}}=8.67 \mathrm{~m} /$ day, $\mathrm{K}_{\mathrm{D}}=0.03, \mathrm{~S}=0.009$, and $\mathrm{S}_{\mathrm{y}} \geq 0.015$. As noted for previously discussed well analyses, the estimated value for $S_{\mathrm{y}}$ represents only a lower bounding value for the well couplet.

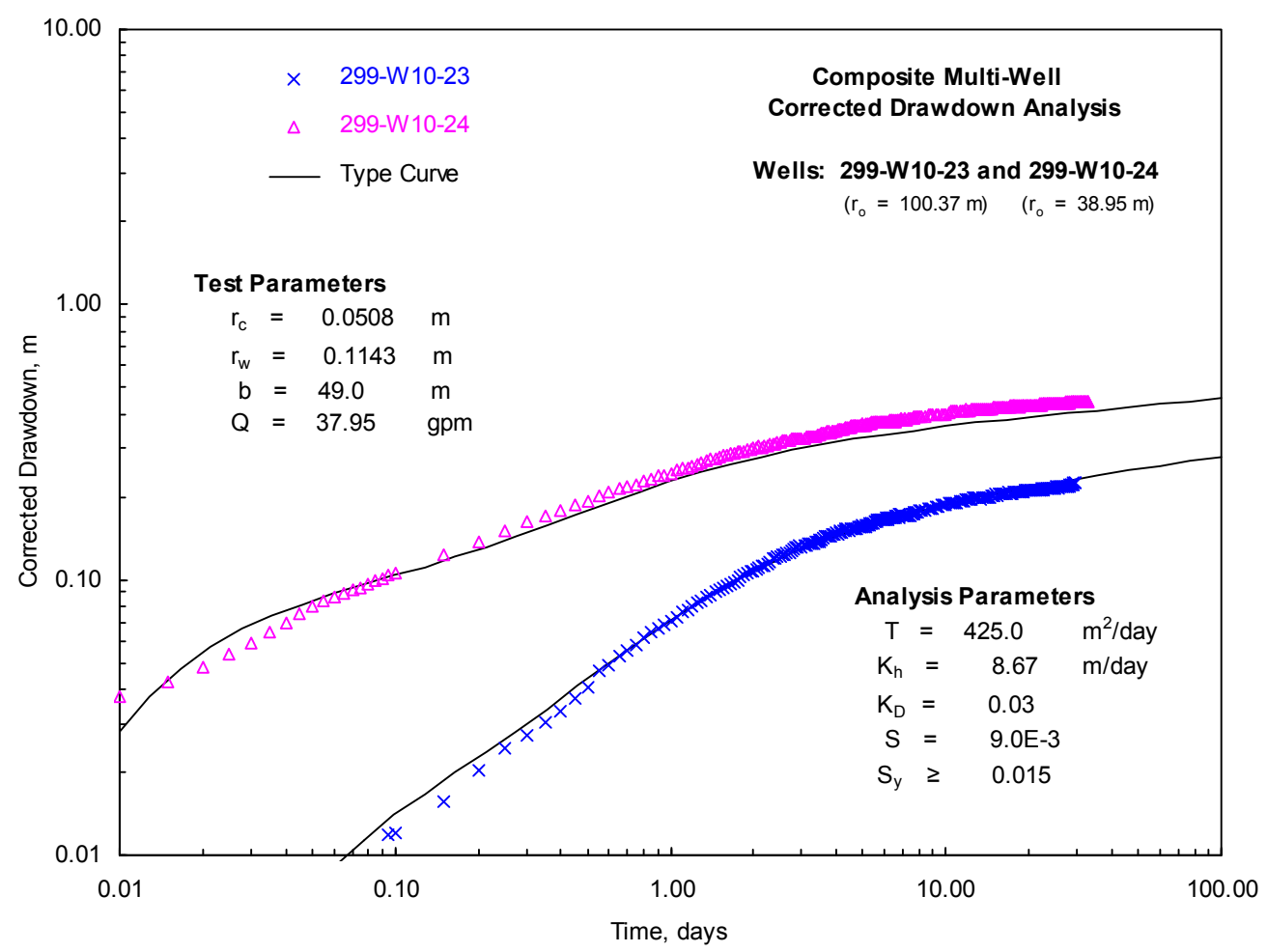

Figure 5.5. Composite Multi-Well Corrected Drawdown Analysis: Wells 299-W10-23 and 299-W10-24

\subsubsection{Composite Analysis: Wells 299-W11-40 and 299-W11-41}

A composite multi-well analysis of monitor wells 299-W11-40 and 299-W11-41 was performed to provide directional interwell characterization information between the extraction well and monitor well locations. Monitor wells 299-W11-40 and 299-W11-41 are located in a south-southeasterly azimuth direction $\left(\sim 285^{\circ}\right)$ from extraction well 299-W11-46 at radial distances of 64.72 and $97.70 \mathrm{~m}$, respectively. 
Both wells are screened within the upper $\sim 9 \mathrm{~m}$ of the unconfined aquifer. Table 2.1 presents specific details pertaining to the two monitor wells completion relationships.

Figure 5.6 shows a log-log plot of the corrected drawdown data for both monitor wells. As shown, the predicted composite type-curve analytical solution provides a good match to the corrected drawdown data for all but the early-time data (i.e., $<0.2$ days). Efforts to improve the early-time fit were made for individual monitor wells by adjusting $\mathrm{S}$; however, a composite early-time match at both wells could not be realized. The lack of a complete corrected drawdown analysis match may be attributed to slight variations in elastic storage properties $(\mathrm{S})$ of the unconfined aquifer over the monitoring well distance. The best-fit analysis results shown are considered to provide representative, integrated results for the inter-well distances in this azimuth direction from the extraction well location. The best-fit type curve solution was obtained using the following hydrologic properties: $T=475.0 \mathrm{~m}^{2} / \mathrm{d}, \mathrm{K}_{\mathrm{h}}=9.69 \mathrm{~m} /$ day, $\mathrm{K}_{\mathrm{D}}=0.02, \mathrm{~S}=0.0024$, and $\mathrm{S}_{\mathrm{y}} \geq 0.013$. As noted for previously discussed well analyses, the estimated value for $S_{\mathrm{y}}$ represents only a lower bounding value for the well couplet.

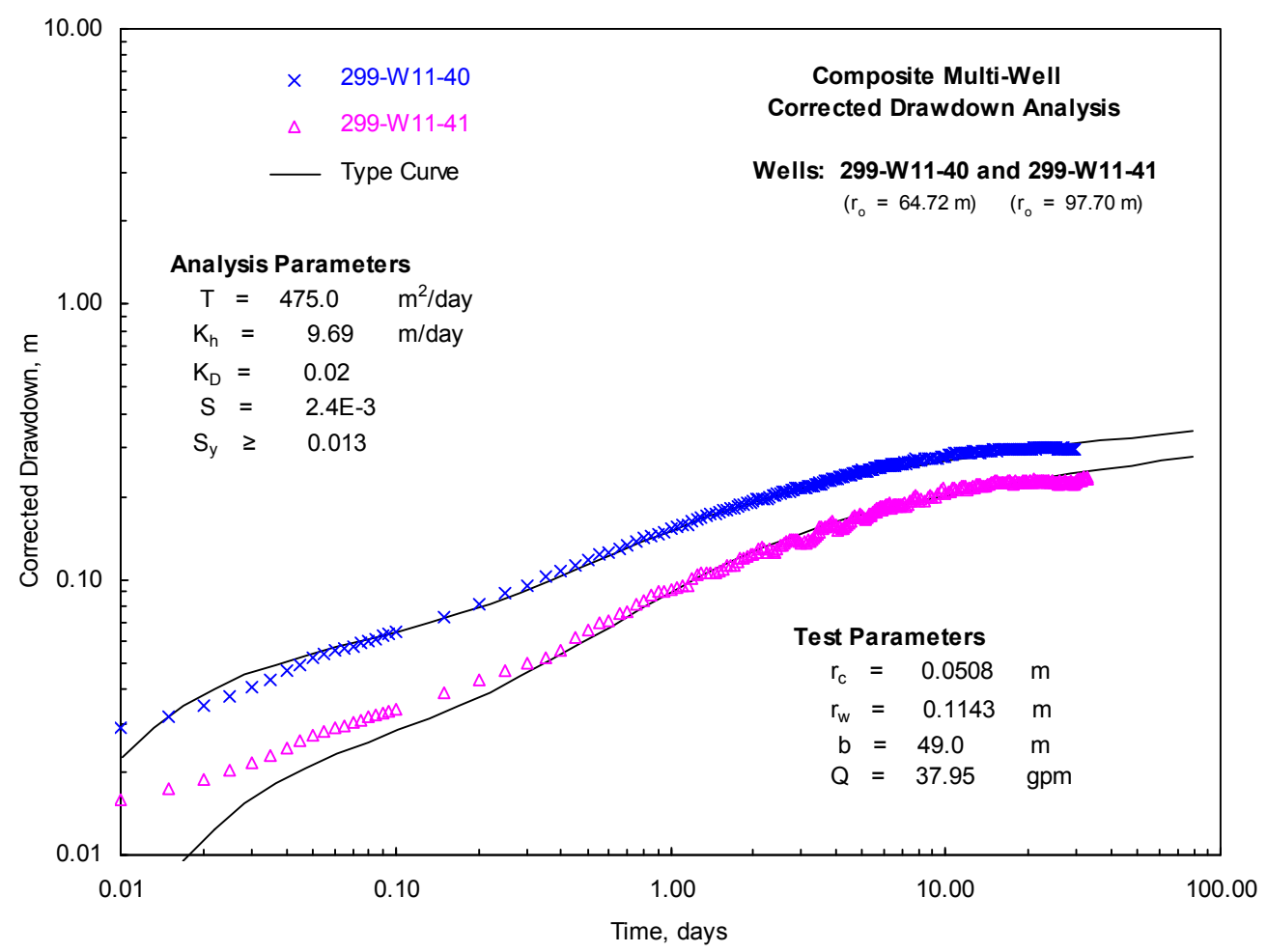

Figure 5.6. Composite Multi-Well Corrected Drawdown Analysis: Wells 299-W11-40 and 299-W11-41

\subsubsection{Well 299-W11-45}

Well 299-W11-45 is located at a distance of $78.02 \mathrm{~m}$ east $\left(\sim 5^{\circ}\right)$ from extraction well 299-W11-46. Table 2.1 presents details pertaining to the well's completion relationship as it relates to the extraction well. As noted previously, well 299-W11-45 did not have an automated data recording system for waterlevel measurements. Water-level measurements were recorded routinely in field notebooks during the 
initial day of both shutdown/recovery and restart/drawdown, and then were infrequently based on field site visits during the subsequent recovery and drawdown periods.

Figure 5.7 shows a log-log plot of the corrected drawdown data for this well, based on drawdown corrections calculated and applied at nearby monitor well 299-W11-42. Because of the variability imposed in the corrected drawdown data due to the infrequency of the drawdown measurements, no quantitative analysis was initially expected for this data set. An attempt was made, however, to fit a drawdown type curve to the corrected drawdown data. The predicted drawdown type-curve analytical solution shown in the figure provides a reasonable match to the corrected drawdown data and provided comparable hydrologic property estimates as obtained from the more quantitative monitor well data sets. As shown in Figure 5.7, the best-fit type curve solution was obtained using the following hydrologic properties: $\mathrm{T}=375.0 \mathrm{~m}^{2} / \mathrm{d}, \mathrm{K}_{\mathrm{h}}=7.65 \mathrm{~m} /$ day, $\mathrm{K}_{\mathrm{D}}=0.03, \mathrm{~S}=0.0024$, and $\mathrm{S}_{\mathrm{y}} \geq 0.030$.

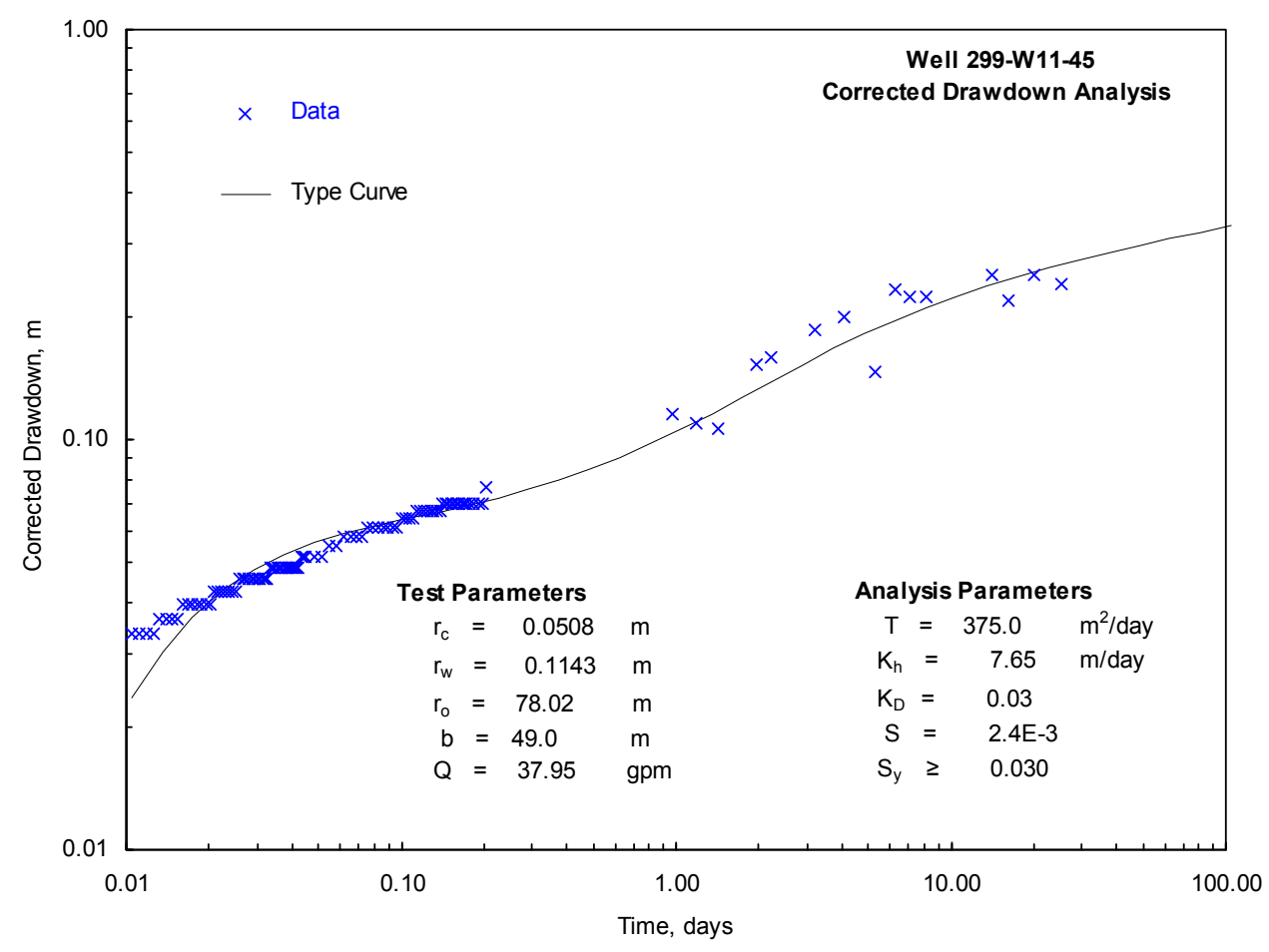

Figure 5.7. Combined Type-Curve and Derivative Plot Analysis of Corrected Drawdown Test Data: Well 299-W11-45

\subsubsection{Well 299-W11-47}

Well 299-W11-47 is located at a distance of $94.49 \mathrm{~m}$ south-southeast $\left(\sim 287^{\circ}\right)$ from the extraction well location. Table 2.1 presents details pertaining to the well's completion relationship as it relates to extraction well 299-W11-46. Figure 5.8 shows a log-log plot of the corrected drawdown and drawdown derivative for this well. The variability exhibited, particularly in the drawdown derivative, is attributed to random transducer noise, which was noted during the baseline monitoring period. Figure 5.8 also shows the best-fit, combined type-curve and derivative plot match for corrected drawdown data. As indicated, 
the predicted type-curve and derivative plot solution provides a consistent fit over the entire drawdown period. The best-fit type curve and derivative plot solution was obtained using the following hydrologic properties: $\mathrm{T}=425.0 \mathrm{~m}^{2} / \mathrm{d}, \mathrm{K}_{\mathrm{h}}=8.67 \mathrm{~m} /$ day, $\mathrm{K}_{\mathrm{D}}=0.04, \mathrm{~S}=0.0018$, and $\mathrm{S}_{\mathrm{y}} \geq 0.010$. As noted for previously discussed well analyses, the estimated value for $\mathrm{S}_{\mathrm{y}}$ represents only a lower bounding value.

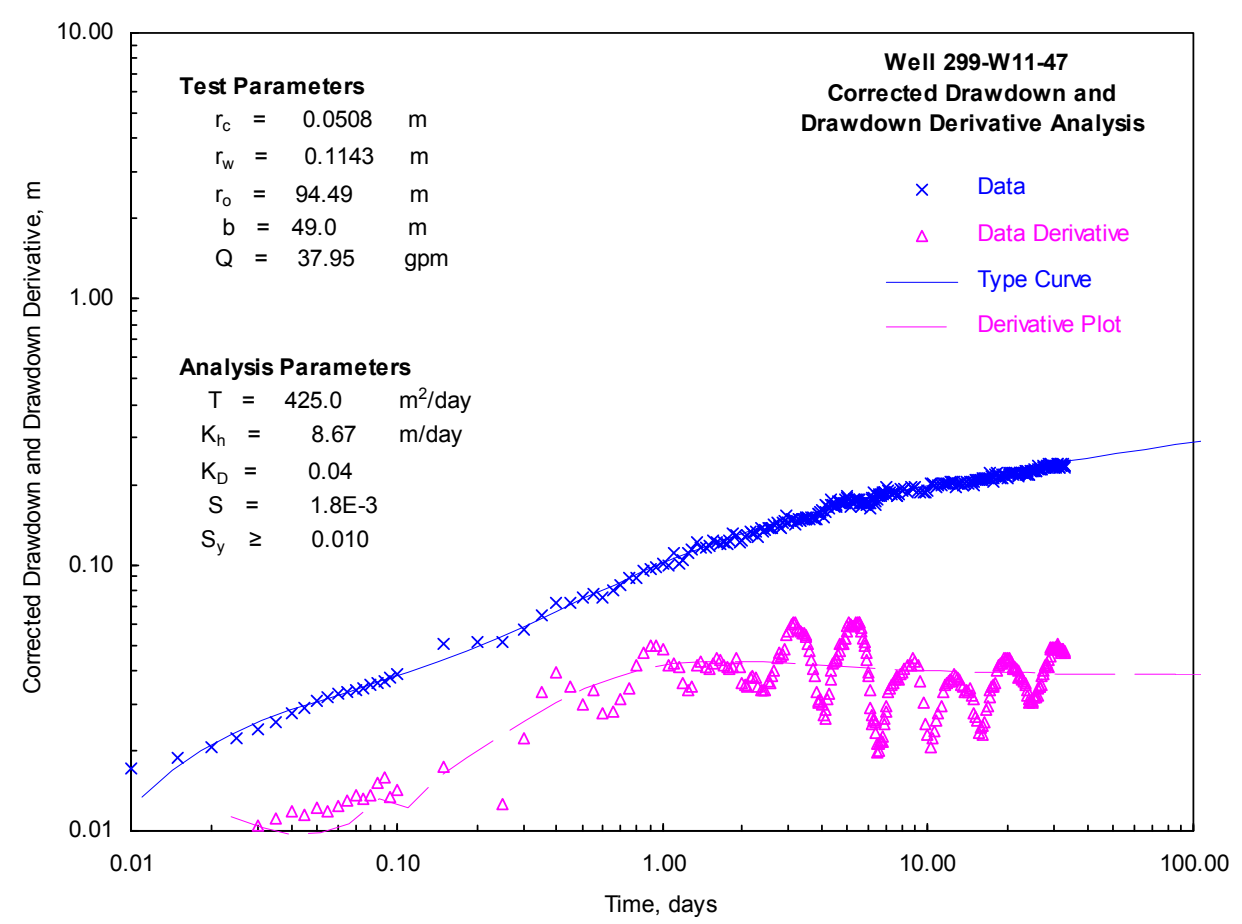

Figure 5.8. Combined Type-Curve and Derivative Plot Analysis of Corrected Drawdown Test Data: Well 299-W11-47

\subsubsection{Well 299-W11-48}

Well 299-W11-48 is located at a distance of $79.99 \mathrm{~m}$ north $\left(\sim 87^{\circ}\right)$ from the extraction well location. Table 2.1 presents details pertaining to the well's completion relationship as it relates to extraction well 299-W11-46. Figure 5.9 shows a log-log plot of the corrected drawdown and drawdown derivative for this well. Also shown is the best-fit, combined type-curve and derivative plot match for corrected drawdown data. As indicated, the predicted type-curve and derivative plot solution provides a consistent fit over the entire drawdown period. The best-fit type curve and derivative plot solution was obtained using the following hydrologic properties: $\mathrm{T}=355.0 \mathrm{~m}^{2} / \mathrm{d}, \mathrm{K}_{\mathrm{h}}=7.24 \mathrm{~m} /$ day, $\mathrm{K}_{\mathrm{D}}=0.09, \mathrm{~S}=0.019$, and $\mathrm{S}_{\mathrm{y}} \geq 0.010$. As noted for previously discussed well analyses, the estimated value for $\mathrm{S}_{\mathrm{y}}$ represents only a lower bounding value. 


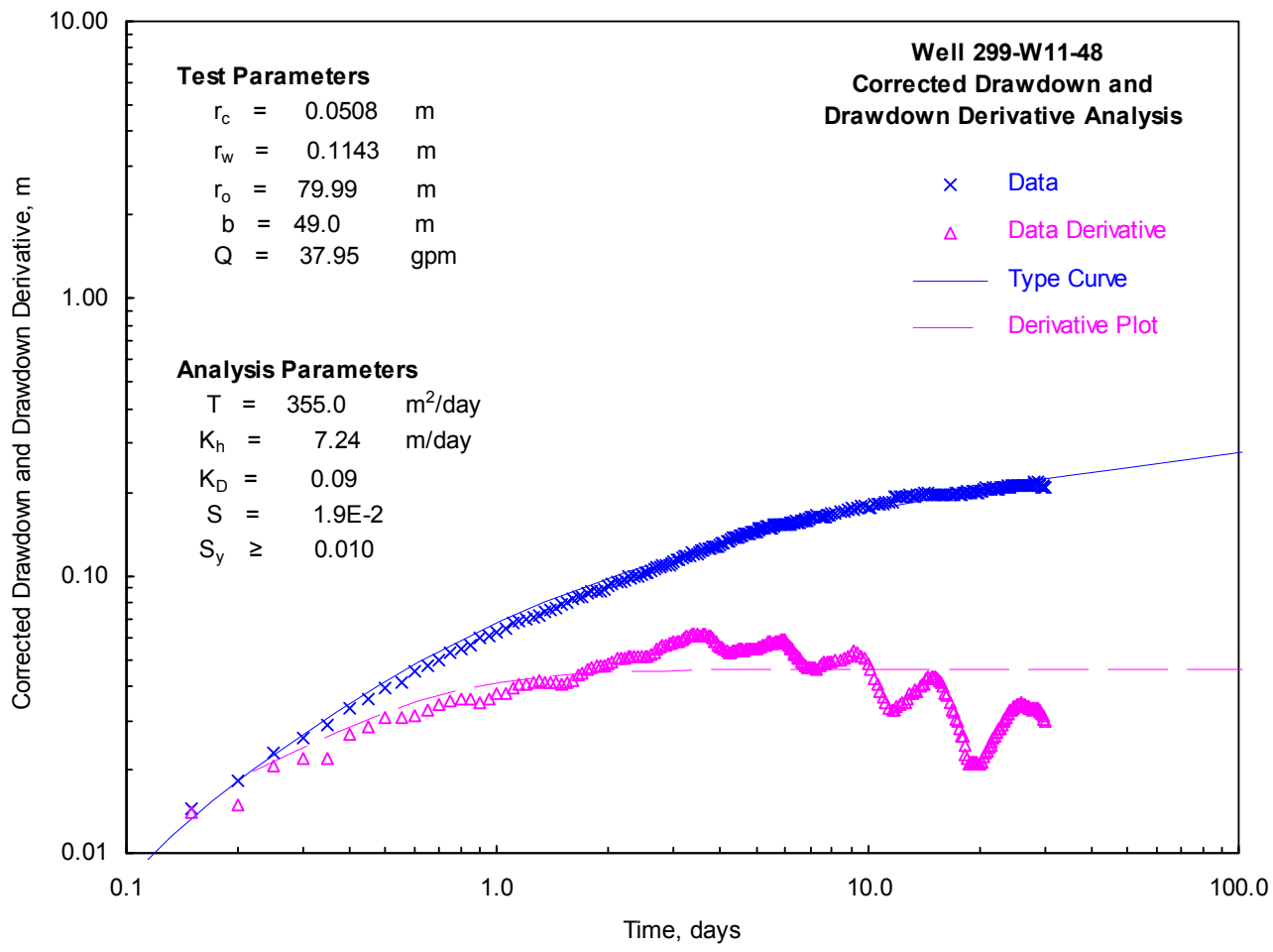

Figure 5.9. Combined Type-Curve and Derivative Plot Analysis of Corrected Drawdown Test Data: Well 299-W11-48 


\subsection{Conclusions}

Specific findings pertaining to barometric response removal, hydraulic property characterization, and imposed hydrologic influence of the shutdown and restart of the WMA T Tank Farm pump-and-treat facility are summarized below:

1. Removal of barometric pressure fluctuations using the multiple-regression deconvolution technique significantly improves the ability to detect and analyze small magnitude hydrologic stresses (e.g., $0.01 \mathrm{~m}$ ) imposed by the pump-and-treat system, particularly for distant monitor well responses.

2. The barometric response pattern for the T Tank Farm monitor wells examined in this study indicate very similar time-lag characteristics and exhibit time-lag dependence ranging from 92 to 134 hours.

3. Of the monitor wells examined, only monitor well 299-W11-48 exhibits a different barometric response pattern. The difference in behavior exhibited by well 299-W11-48 may be attributed to inclusion of atmospheric pressure change values in the in-well pressure transducer readings, which could be caused by a blockage of the reference vent tube for the pressure transducer readings within this well.

4. Operating the WMA T Tank Farm pump-and-treat system imposes variable hydrologic pressure responses both laterally and vertically (i.e., with depth) over a significant distance within the surrounding unconfined aquifer. Observable responses at monitor well distances of $\sim 100 \mathrm{~m}$ were detected within 1 day of pump-and-treat operation. It is likely that the lateral radius of influence for the facility exceeds $300 \mathrm{~m}$ for facility operation times of 1 month or more.

5. In all, the $10 \mathrm{~T}$ Tank Farm wells monitored during this investigation provided results for six composite and individual interwell tests for unconfined aquifer characterization. These largescale aquifer characterization results will be utilized for optimization and site selection of additional extraction wells within the WMA T Tank Farm pump-and-treat system.

6. Analysis of the barometric-corrected drawdown well data during the restart pumping phase of the study provided hydraulic property estimates for transmissivity that ranged from 299 to $475 \mathrm{~m}^{2} / \mathrm{d}$. The calculated value range compares closely with large-scale values of 300 and $327 \mathrm{~m}^{2} / \mathrm{d}$ previously reported in Newcomb and Strand (1953) and Wurstner et al. (1995), respectively, for the unconfined aquifer within the 200-West Area. These previously reported values were based on analyzing the areal growth and decline of the groundwater mound that developed in this area as a result of wastewater disposal activities. Additionally, the transmissivity value range compares favorably with the transmissivity range of 230 and $430 \mathrm{~m}^{2} / \mathrm{d}$ reported by Spane and Thorne (2000) for the unconfined aquifer south of the WMA TX Tank Farm, which was derived using a similar hydrologic operational pump-and-treat assessment. 
7. Estimates for hydraulic conductivity ranged from 6.11 to $9.69 \mathrm{~m} / \mathrm{d}$ (geometric mean $=8.01 \mathrm{~m} / \mathrm{d}$ ). The calculated geometric mean value from the large-scale restart/drawdown analysis is slightly higher than the geometric mean value $5.22 \mathrm{~m} /$ day (range: 1.24 and $28.1 \mathrm{~m} /$ day) obtained from single-well slug test characterizations performed for 12 WMA T Tank Farm wells as reported in Spane and Newcomer (2008) and Spane (2008). The calculated geometric value is also slightly greater than the baseline value of $5.2 \mathrm{~m} / \mathrm{d}$ used for this area in previous numerical simulations of sitewide groundwater flow (e.g., Law et al. 1996) and pump-and-treat activities (Freeman-Pollard et al. 1996).

8. Estimates for storativity ranged from $1.8 \mathrm{E}-3$ to $1.9 \mathrm{E}-2$. This yields an equivalent specific storage value range of $3.7 \mathrm{E}-5$ to $3.9 \mathrm{E}-4 \mathrm{~m}^{-1}$, based on an average aquifer thickness of $49 \mathrm{~m}$. Specific yield estimates for the multi-well restart analyses generally ranged from $\geq 0.01$ to $\geq 0.03$ and represent lower bounding values for this hydrologic parameter. The lower bounding values are lower than expected (i.e., between 0.05 and 0.15 ) for this hydrogeologic unit. The reason for this apparent discrepancy is related to the dependence of this hydrologic parameter on late-time test data, which is highly impacted by water-level trends (which are difficult to resolve with a high degree of certainty within a dynamically perturbed hydrologic system. Additionally, the partial aquifer penetration aspect of the WMA T Tank Farm well completions greatly extends the time requirement for fully resolving specific yield for hydrologic test conditions. For these reasons, estimates for specific yield obtained from the restart/drawdown analysis are considered to be less reliable in comparison to estimates derived for hydraulic conductivity. However, it should also be noted that these lower-than-expected specific yield values are similar to previous findings from other unconfined aquifer location investigations where type-curve analysis methods were used (e.g., Mock and Merz 1993; Moench 1994; Spane and Thorne 2000).

9. Estimates obtained for vertical anisotropy $\left(\mathrm{K}_{\mathrm{D}}=\mathrm{K}_{\mathrm{v}} / \mathrm{K}_{\mathrm{h}}\right)$ ranged from 0.02 to 0.09 . These values are within the anticipated range for layered sedimentary units like the Ringold Formation Unit $\mathrm{E}$ in which the pump-and-treat and monitor well systems are completed. No quantitative estimates for horizontal anisotropy were possible from the inter-well tests. This was due to the generally restricted azimuth deployment (i.e., north-south) of the WMA T Tank Farm monitor well locations. The relative correspondence of hydraulic property results for composite and individual inter-well tests, however, suggests that there is little large-scale horizontal anisotropy within the unconfined aquifer system at this location.

In conclusion, the analysis of barometric-corrected well water-level responses imposed by the 200-ZP-1 pump-and-treat system provides an opportunity for obtaining detailed, large-scale information for a wide range of hydrologic properties (i.e., transmissivity, hydraulic conductivity, vertical and horizontal anisotropy, storativity, and specific yield). Many of these properties cannot be reliably estimated using standard single-well tests or hydrologic tests of short duration. This type of large-scale hydrologic characterization information can provide valuable input for assessing the performance of pump-and-treat facilities and for predicting contaminant movement and capture within the remediated area. It is recommended for future studies of shutdown and restart cycles that each cycle be maintained for a minimum of 3 continuous months. Extending the shutdown and restart periods from the $\sim 1$ month 
period (used in this investigation) to a 3-month period may reduce the uncertainty in estimating aquiferspecific yield, which is highly dependent on late-time test response. 


\subsection{References}

Bourdet DJ, A Ayoub, and YM Pirard. 1989. "Use of pressure derivative in well-test interpretation." SPE Formation Evaluation June 1989:293-302.

Cooper HH, Jr., and CE Jacob. 1946. "A generalized graphical method for evaluating formation constants and summarizing well-field history." Amer. Geophys. Union, Transactions 27(4):526-534.

DOE (see U.S. Department of Energy)

EPA (see U.S. Environmental Protection Agency)

Fix NJ. 2008. Fluor Hanford, Inc. groundwater and technical integration support (master project) quality assurance management plan. PNNL-17346, Pacific Northwest National Laboratory, Richland, Washington.

Freeman-Pollard JR, ID Jacques, WJ McMahon, KM Singleton, SA Strope, LC Swanson, and CR Winmueller. 1996. 200-ZP-1 phase II interim remedial measure quarterly report; August-October 1996, BHI-00952-01, Rev. 0. Bechtel Hanford, Inc., Richland, Washington.

Hantush MS. 1964. "Hydraulics of wells." Advances in Hydroscience (editor V.T. Chow) 1:282-433, Academic Press, New York.

Horton DG. 2006. RCRA assessment plan for single-shell tank waste management area T. PNNL15301, Pacific Northwest National Laboratory, Richland, Washington.

HydraLogic. 1989. ISOAQX: a computer program for aquifer characterization type-curve matching and drawdown projections under horizontally isotropic assumptions - operations guide. HydraLogic, P.O. Box 4722, Missoula, Montana.

Jacob CE. 1963. "Determining the permeability of water-table aquifers." In Bentall R. (compiler), Methods of determining permeability, transmissibility, and drawdown." U.S. Geological Survey, WaterSupply Paper 1536-I:245-271.

Law A, S Panday, C Denslow, K Fecht, and A Knepp. 1996. Hanford sitewide groundwater flow and transport model calibration report. BHI-00608, Rev. 1, Bechtel Hanford, Inc., Richland, Washington.

Lindsey KA. 1995. Miocene- to Pliocene-aged suprabasalt sediments of the Hanford Site, south-central Washington. BHI-00184, Bechtel Hanford, Inc., Richland, Washington.

Mock P and J Merz. 1993. "Observations of delayed gravity response in partially penetrating wells." Ground Water 28(1):11-16 
Moench AF. 1994. "Specific yield as determined by type-curve analysis of aquifer-test data." Ground Water 32(6):949-957.

Moench AF. 1997. "Flow to a well of finite diameter in a homogeneous, anisotropic water-table aquifer." Water Resources Research 33(6):1397-1407.

Neuman SP. 1972. "Theory of flow in unconfined aquifers considering delayed response of the water table." Water Resources Research 8(4):1031-1045.

Neuman SP. 1974. "Effect of partial penetration of flow in unconfined aquifer considering delayed gravity response.” Water Resources Research 10(2):303-312.

Neuman SP. 1975. "Analysis of pumping test data from anisotropic unconfined aquifers considering delayed gravity response." Water Resources Research 11(2):329-342.

Newcomb RC and JR Strand. 1953. Geology and ground-water characteristics of the Hanford reservation of the U.S. Atomic Energy Commission, Washington. U.S. Geological Survey Administrative Report WP-8, U.S. Geological Survey, Washington, D.C.

PNL-MA-567. 1993, as amended. Procedures for ground-water investigations. Pacific Northwest National Laboratory, Richland, Washington.

Rasmussen TC and LA Crawford. 1997. "Identifying and removing barometric pressure effects in confined and unconfined aquifers." Ground Water 35(3):502-511.

Shestakov, VM. 2002. "Development of relationship between specific storage and depth of sandy and clay formations." Environmental Geology 42:127-129.

Spane FA, Jr. 1993. Selected hydraulic test analysis techniques for constant-rate discharge tests. PNL-8539, Pacific Northwest Laboratory, Richland, Washington.

Spane FA, Jr. 1999. Effects of barometric fluctuations on well water-level measurements and aquifer test data. PNNL-13078, Pacific Northwest National Laboratory, Richland, Washington.

Spane FA, Jr. 2002. “Considering barometric pressure in groundwater flow investigations.” Water Resources Research 38(6), 14:1-18.

Spane FA. 2008. Aquifer testing recommendations for supporting phase II of the T-Area technetium-99 data objectives process - letter report. PNNL-17433, Pacific Northwest National Laboratory, Richland, Washington.

Spane FA., Jr., and DR Newcomer. 2008. Results of detailed hydrologic characterization tests - fiscal and calendar year 2005. PNNL-17348, Pacific Northwest National Laboratory, Richland, Washington. 
Spane FA and PD Thorne. 2000. Analysis of the hydrologic response associated with shutdown and restart of the 200-ZP-1 pump-and-treat system. PNNL-13342, Pacific Northwest National Laboratory, Richland, Washington.

Spane FA, Jr. and SK Wurstner. 1993. "DERIV: A program for calculating pressure derivatives for use in hydraulic test analysis." Ground Water 31(5):814-822.

Theis CV. 1935. "The relationship between the lowering of the piezometric surface and the rate and duration of discharge of a well using ground-water storage." Amer. Geophys. Union, Transactions, 2: 519-524; reprinted in Society of Petroleum Engineers, "Pressure Transient Testing Methods.", SPE Reprint Series (14):27-32.

U.S. Department of Energy Richland Operations (DOE/RL). 2000. Fiscal year 1999 annual summary report for the 200-UP-1, 200-ZP-1, and 100-NR-2 pump and treat operations and operable units. DOE/RL-99-79, Rev. 0. U.S. Department of Energy, Richland Operations Office, Richland, Washington.

U.S. Department of Energy Richland Operations (DOE/RL). 2008. Sampling and analysis plan for performing aquifer recovery tests in wells 299-W11-45 and 299-W11-46. DOE/RL-2008-32, Rev. 0. U.S. Department of Energy, Richland Operations Office, Richland, Washington.

U.S. Environmental Protection Agency (EPA), Ecology, and DOE. 1995. Declaration of the Interim Record of Decision for the 200-ZP-1 Operable Unit, U.S. Environmental Protection Agency, Washington State Department of Ecology, and U.S. Department of Energy, Olympia, Washington.

Waste Management Program (WMP)-28389. 2007. T-Area Technetium-99 Data Quality Objectives Summary Report, Rev. 0. Fluor Hanford, Inc., Richland, Washington.

Weeks EP. 1979. "Barometric fluctuations in wells tapping deep unconfined aquifers." Water Resources Research 15(5):1167-1176.

Wurstner SK, PD Thorne, MA Chamness, MD Freshley, and MD Williams. 1995. Development of a three-dimensional ground-water model of the Hanford Site unconfined aquifer system: FY 1995 status report. PNL-10886, Pacific Northwest Laboratory, Richland, Washington.

Yager, RM and JC Fountain. 2001. "Effect of natural gas exsolution on specific storage in a confined aquifer undergoing water level decline." Ground Water 39(4):517-525. 


\section{Appendix A}

\section{Daily Groundwater Pumping Rate Data for WMA T Tank Farm Extraction Wells: 299-W11-45 and 299-W11-46}

(Information provided by R.S. Edrington. Note: the two daily readings represent observed pumping rate measurements taken in the morning and afternoon, respectively.) 
Appendix A: Daily Groundwater Pumping Rate Data for WMA T Tank Farm Extraction Wells: 299-W11-45 and 299-W11-46 


\begin{tabular}{|c|c|c|c|c|c|}
\hline Date & $\begin{array}{c}\text { W11-45 } \\
\text { Flow } \\
\text { (gpm) }\end{array}$ & $\begin{array}{c}\text { W11-46 } \\
\text { Flow } \\
\text { (gpm) }\end{array}$ & Date & $\begin{array}{c}\text { W11-45 } \\
\text { Flow } \\
\text { (gpm) }\end{array}$ & $\begin{array}{r}\text { W11-46 } \\
\text { Flow } \\
\text { (gpm) }\end{array}$ \\
\hline $1 / 1 / 2008$ & 11.6 & 37.1 & $1 / 21 / 2008$ & 11.5 & 36.9 \\
\hline $1 / 1 / 2008$ & 11.6 & 37.2 & $1 / 21 / 2008$ & 11.6 & 36.9 \\
\hline $1 / 2 / 2008$ & 11.6 & 37.1 & $1 / 22 / 2008$ & 11.6 & 37 \\
\hline $1 / 2 / 2008$ & 11.6 & 37.2 & $1 / 22 / 2008$ & 11.6 & 37 \\
\hline $1 / 3 / 2008$ & 11.6 & 37.1 & $1 / 23 / 2008$ & 11.6 & 37.1 \\
\hline $1 / 3 / 2008$ & 11.6 & 37.2 & $1 / 23 / 2008$ & 11.6 & 37 \\
\hline $1 / 4 / 2008$ & 11.6 & 37.1 & $1 / 24 / 2008$ & 11.6 & 37 \\
\hline $1 / 4 / 2008$ & 11.6 & 37.1 & $1 / 24 / 2008$ & 11.6 & 37 \\
\hline $1 / 5 / 2008$ & 11.6 & 37.1 & $1 / 25 / 2008$ & 11.5 & 37 \\
\hline $1 / 5 / 2008$ & 11.6 & 37.1 & $1 / 25 / 2008$ & 11.6 & 37 \\
\hline $1 / 6 / 2008$ & 11.6 & 37.1 & $1 / 26 / 2008$ & 11.6 & 36.9 \\
\hline $1 / 6 / 2008$ & 11.6 & 37.1 & $1 / 26 / 2008$ & 11.6 & 37 \\
\hline $1 / 7 / 2008$ & 11.6 & 37.1 & $1 / 27 / 2008$ & 11.6 & 36.9 \\
\hline $1 / 7 / 2008$ & 11.6 & 37 & $1 / 27 / 2008$ & 11.6 & 37 \\
\hline $1 / 8 / 2008$ & 11.6 & 36.4 & $1 / 28 / 2008$ & 11.6 & 37 \\
\hline $1 / 8 / 2008$ & 11.6 & 37.1 & $1 / 28 / 2008$ & 11.5 & 36.8 \\
\hline $1 / 9 / 2008$ & 11.6 & 36.9 & $1 / 29 / 2008$ & 11.6 & 37 \\
\hline $1 / 9 / 2008$ & 11.6 & 37.1 & $1 / 29 / 2008$ & 11.5 & 36.9 \\
\hline $1 / 10 / 2008$ & 11.6 & 37.1 & $1 / 30 / 2008$ & 0 & 0 \\
\hline $1 / 10 / 2008$ & 11.6 & 37 & $1 / 30 / 2008$ & 11.7 & 36.8 \\
\hline $1 / 11 / 2008$ & 11.6 & 36.9 & $1 / 31 / 2008$ & 11.6 & 36.9 \\
\hline $1 / 11 / 2008$ & 11.6 & 37 & $1 / 31 / 2008$ & 11.6 & 36.8 \\
\hline $1 / 12 / 2008$ & 11.6 & 37.1 & $2 / 1 / 2008$ & 11.6 & 36.9 \\
\hline $1 / 12 / 2008$ & 11.6 & 37 & $2 / 1 / 2008$ & 11.6 & 36.8 \\
\hline $1 / 13 / 2008$ & 11.6 & 36.9 & $2 / 2 / 2008$ & 11.6 & 37 \\
\hline $1 / 13 / 2008$ & 11.6 & 37 & $2 / 2 / 2008$ & 11.6 & 36.9 \\
\hline $1 / 14 / 2008$ & 11.6 & 37 & $2 / 3 / 2008$ & 11.6 & 37 \\
\hline $1 / 14 / 2008$ & 11.6 & 37 & $2 / 3 / 2008$ & 11.6 & 36.9 \\
\hline $1 / 15 / 2008$ & 0 & 0 & $2 / 4 / 2008$ & 11.6 & 36.9 \\
\hline $1 / 15 / 2008$ & 11.6 & 37.1 & $2 / 4 / 2008$ & 11.6 & 36.9 \\
\hline $1 / 16 / 2008$ & 11.6 & 37.1 & $2 / 5 / 2008$ & 11.7 & 36.9 \\
\hline $1 / 16 / 2008$ & 11.6 & 36.9 & $2 / 5 / 2008$ & 11.6 & 36.7 \\
\hline $1 / 17 / 2008$ & 11.6 & 37.1 & $2 / 6 / 2008$ & 11.6 & 36.7 \\
\hline $1 / 17 / 2008$ & 11.6 & 37.1 & $2 / 6 / 2008$ & 11.6 & 36.9 \\
\hline $1 / 18 / 2008$ & 11.6 & 37 & $2 / 7 / 2008$ & 11.6 & 37.6 \\
\hline $1 / 18 / 2008$ & 11.6 & 37 & $2 / 7 / 2008$ & 0 & 0 \\
\hline $1 / 19 / 2008$ & 11.6 & 37 & $2 / 8 / 2008$ & 0 & 0 \\
\hline $1 / 19 / 2008$ & 11.6 & 37.1 & $2 / 8 / 2008$ & 0 & 0 \\
\hline $1 / 20 / 2008$ & 11.6 & 37 & 2/9/2008 & 0 & 0 \\
\hline $1 / 20 / 2008$ & 11.6 & 36.9 & $2 / 9 / 2008$ & 0 & 0 \\
\hline
\end{tabular}




\begin{tabular}{|c|c|c|c|c|c|}
\hline Date & $\begin{array}{c}\text { W11-45 } \\
\text { Flow } \\
\text { (gpm) }\end{array}$ & $\begin{array}{c}\text { W11-46 } \\
\text { Flow } \\
\text { (gpm) }\end{array}$ & Date & $\begin{array}{c}\text { W11-45 } \\
\text { Flow } \\
\text { (gpm) }\end{array}$ & $\begin{array}{c}\text { W11-46 } \\
\text { Flow } \\
\text { (gpm) }\end{array}$ \\
\hline $2 / 10 / 2008$ & 0 & 0 & $3 / 1 / 2008$ & 11.6 & 37.1 \\
\hline $2 / 10 / 2008$ & 0 & 0 & $3 / 1 / 2008$ & 11.6 & 36.9 \\
\hline $2 / 11 / 2008$ & 11.6 & 37.1 & $3 / 2 / 2008$ & 11.6 & 36.9 \\
\hline $2 / 11 / 2008$ & 11.6 & 37.1 & $3 / 2 / 2008$ & 11.6 & 37 \\
\hline $2 / 12 / 2008$ & 11.6 & 36.9 & $3 / 3 / 2008$ & 11.6 & 36.9 \\
\hline $2 / 12 / 2008$ & 11.6 & 37 & $3 / 3 / 2008$ & 11.6 & 36.9 \\
\hline $2 / 13 / 2008$ & 0 & 0 & $3 / 4 / 2008$ & 11.6 & 37 \\
\hline $2 / 13 / 2008$ & 11.6 & 37.1 & $3 / 4 / 2008$ & 11.6 & 36.9 \\
\hline $2 / 14 / 2008$ & 11.6 & 37 & $3 / 5 / 2008$ & 11.6 & 36.8 \\
\hline $2 / 14 / 2008$ & 11.6 & 36.9 & $3 / 5 / 2008$ & 11.6 & 36.9 \\
\hline $2 / 15 / 2008$ & 11.6 & 36.9 & $3 / 6 / 2008$ & 0 & 39.1 \\
\hline $2 / 15 / 2008$ & 11.6 & 36.9 & $3 / 6 / 2008$ & 0 & 39 \\
\hline $2 / 16 / 2008$ & 11.6 & 37 & $3 / 7 / 2008$ & 0 & 39.1 \\
\hline $2 / 16 / 2008$ & 11.7 & 36.9 & $3 / 7 / 2008$ & 0 & 39.1 \\
\hline $2 / 17 / 2008$ & 11.7 & 37 & $3 / 8 / 2008$ & 0 & 39.1 \\
\hline $2 / 17 / 2008$ & 11.6 & 36.6 & $3 / 8 / 2008$ & 0 & 39.1 \\
\hline $2 / 18 / 2008$ & 11.6 & 36.8 & $3 / 9 / 2008$ & 0 & 39 \\
\hline $2 / 18 / 2008$ & 11.6 & 36.9 & $3 / 9 / 2008$ & 0 & 39.1 \\
\hline $2 / 19 / 2008$ & 11.6 & 36.8 & $3 / 10 / 2008$ & 0 & 39.1 \\
\hline $2 / 19 / 2008$ & 11.6 & 36.9 & $3 / 10 / 2008$ & 0 & 39.2 \\
\hline $2 / 20 / 2008$ & 11.6 & 36.9 & $3 / 11 / 2008$ & 0 & 39.2 \\
\hline $2 / 20 / 2008$ & 11.6 & 36.9 & $3 / 11 / 2008$ & 0 & 39.4 \\
\hline $2 / 21 / 2008$ & 11.6 & 37 & $3 / 12 / 2008$ & 0 & 39.3 \\
\hline $2 / 21 / 2008$ & 11.6 & 36.9 & $3 / 12 / 2008$ & 0 & 39.3 \\
\hline $2 / 22 / 2008$ & 11.6 & 36.9 & $3 / 13 / 2008$ & 0 & 39.4 \\
\hline $2 / 22 / 2008$ & 11.6 & 36.9 & $3 / 13 / 2008$ & 0 & 39.2 \\
\hline $2 / 23 / 2008$ & 11.6 & 36.9 & $3 / 14 / 2008$ & 0 & 39.5 \\
\hline $2 / 23 / 2008$ & 11.6 & 36.9 & $3 / 14 / 2008$ & 0 & 39.4 \\
\hline $2 / 24 / 2008$ & 11.6 & 36.8 & $3 / 15 / 2008$ & 0 & 39.3 \\
\hline $2 / 24 / 2008$ & 11.6 & 36.9 & $3 / 15 / 2008$ & 0 & 39.4 \\
\hline $2 / 25 / 2008$ & 11.6 & 37 & $3 / 16 / 2008$ & 0 & 39.4 \\
\hline $2 / 25 / 2008$ & 11.6 & 36.8 & $3 / 16 / 2008$ & 0 & 39.3 \\
\hline $2 / 26 / 2008$ & 11.6 & 36.9 & $3 / 17 / 2008$ & 0 & 39.4 \\
\hline $2 / 26 / 2008$ & 11.6 & 36.9 & $3 / 17 / 2008$ & 0 & 0 \\
\hline $2 / 27 / 2008$ & 11.6 & 36.9 & $3 / 18 / 2008$ & 0 & 0 \\
\hline $2 / 27 / 2008$ & 11.6 & 36.8 & $3 / 18 / 2008$ & 0 & 0 \\
\hline $2 / 28 / 2008$ & 11.6 & 37 & $3 / 19 / 2008$ & 0 & 0 \\
\hline $2 / 28 / 2008$ & 11.6 & 36.9 & $3 / 19 / 2008$ & 0 & 0 \\
\hline $2 / 29 / 2008$ & 11.6 & 36.9 & $3 / 20 / 2008$ & 0 & 0 \\
\hline $2 / 29 / 2008$ & 11.6 & 37 & $3 / 20 / 2008$ & 0 & 39 \\
\hline
\end{tabular}




\begin{tabular}{|c|c|c|c|c|c|}
\hline Date & $\begin{array}{c}\text { W11-45 } \\
\text { Flow } \\
\text { (gpm) }\end{array}$ & $\begin{array}{c}\text { W11-46 } \\
\text { Flow } \\
\text { (gpm) }\end{array}$ & Date & $\begin{array}{c}\text { W11-45 } \\
\text { Flow } \\
\text { (gpm) }\end{array}$ & $\begin{array}{c}\text { W11-46 } \\
\text { Flow } \\
\text { (gpm) }\end{array}$ \\
\hline $3 / 21 / 2008$ & 0 & 39 & $4 / 10 / 2008$ & 0 & 40.1 \\
\hline $3 / 21 / 2008$ & 0 & 39.1 & $4 / 10 / 2008$ & 0 & 40 \\
\hline $3 / 22 / 2008$ & 0 & 39.1 & $4 / 11 / 2008$ & 0 & 40.2 \\
\hline $3 / 22 / 2008$ & 0 & 39.1 & $4 / 11 / 2008$ & 0 & 40.2 \\
\hline $3 / 23 / 2008$ & 0 & 39.2 & $4 / 12 / 2008$ & 0 & 40.1 \\
\hline $3 / 23 / 2008$ & 0 & 39.4 & $4 / 12 / 2008$ & 0 & 40.2 \\
\hline $3 / 24 / 2008$ & 0 & 39.3 & $4 / 13 / 2008$ & 0 & 40.4 \\
\hline $3 / 24 / 2008$ & 0 & 39.3 & $4 / 13 / 2008$ & 0 & 40.3 \\
\hline $3 / 25 / 2008$ & 0 & 0 & $4 / 14 / 2008$ & 0 & 40.4 \\
\hline $3 / 25 / 2008$ & 0 & 39.3 & $4 / 14 / 2008$ & 0 & 0 \\
\hline $3 / 26 / 2008$ & 0 & 39.4 & $4 / 15 / 2008$ & 0 & 0 \\
\hline $3 / 26 / 2008$ & 0 & 39.4 & $4 / 15 / 2008$ & 0 & 0 \\
\hline $3 / 27 / 2008$ & 0 & 39.3 & $4 / 16 / 2008$ & 0 & 0 \\
\hline $3 / 27 / 2008$ & 0 & 39.5 & $4 / 16 / 2008$ & 0 & 0 \\
\hline $3 / 28 / 2008$ & 0 & 39.6 & $4 / 17 / 2008$ & 0 & 40 \\
\hline $3 / 28 / 2008$ & 0 & 39.7 & $4 / 17 / 2008$ & 0 & 40.1 \\
\hline $3 / 29 / 2008$ & 0 & 39.6 & $4 / 18 / 2008$ & 0 & 40.2 \\
\hline $3 / 29 / 2008$ & 0 & 39.7 & $4 / 18 / 2008$ & 0 & 40.1 \\
\hline $3 / 30 / 2008$ & 0 & 39.6 & $4 / 19 / 2008$ & 0 & 40.2 \\
\hline $3 / 30 / 2008$ & 0 & 39.8 & $4 / 19 / 2008$ & 0 & 39.9 \\
\hline $3 / 31 / 2008$ & 0 & 39.6 & $4 / 20 / 2008$ & 0 & 40 \\
\hline $3 / 31 / 2008$ & 0 & 39.7 & $4 / 20 / 2008$ & 0 & 39.8 \\
\hline 4/1/2008 & 0 & 39.8 & $4 / 21 / 2008$ & 0 & 39.9 \\
\hline $4 / 1 / 2008$ & 0 & 39.9 & $4 / 21 / 2008$ & 0 & 39.9 \\
\hline $4 / 2 / 2008$ & 0 & 39.9 & $4 / 22 / 2008$ & 0 & 39.9 \\
\hline $4 / 2 / 2008$ & 0 & 39.9 & $4 / 22 / 2008$ & 0 & 39.9 \\
\hline $4 / 3 / 2008$ & 0 & 40.1 & $4 / 23 / 2008$ & 0 & 39.7 \\
\hline $4 / 3 / 2008$ & 0 & 40 & $4 / 23 / 2008$ & 0 & 39.7 \\
\hline $4 / 4 / 2008$ & 0 & 40.2 & $4 / 24 / 2008$ & 0 & 39.8 \\
\hline $4 / 4 / 2008$ & 0 & 40 & $4 / 24 / 2008$ & 0 & 39.6 \\
\hline $4 / 5 / 2008$ & 0 & 40.3 & $4 / 25 / 2008$ & 0 & 39.7 \\
\hline $4 / 5 / 2008$ & 0 & 40.1 & $4 / 25 / 2008$ & 0 & 39.7 \\
\hline $4 / 6 / 2008$ & 0 & 40.1 & $4 / 26 / 2008$ & 0 & 39.7 \\
\hline $4 / 6 / 2008$ & 0 & 40.1 & $4 / 26 / 2008$ & 0 & 39.7 \\
\hline $4 / 7 / 2008$ & 0 & 40 & $4 / 27 / 2008$ & 0 & 39.7 \\
\hline $4 / 7 / 2008$ & 0 & 40 & $4 / 27 / 2008$ & 0 & 39.7 \\
\hline $4 / 8 / 2008$ & 0 & 40 & $4 / 28 / 2008$ & 0 & 39.7 \\
\hline $4 / 8 / 2008$ & 0 & 40.3 & $4 / 28 / 2008$ & 0 & 39.6 \\
\hline $4 / 9 / 2008$ & 0 & 40.2 & $4 / 29 / 2008$ & 0 & 39.4 \\
\hline 4/9/2008 & 0 & 40.3 & $4 / 29 / 2008$ & 0 & 39.6 \\
\hline
\end{tabular}




\begin{tabular}{|c|c|c|c|c|c|}
\hline Date & $\begin{array}{c}\text { W11-45 } \\
\text { Flow } \\
\text { (gpm) }\end{array}$ & $\begin{array}{c}\text { W11-46 } \\
\text { Flow } \\
\text { (gpm) }\end{array}$ & Date & $\begin{array}{c}\text { W11-45 } \\
\text { Flow } \\
\text { (gpm) }\end{array}$ & $\begin{array}{c}\text { W11-46 } \\
\text { Flow } \\
\text { (gpm) }\end{array}$ \\
\hline $4 / 30 / 2008$ & 0 & 39.6 & $5 / 20 / 2008$ & 0 & 0 \\
\hline $4 / 30 / 2008$ & 0 & 39.4 & $5 / 20 / 2008$ & 0 & 0 \\
\hline $5 / 1 / 2008$ & 0 & 0 & $5 / 21 / 2008$ & 0 & 0 \\
\hline $5 / 1 / 2008$ & 0 & 0 & $5 / 21 / 2008$ & 0 & 0 \\
\hline $5 / 2 / 2008$ & 0 & 0 & $5 / 22 / 2008$ & 0 & 0 \\
\hline $5 / 2 / 2008$ & 0 & 0 & $5 / 22 / 2008$ & 0 & 0 \\
\hline $5 / 3 / 2008$ & 0 & 0 & $5 / 23 / 2008$ & 0 & 0 \\
\hline $5 / 3 / 2008$ & 0 & 0 & $5 / 23 / 2008$ & 0 & 0 \\
\hline $5 / 4 / 2008$ & 0 & 0 & $5 / 24 / 2008$ & 0 & 0 \\
\hline $5 / 4 / 2008$ & 0 & 0 & $5 / 24 / 2008$ & 0 & 0 \\
\hline $5 / 5 / 2008$ & 0 & 0 & $5 / 25 / 2008$ & 0 & 0 \\
\hline $5 / 5 / 2008$ & 0 & 0 & $5 / 25 / 2008$ & 0 & 0 \\
\hline $5 / 6 / 2008$ & 0 & 0 & $5 / 26 / 2008$ & 0 & 0 \\
\hline $5 / 6 / 2008$ & 0 & 0 & $5 / 26 / 2008$ & 0 & 0 \\
\hline $5 / 7 / 2008$ & 0 & 0 & $5 / 27 / 2008$ & 0 & 0 \\
\hline $5 / 7 / 2008$ & 0 & 0 & $5 / 27 / 2008$ & 0 & 0 \\
\hline $5 / 8 / 2008$ & 0 & 0 & $5 / 28 / 2008$ & 0 & 0 \\
\hline $5 / 8 / 2008$ & 0 & 0 & $5 / 28 / 2008$ & 0 & 0 \\
\hline $5 / 9 / 2008$ & 0 & 0 & $5 / 29 / 2008$ & 0 & 0 \\
\hline $5 / 9 / 2008$ & 0 & 0 & $5 / 29 / 2008$ & 0 & 0 \\
\hline $5 / 10 / 2008$ & 0 & 0 & $5 / 30 / 2008$ & 0 & 0 \\
\hline $5 / 10 / 2008$ & 0 & 0 & $5 / 30 / 2008$ & 0 & 0 \\
\hline $5 / 11 / 2008$ & 0 & 0 & $5 / 31 / 2008$ & 0 & 0 \\
\hline $5 / 11 / 2008$ & 0 & 0 & $5 / 31 / 2008$ & 0 & 0 \\
\hline $5 / 12 / 2008$ & 0 & 0 & 6/1/2008 & 0 & 0 \\
\hline $5 / 12 / 2008$ & 0 & 0 & $6 / 1 / 2008$ & 0 & 0 \\
\hline $5 / 13 / 2008$ & 0 & 0 & $6 / 2 / 2008$ & 0 & 0 \\
\hline $5 / 13 / 2008$ & 0 & 0 & $6 / 2 / 2008$ & 0 & 0 \\
\hline $5 / 14 / 2008$ & 0 & 0 & $6 / 3 / 2008$ & 0 & 0 \\
\hline $5 / 14 / 2008$ & 0 & 0 & $6 / 3 / 2008$ & 0 & 0 \\
\hline $5 / 15 / 2008$ & 0 & 0 & $6 / 4 / 2008$ & 0 & 0 \\
\hline $5 / 15 / 2008$ & 0 & 0 & $6 / 4 / 2008$ & 0 & 39.2 \\
\hline $5 / 16 / 2008$ & 0 & 0 & $6 / 5 / 2008$ & 0 & 39.1 \\
\hline $5 / 16 / 2008$ & 0 & 0 & $6 / 5 / 2008$ & 0 & 38.7 \\
\hline $5 / 17 / 2008$ & 0 & 0 & $6 / 6 / 2008$ & 0 & 38.9 \\
\hline $5 / 17 / 2008$ & 0 & 0 & $6 / 6 / 2008$ & 0 & 38.6 \\
\hline $5 / 18 / 2008$ & 0 & 0 & $6 / 7 / 2008$ & 0 & 38.4 \\
\hline $5 / 18 / 2008$ & 0 & 0 & $6 / 7 / 2008$ & 0 & 38.4 \\
\hline $5 / 19 / 2008$ & 0 & 0 & $6 / 8 / 2008$ & 0 & 38.3 \\
\hline $5 / 19 / 2008$ & 0 & 0 & $6 / 8 / 2008$ & 0 & 38.3 \\
\hline
\end{tabular}




\begin{tabular}{|c|c|c|c|c|c|}
\hline Date & $\begin{array}{c}\text { W11-45 } \\
\text { Flow } \\
\text { (gpm) }\end{array}$ & $\begin{array}{c}\text { W11-46 } \\
\text { Flow } \\
\text { (gpm) }\end{array}$ & Date & $\begin{array}{c}\text { W11-45 } \\
\text { Flow } \\
\text { (gpm) }\end{array}$ & $\begin{array}{c}\text { W11-46 } \\
\text { Flow } \\
\text { (gpm) }\end{array}$ \\
\hline $6 / 9 / 2008$ & 0 & 38.4 & $6 / 29 / 2008$ & 0 & 37.7 \\
\hline $6 / 9 / 2008$ & 0 & 38.2 & $6 / 29 / 2008$ & 0 & 37.6 \\
\hline $6 / 10 / 2008$ & 0 & 38.2 & $6 / 30 / 2008$ & 0 & 37.8 \\
\hline $6 / 10 / 2008$ & 0 & 38.1 & $6 / 30 / 2008$ & 0 & 37.7 \\
\hline $6 / 11 / 2008$ & 0 & 38.1 & $7 / 1 / 2008$ & 0 & 37.6 \\
\hline $6 / 11 / 2008$ & 0 & 38.2 & $7 / 1 / 2008$ & 0 & 37.6 \\
\hline $6 / 12 / 2008$ & 0 & 38.1 & $7 / 2 / 2008$ & 0 & 37.6 \\
\hline $6 / 12 / 2008$ & 0 & 38.1 & $7 / 2 / 2008$ & 0 & 37.5 \\
\hline $6 / 13 / 2008$ & 0 & 38.2 & $7 / 3 / 2008$ & 0 & 37.7 \\
\hline $6 / 13 / 2008$ & 0 & 38.1 & $7 / 3 / 2008$ & 0 & 37.6 \\
\hline $6 / 14 / 2008$ & 0 & 38.1 & $7 / 4 / 2008$ & 0 & 37.6 \\
\hline $6 / 14 / 2008$ & 0 & 38 & $7 / 4 / 2008$ & 0 & 37.6 \\
\hline $6 / 15 / 2008$ & 0 & 38.1 & $7 / 5 / 2008$ & 0 & 37.7 \\
\hline $6 / 15 / 2008$ & 0 & 38.1 & $7 / 5 / 2008$ & 0 & 37.6 \\
\hline $6 / 16 / 2008$ & 0 & 38 & $7 / 6 / 2008$ & 0 & 37.7 \\
\hline $6 / 16 / 2008$ & 0 & 37.9 & $7 / 6 / 2008$ & 0 & 37.5 \\
\hline $6 / 17 / 2008$ & 0 & 38 & $7 / 7 / 2008$ & 0 & 37.6 \\
\hline $6 / 17 / 2008$ & 0 & 37.8 & $7 / 7 / 2008$ & 0 & 0 \\
\hline $6 / 18 / 2008$ & 0 & 37.9 & $7 / 8 / 2008$ & 0 & 0 \\
\hline $6 / 18 / 2008$ & 0 & 37.8 & $7 / 8 / 2008$ & 0 & 0 \\
\hline $6 / 19 / 2008$ & 0 & 38.1 & & & \\
\hline $6 / 19 / 2008$ & 0 & 37.9 & & & \\
\hline $6 / 20 / 2008$ & 0 & 37.9 & & & \\
\hline $6 / 20 / 2008$ & 0 & 37.8 & & & \\
\hline $6 / 21 / 2008$ & 0 & 37.8 & & & \\
\hline $6 / 21 / 2008$ & 0 & 37.8 & & & \\
\hline $6 / 22 / 2008$ & 0 & 37.9 & & & \\
\hline $6 / 22 / 2008$ & 0 & 37.8 & & & \\
\hline $6 / 23 / 2008$ & 0 & 37.9 & & & \\
\hline $6 / 23 / 2008$ & 0 & 37.8 & & & \\
\hline $6 / 24 / 2008$ & 0 & 37.7 & & & \\
\hline $6 / 24 / 2008$ & 0 & 37.7 & & & \\
\hline $6 / 25 / 2008$ & 0 & 37.7 & & & \\
\hline $6 / 25 / 2008$ & 0 & 37.7 & & & \\
\hline $6 / 26 / 2008$ & 0 & 37.7 & & & \\
\hline
\end{tabular}


Appendix B

Observed Baseline Well Water-Level Response Plots 


\section{Appendix B: Observed Baseline Well Water-Level Response Plots}

B.1 Comparison of Observed Well Water-Level and Barometric Pressure Response: Well 299-W1023

B.2 Comparison of Observed Well Water-Level and Barometric Pressure Response: Well 299-W1024

B.3 Comparison of Observed Well Water-Level and Barometric Pressure Response: Well 299-W1139

B.4 Comparison of Observed Well Water-Level and Barometric Pressure Response: Well 299-W1140

B.5 Comparison of Observed Well Water-Level and Barometric Pressure Response: Well 299-W1141

B.6 Comparison of Observed Well Water-Level and Barometric Pressure Response: Well 299-W1142

B.7 Comparison of Observed Well Water-Level and Barometric Pressure Response: Well 299-W1146

B.8 Comparison of Observed Well Water-Level and Barometric Pressure Response: Well 299-W1147

B.9 Comparison of Observed Well Water-Level and Barometric Pressure Response: Well 299-W1148 


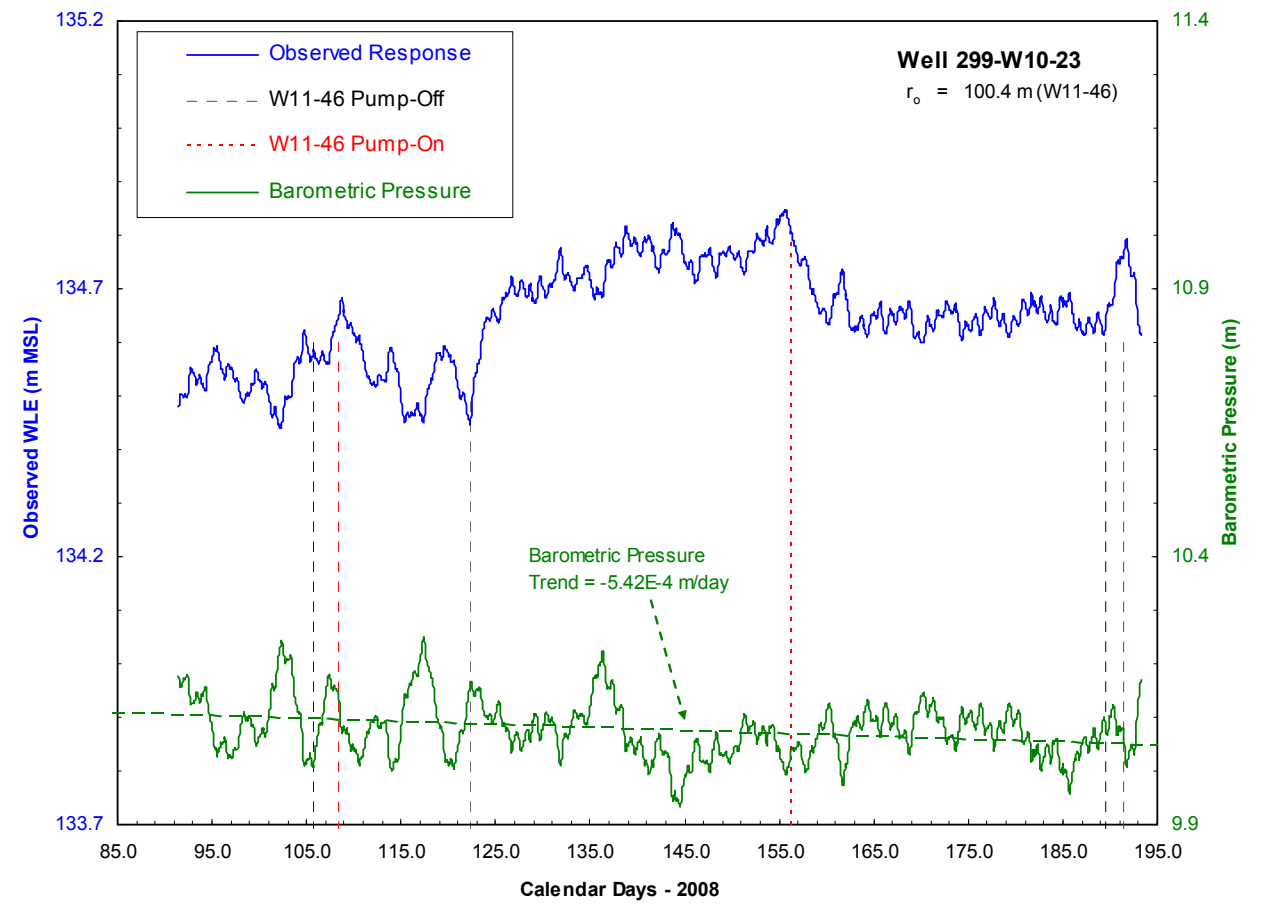

Figure B.1. Comparison of Observed Well Water-Level and Barometric Pressure Response: Well 299W10-23

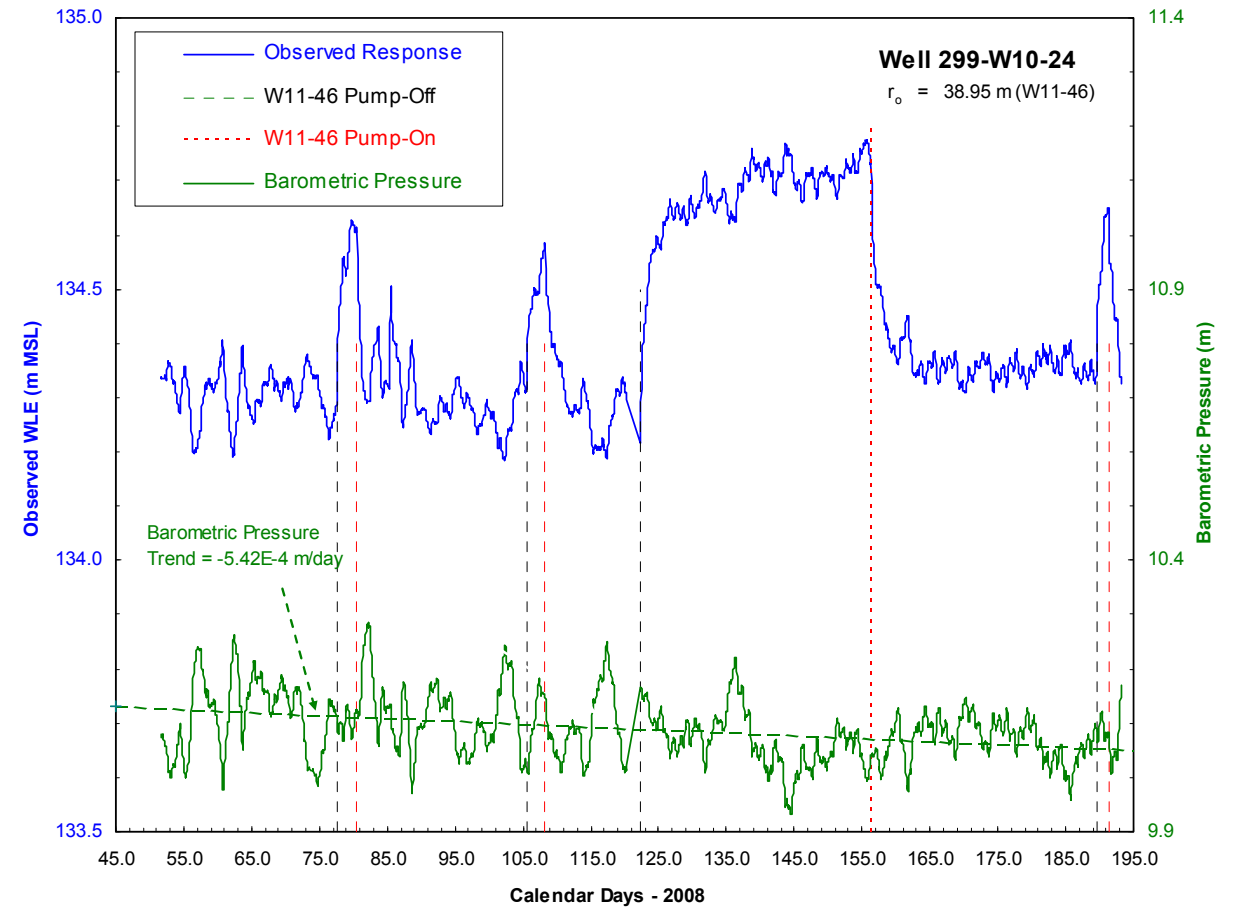

Figure B.2. Comparison of Observed Well Water-Level and Barometric Pressure Response: Well 299W10-24 


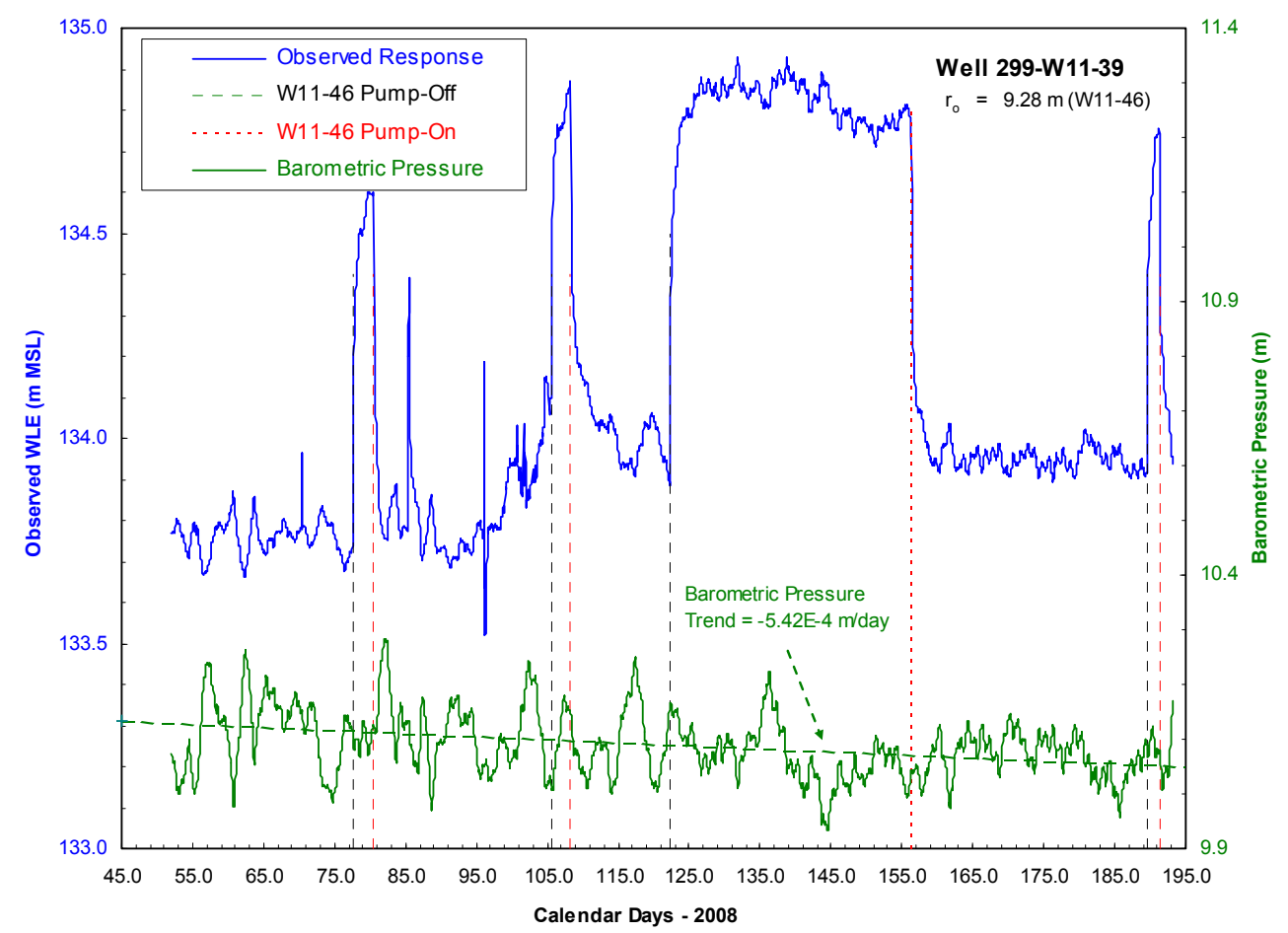

Figure B.3. Comparison of Observed Well Water-Level and Barometric Pressure Response: Well 299W11-39

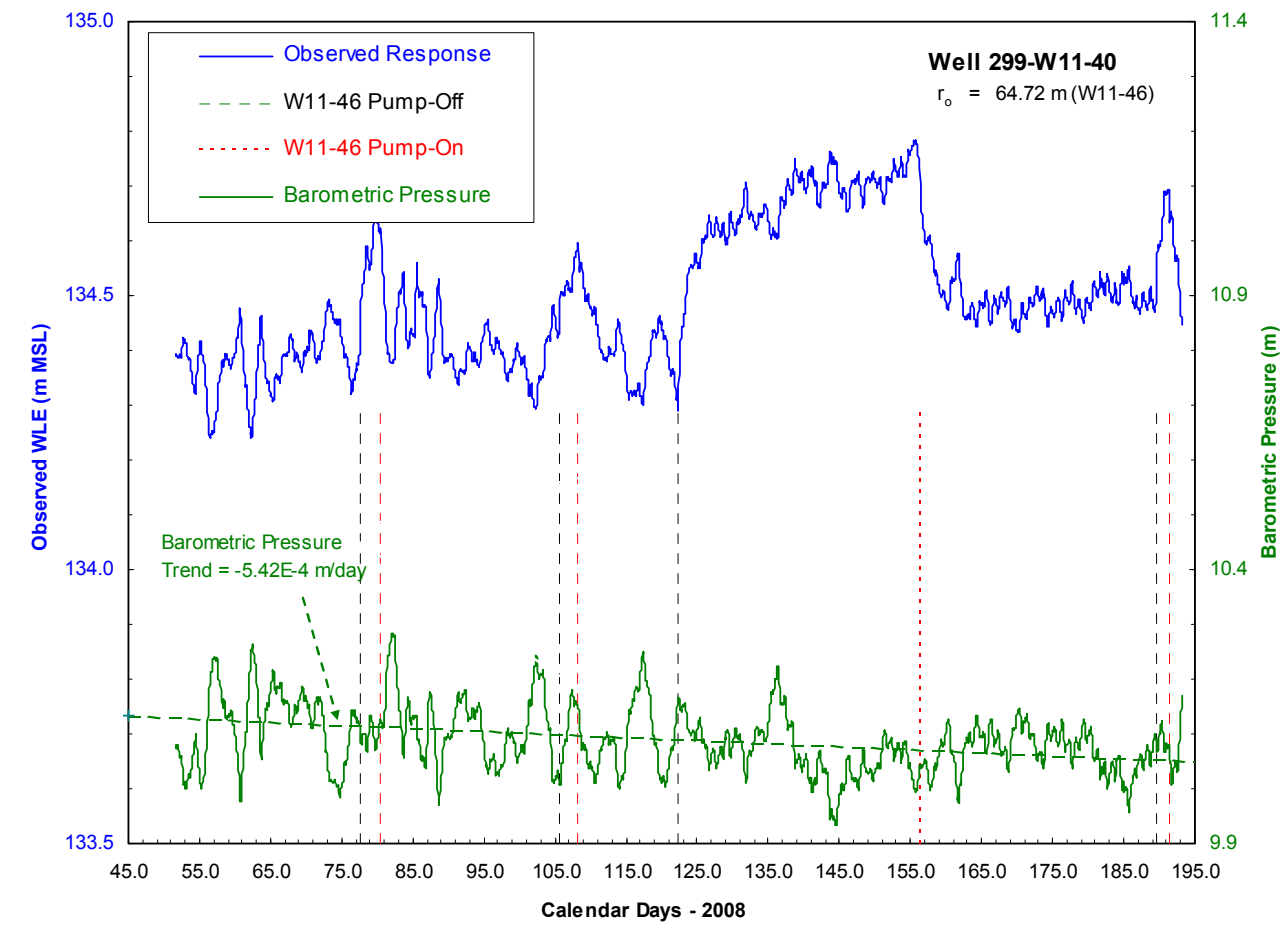

Figure B.4. Comparison of Observed Well Water-Level and Barometric Pressure Response: Well 299W11-40 


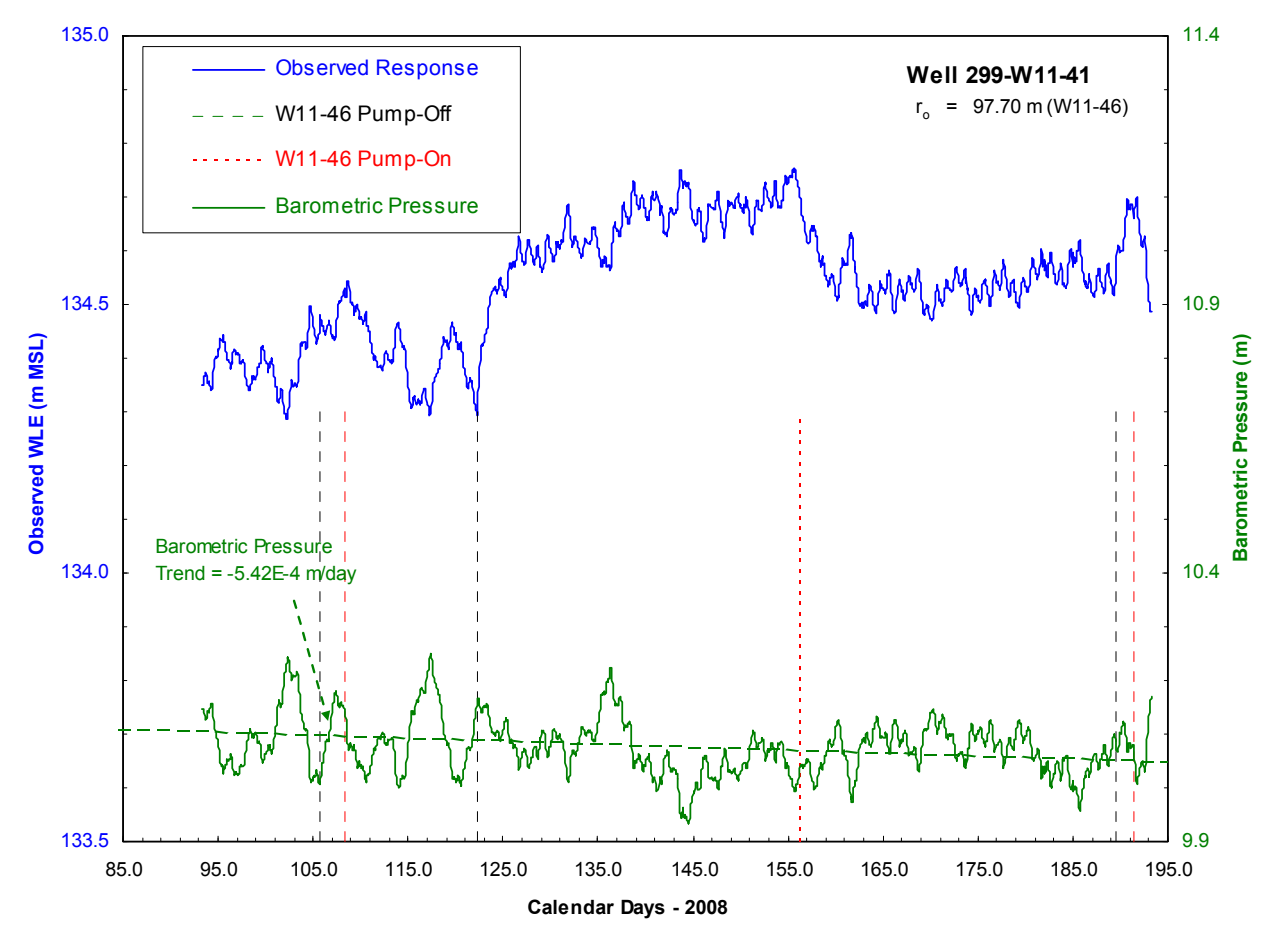

Figure B.5. Comparison of Observed Well Water-Level and Barometric Pressure Response: Well 299W11-41

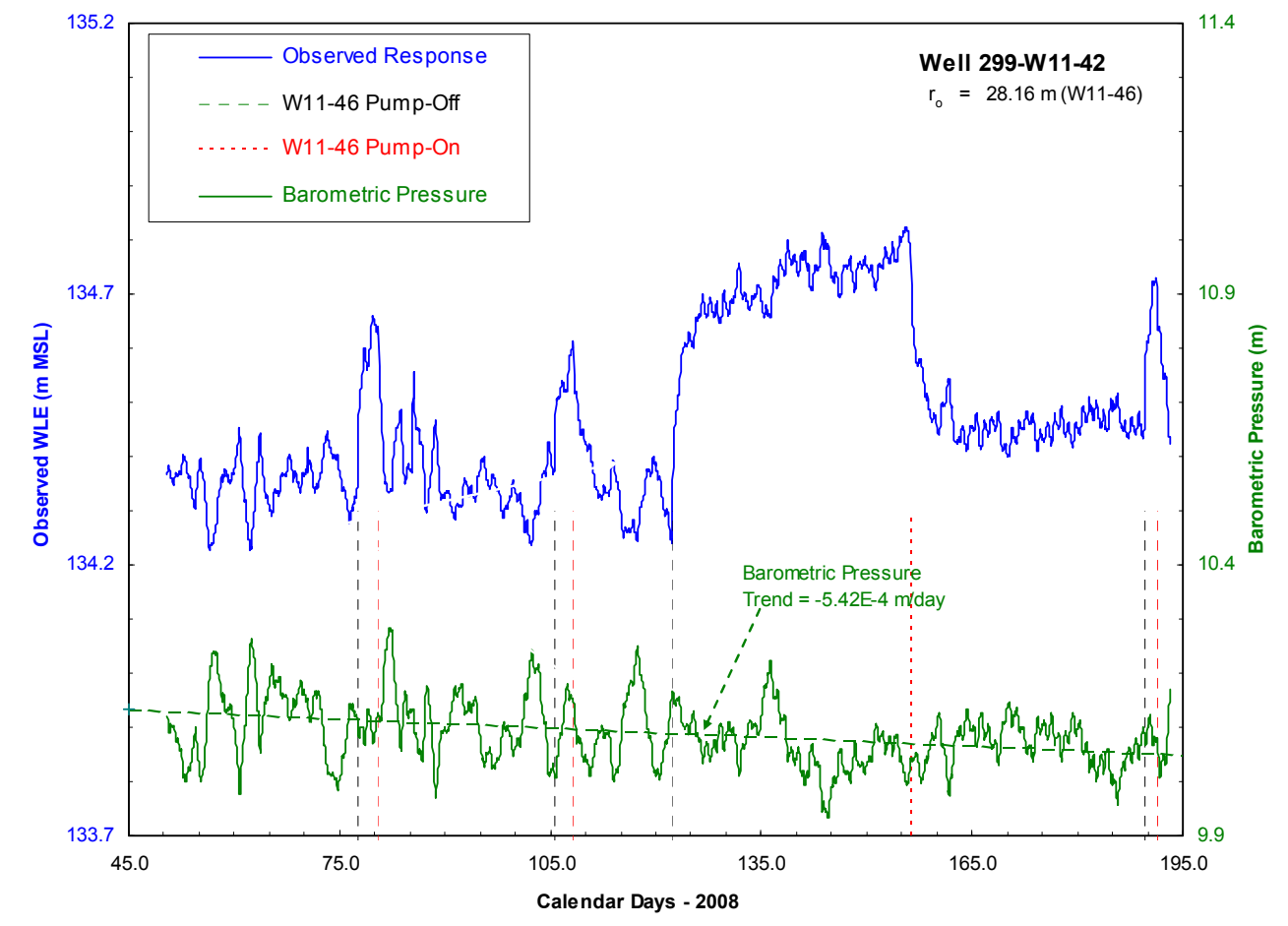

Figure B.6. Comparison of Observed Well Water-Level and Barometric Pressure Response: Well 299W11-42 


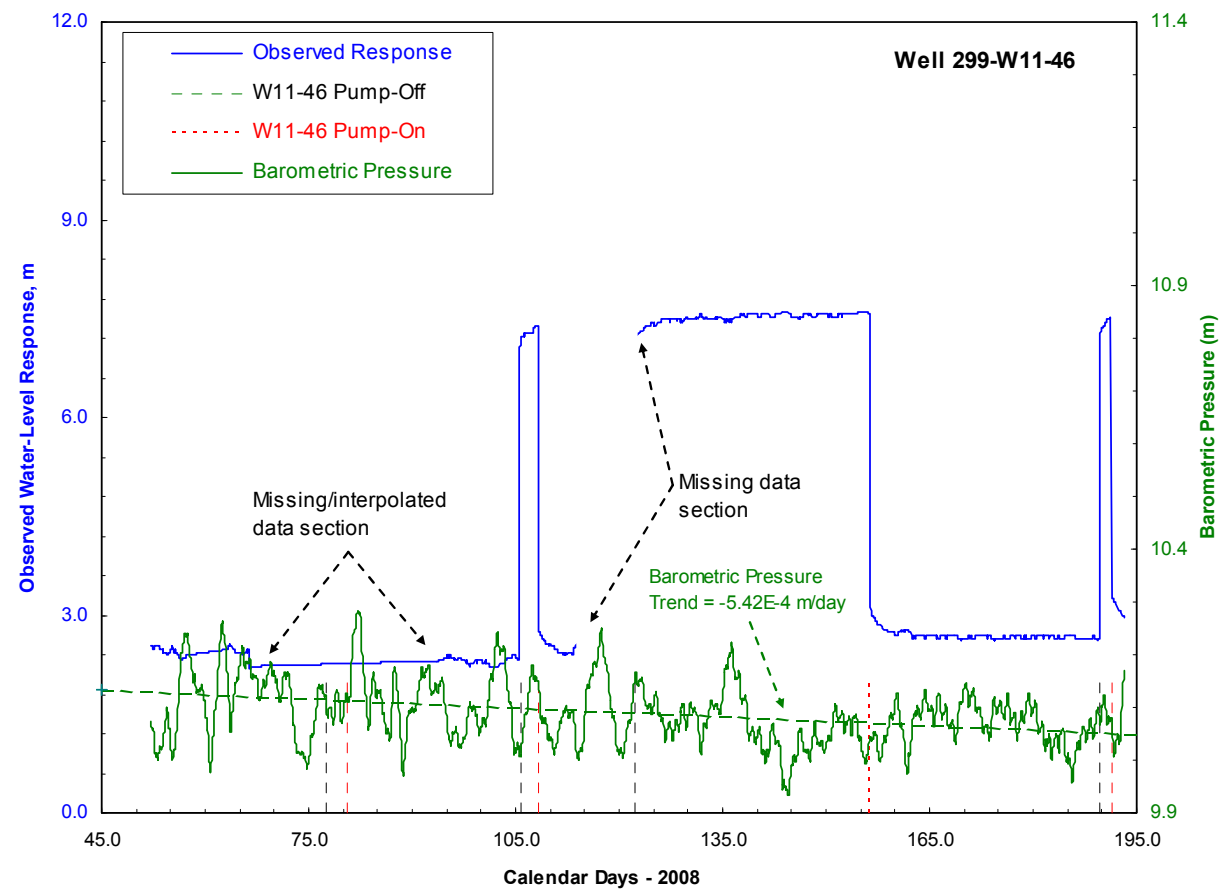

Figure B.7. Comparison of Observed Well Water-Level and Barometric Pressure Response: Well 299W11-46

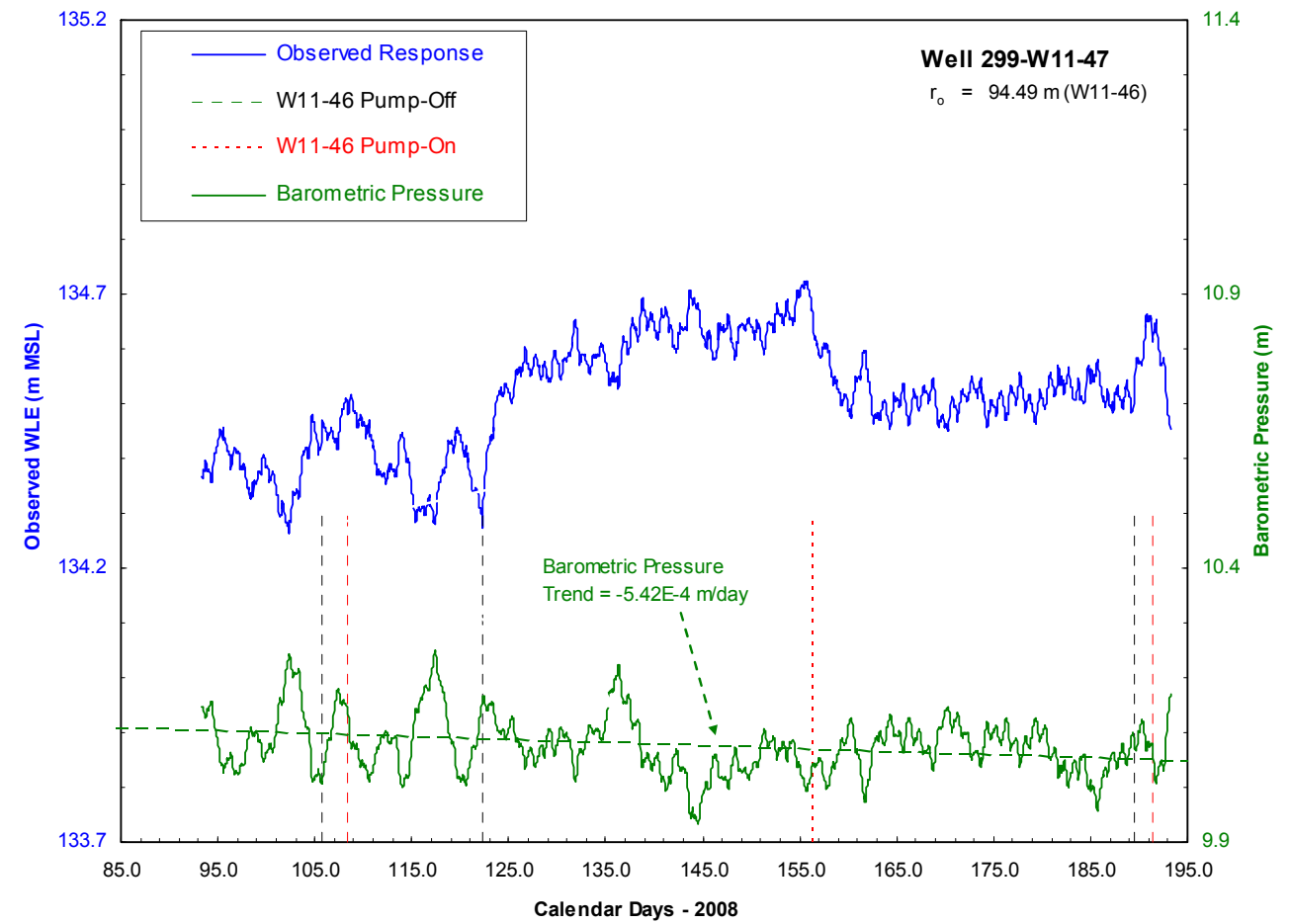

Figure B.8. Comparison of Observed Well Water-Level and Barometric Pressure Response: Well 299W11-47 


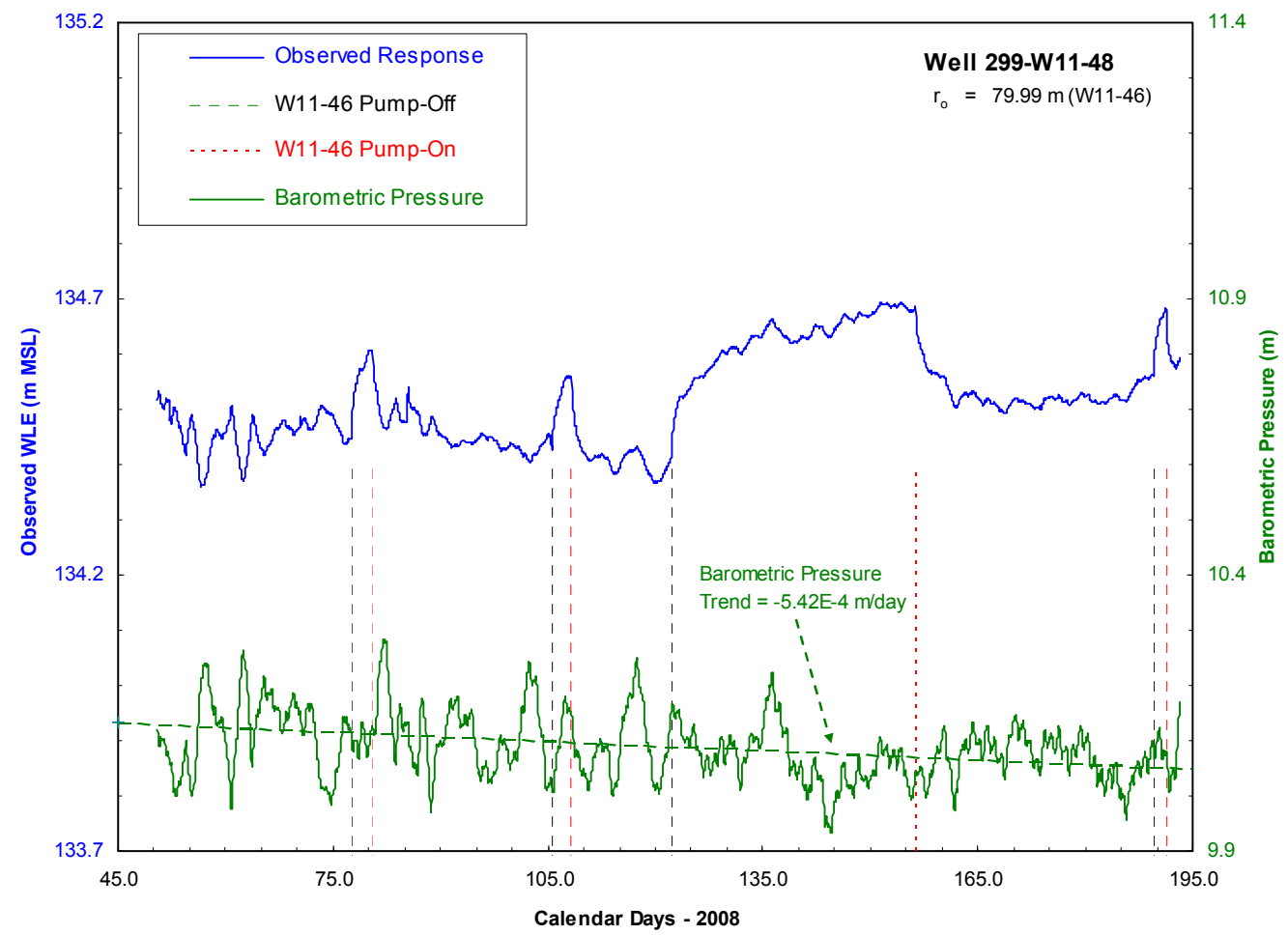

Figure B.9. Comparison of Observed Well Water-Level and Barometric Pressure Response: Well 299W11-48 


\section{Appendix C}

\section{Barometric-Corrected Baseline Well Water-Level Response Plots}




\section{Appendix C: Barometric-Corrected Baseline Well Water-Level Response Plots}

C.1 Comparison of Observed and Barometric-Corrected Well Water-Level Response: Well 299W10-23

C.2 Comparison of Observed and Barometric-Corrected Well Water-Level Response: Well 299W10-24

C.3 Comparison of Observed and Barometric-Corrected Well Water-Level Response: Well 299W11-39

C.4 Comparison of Observed and Barometric-Corrected Well Water-Level Response: Well 299W11-40

C.5 Comparison of Observed and Barometric-Corrected Well Water-Level Response: Well 299W11-41

C.6 Comparison of Observed and Barometric-Corrected Well Water-Level Response: Well 299W11-42

C.7 Comparison of Observed and Barometric-Corrected Well Water-Level Response: Well 299W11-46

C.8 Comparison of Observed and Barometric-Corrected Well Water-Level Response: Well 299W11-47

C.9 Comparison of Observed and Barometric-Corrected Well Water-Level Response: Well 299W11-48 


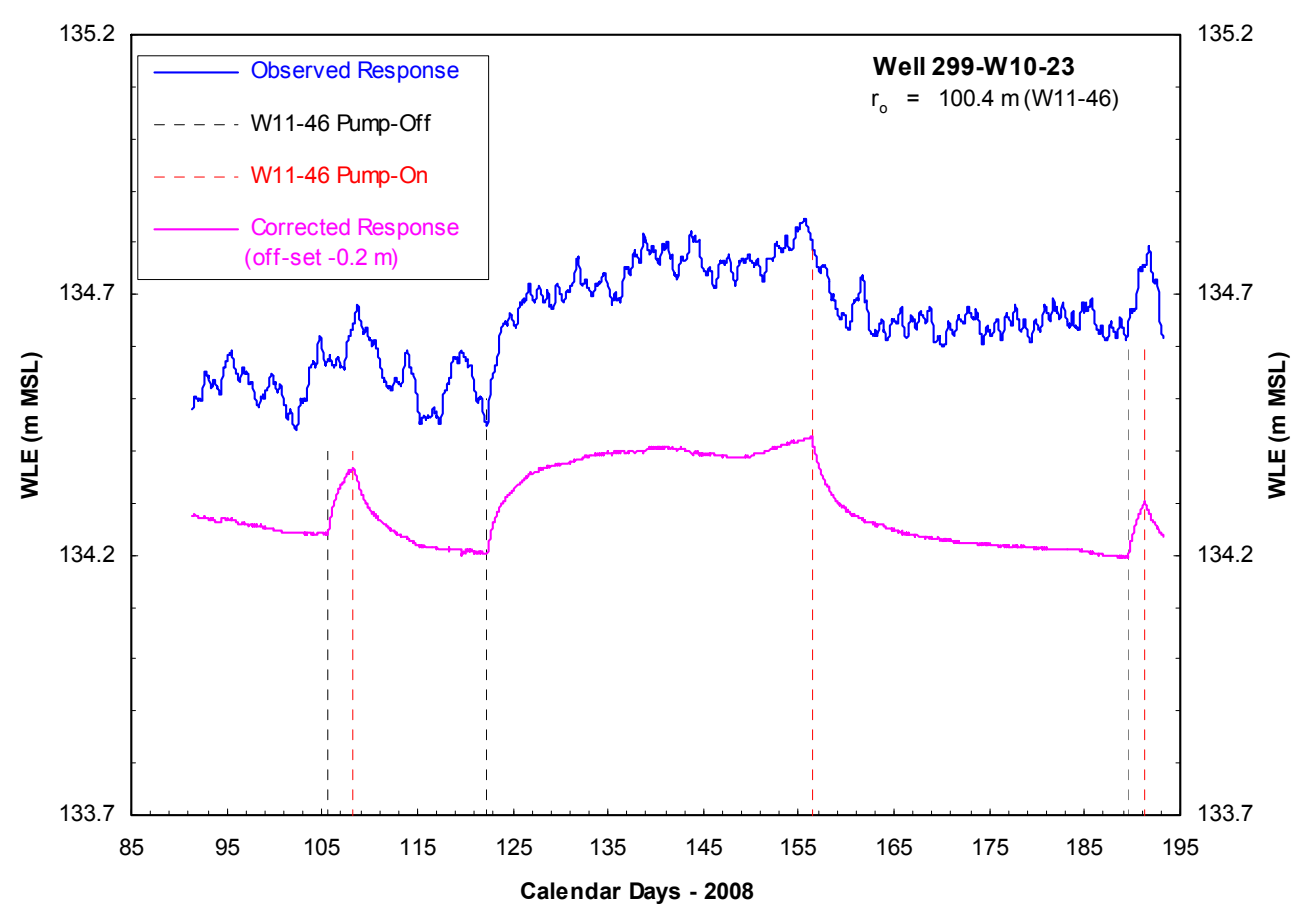

Figure C.1. Comparison of Observed and Barometric-Corrected Well Water-Level Response: Well 299-W10-23

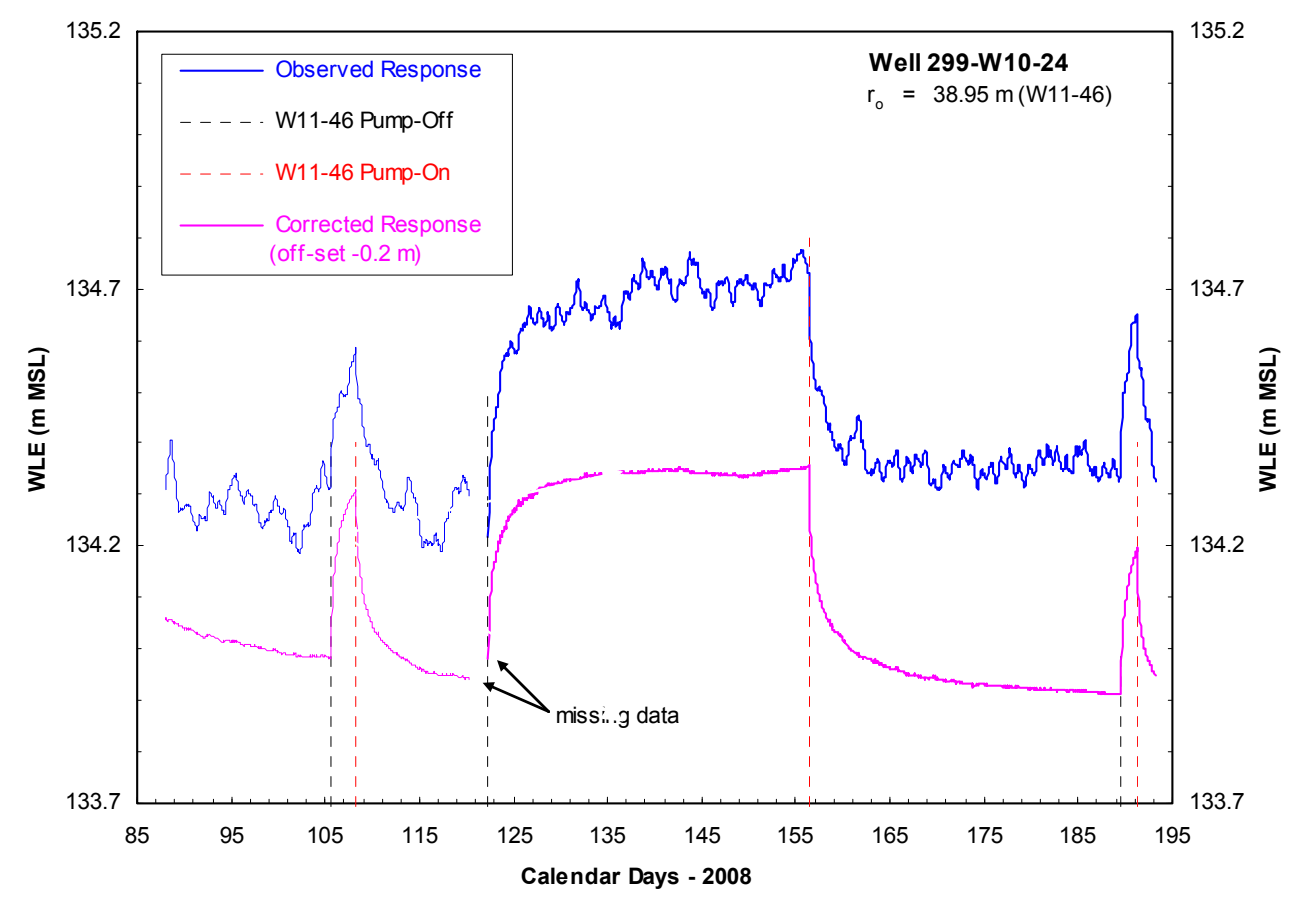

Figure C.2. Comparison of Observed and Barometric-Corrected Well Water-Level Response: Well 299-W10-24 


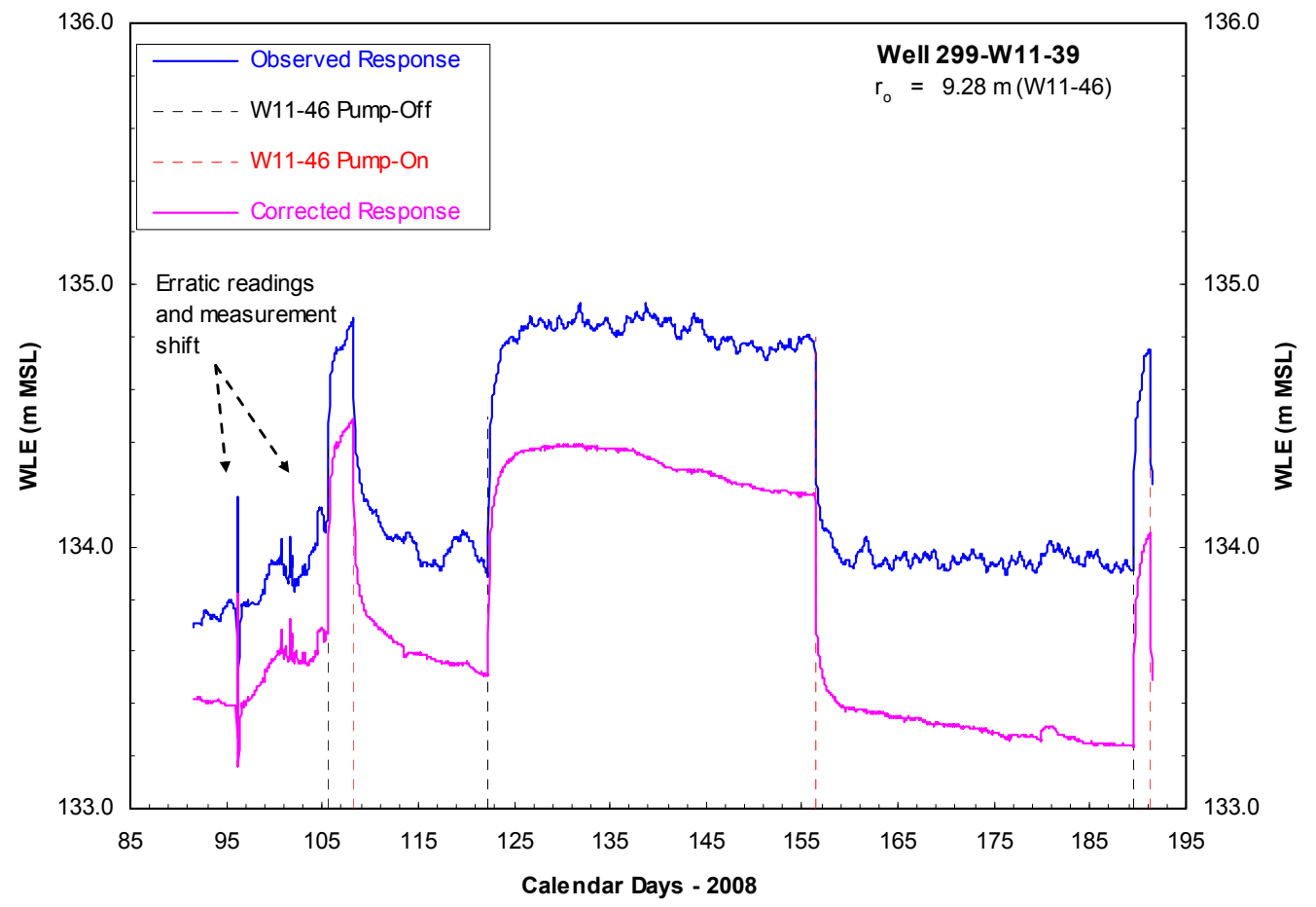

Figure C.3. Comparison of Observed and Barometric-Corrected Well Water-Level Response: Well 299-W11-39

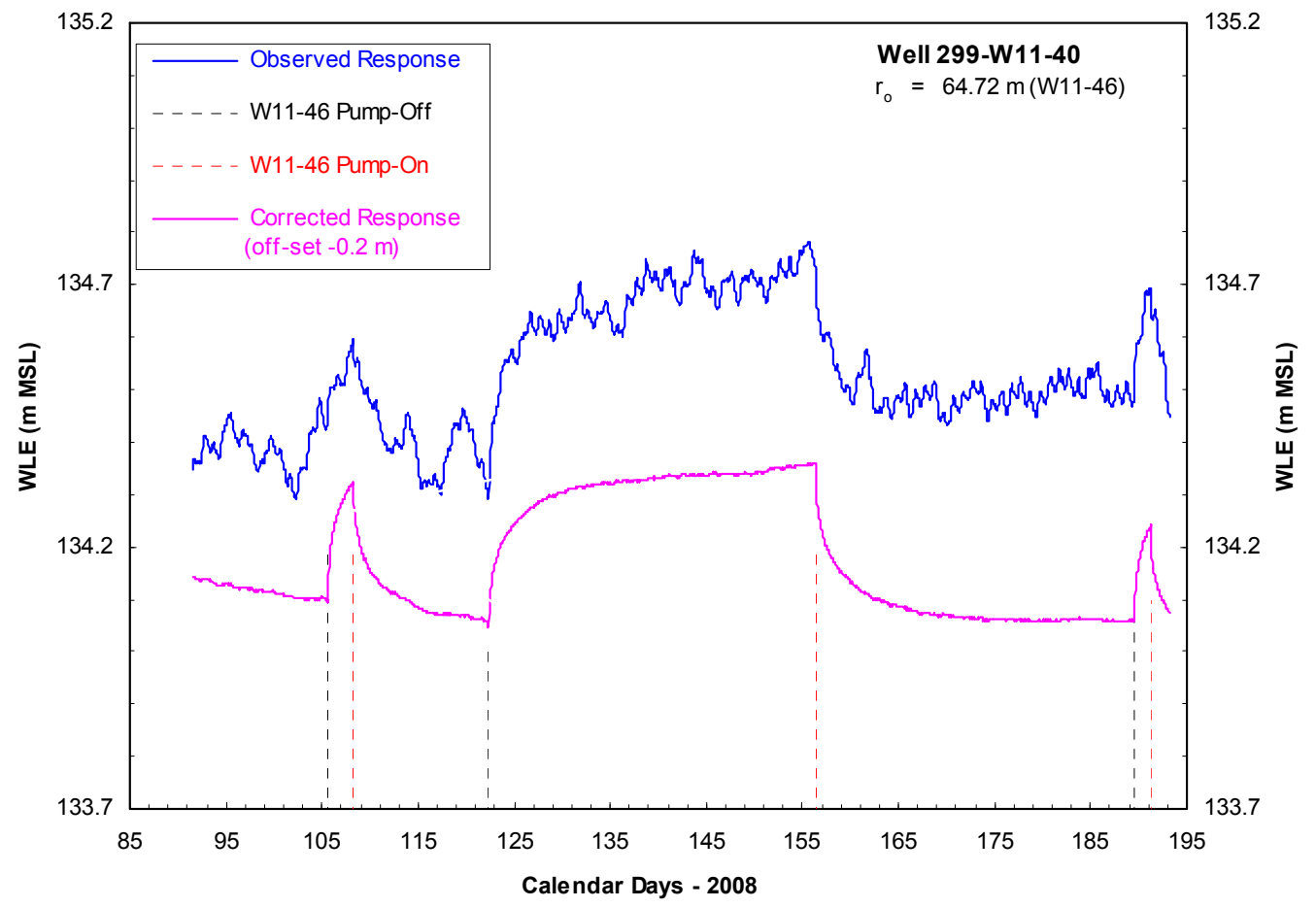

Figure C.4. Comparison of Observed and Barometric-Corrected Well Water-Level Response: Well 299-W11-40 


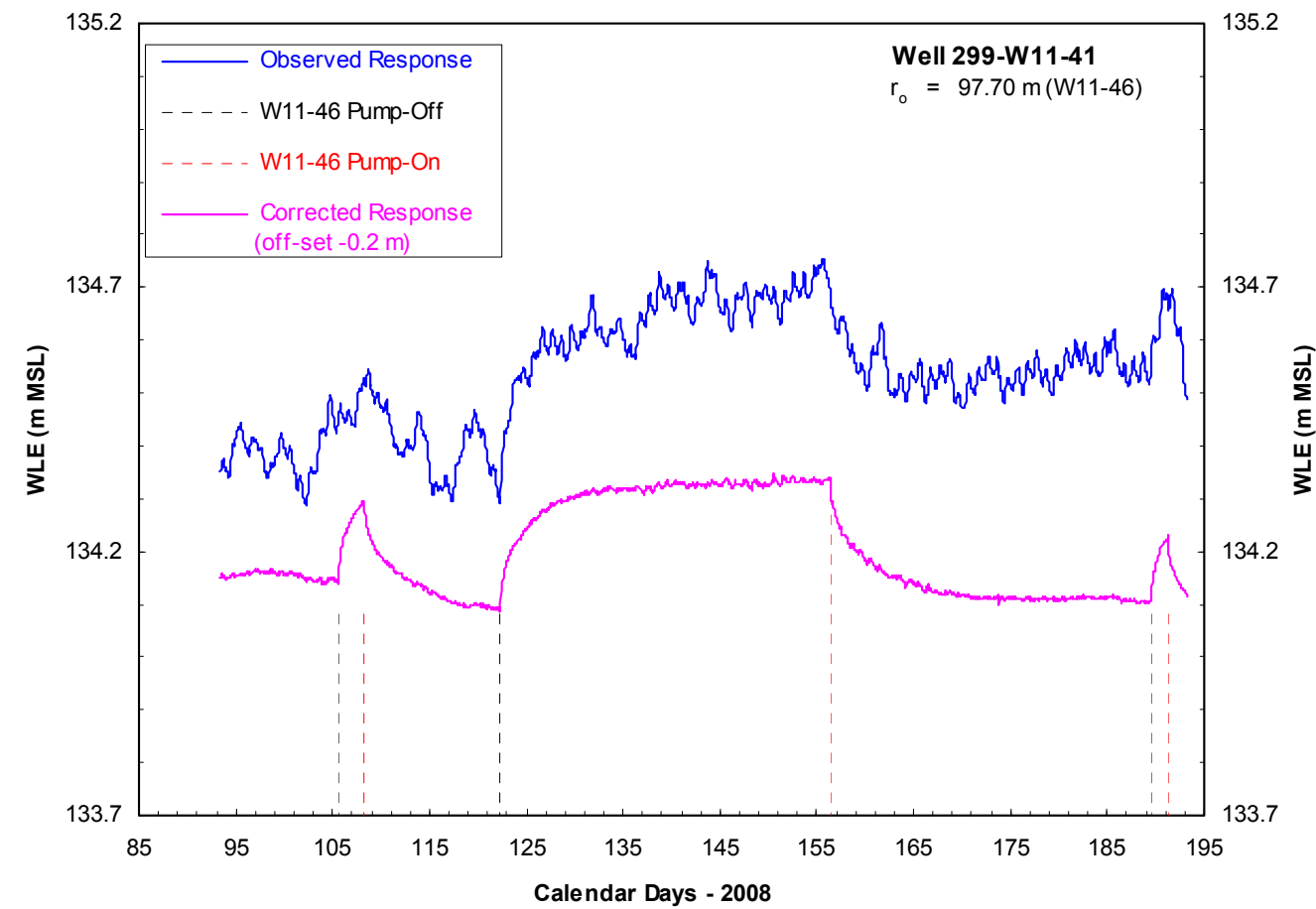

Figure C.5. Comparison of Observed and Barometric-Corrected Well Water-Level Response: Well 299-W11-41

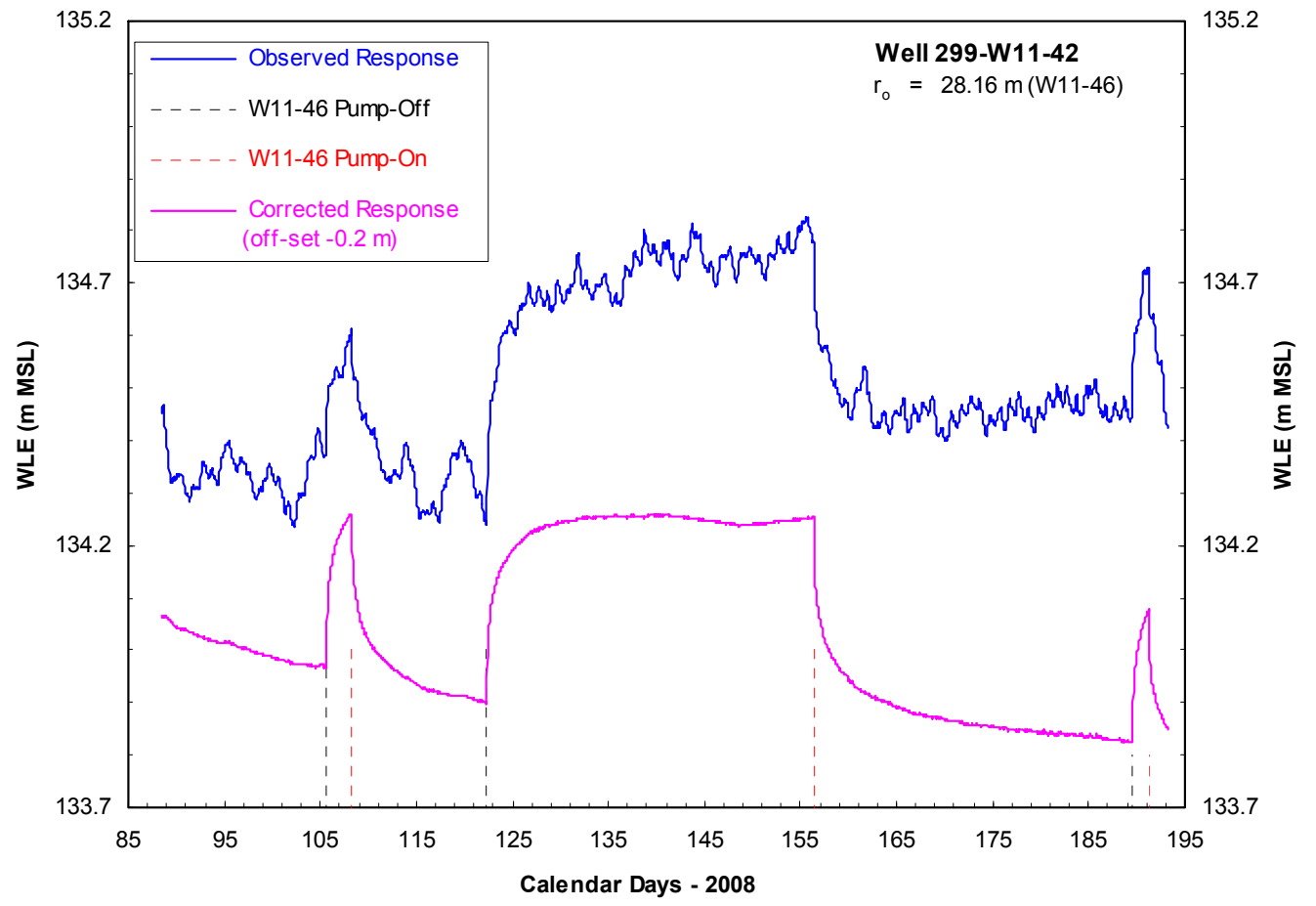

Figure C.6. Comparison of Observed and Barometric-Corrected Well Water-Level Response: Well 299-W11-42 


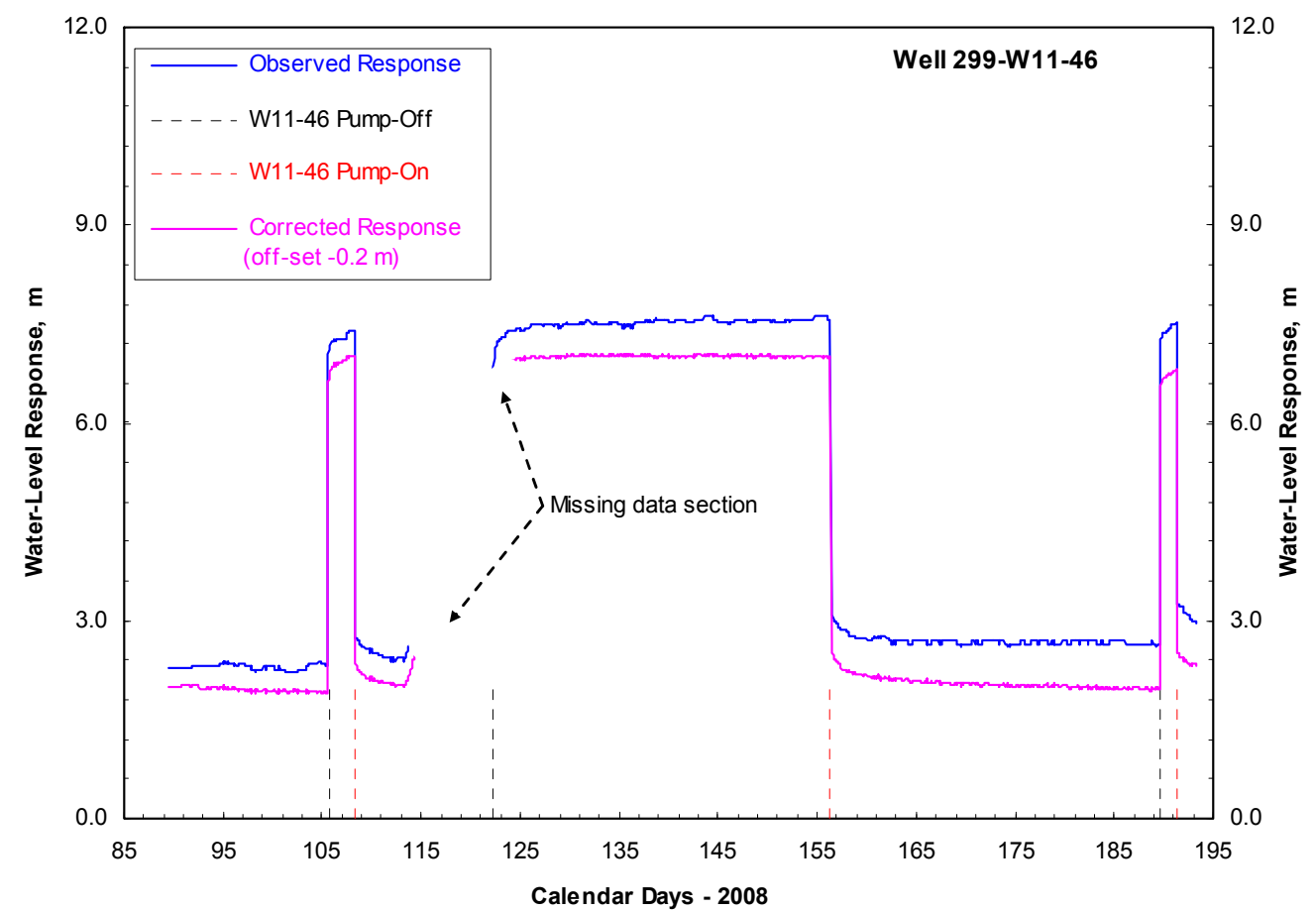

Figure C.7. Comparison of Observed and Barometric-Corrected Well Water-Level Response: Well 299-W11-46

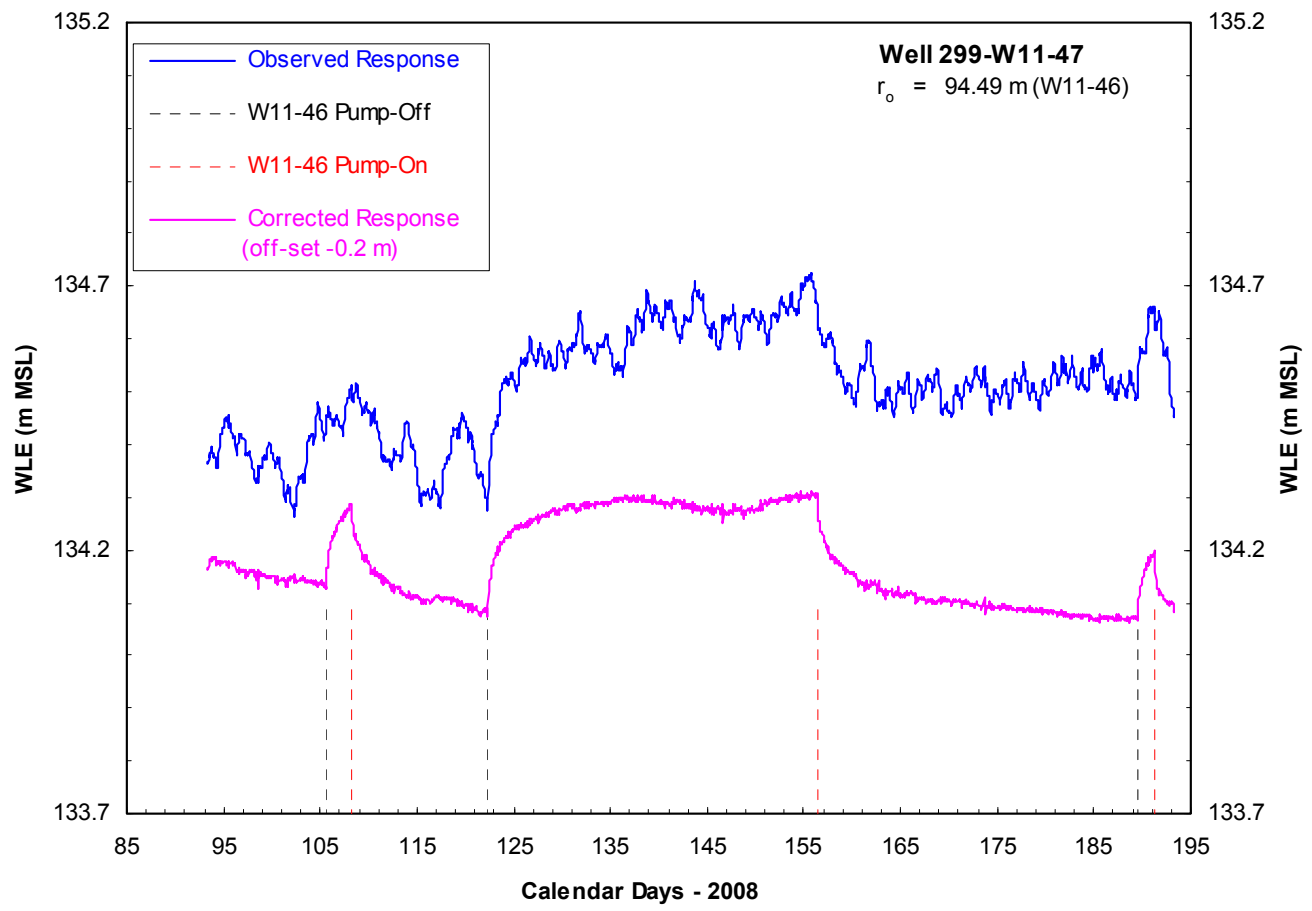

Figure C.8. Comparison of Observed and Barometric-Corrected Well Water-Level Response: Well 299-W11-47 


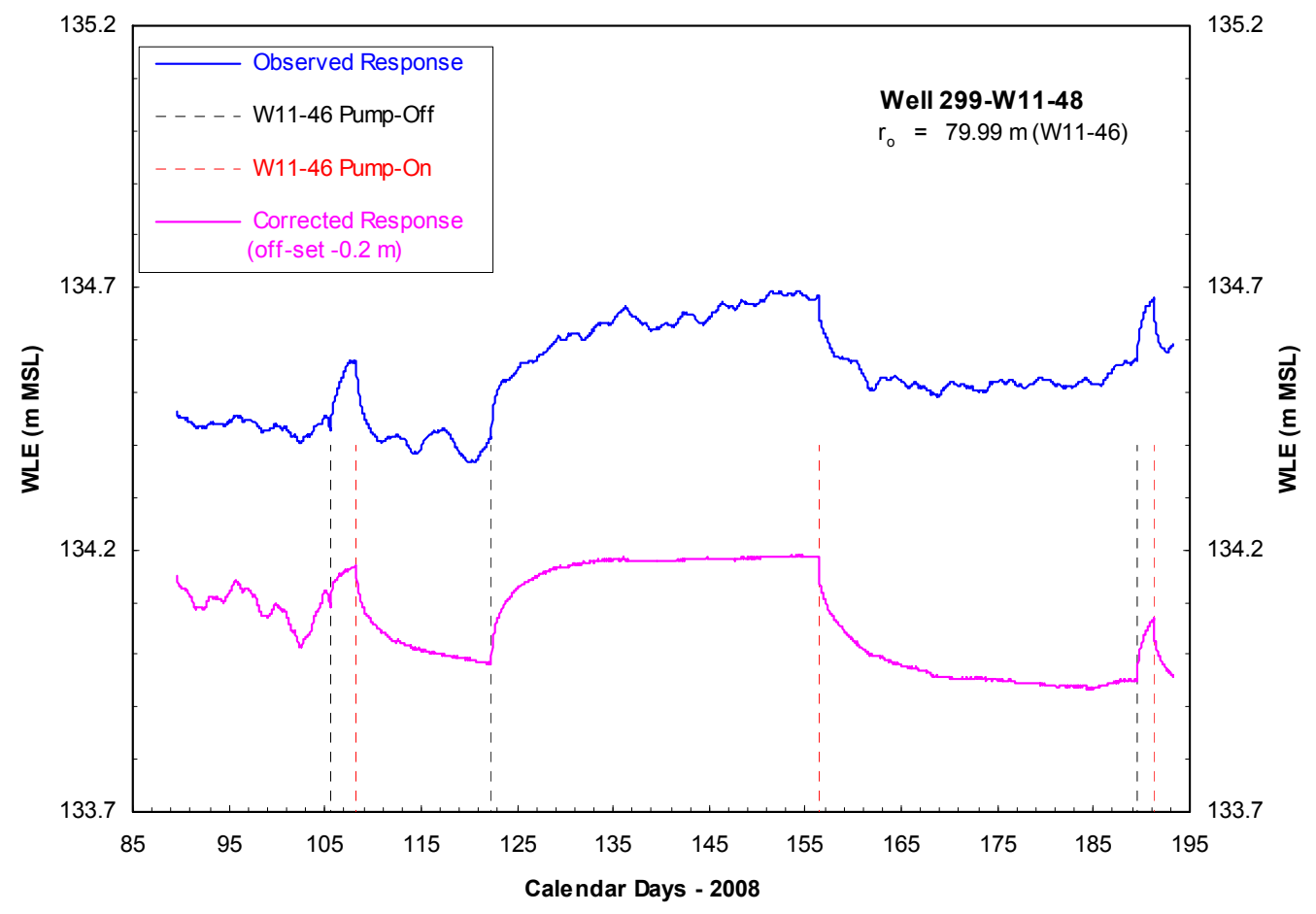

Figure C.9. Comparison of Observed and Barometric-Corrected Well Water-Level Response: Well 299-W11-48 
Appendix D

Observed and Barometric-Corrected Well Drawdown Plots 


\section{Appendix D: Observed and Barometric-Corrected Well Drawdown Plots}

D.1 Comparison of Observed and Barometric-Corrected Well Drawdown: Well 299-W10-23

D.2 Comparison of Observed and Barometric-Corrected Well Drawdown: Well 299-W10-24

D.3 Comparison of Observed and Barometric-Corrected Well Drawdown: Well 299-W11-39

D.4 Comparison of Observed and Barometric-Corrected Well Drawdown: Well 299-W11-40

D.5 Comparison of Observed and Barometric-Corrected Well Drawdown: Well 299-W11-41

D.6 Comparison of Observed and Barometric-Corrected Well Drawdown: Well 299-W11-42

D.7 Comparison of Observed and Barometric-Corrected Well Drawdown: Well 299-W11-46

D.8 Comparison of Observed and Barometric-Corrected Well Drawdown: Well 299-W11-47

D.9 Comparison of Observed and Barometric-Corrected Well Drawdown: Well 299-W11-48 


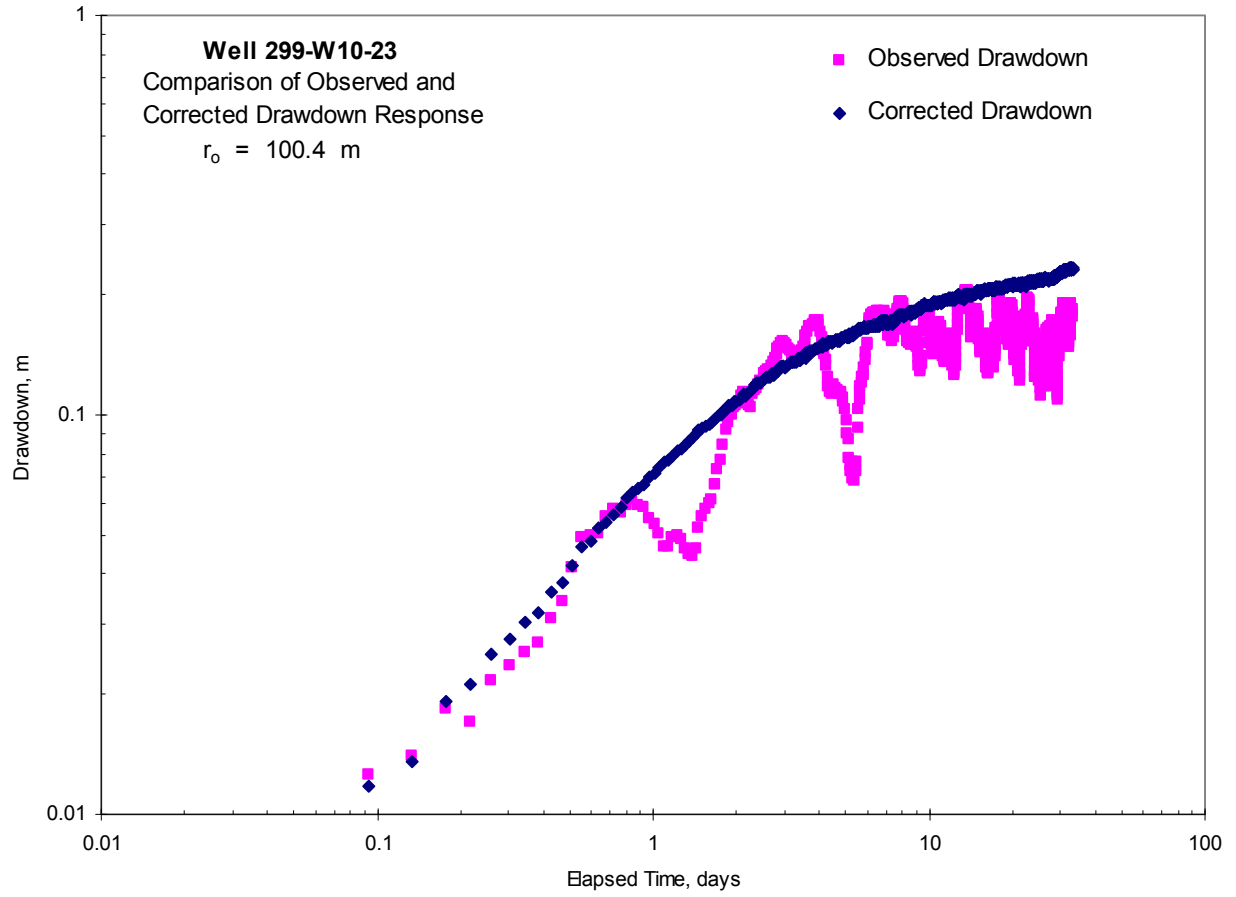

Figure D.1. Comparison of Observed and Barometric-Corrected Well Drawdown: Well 299-W10-23

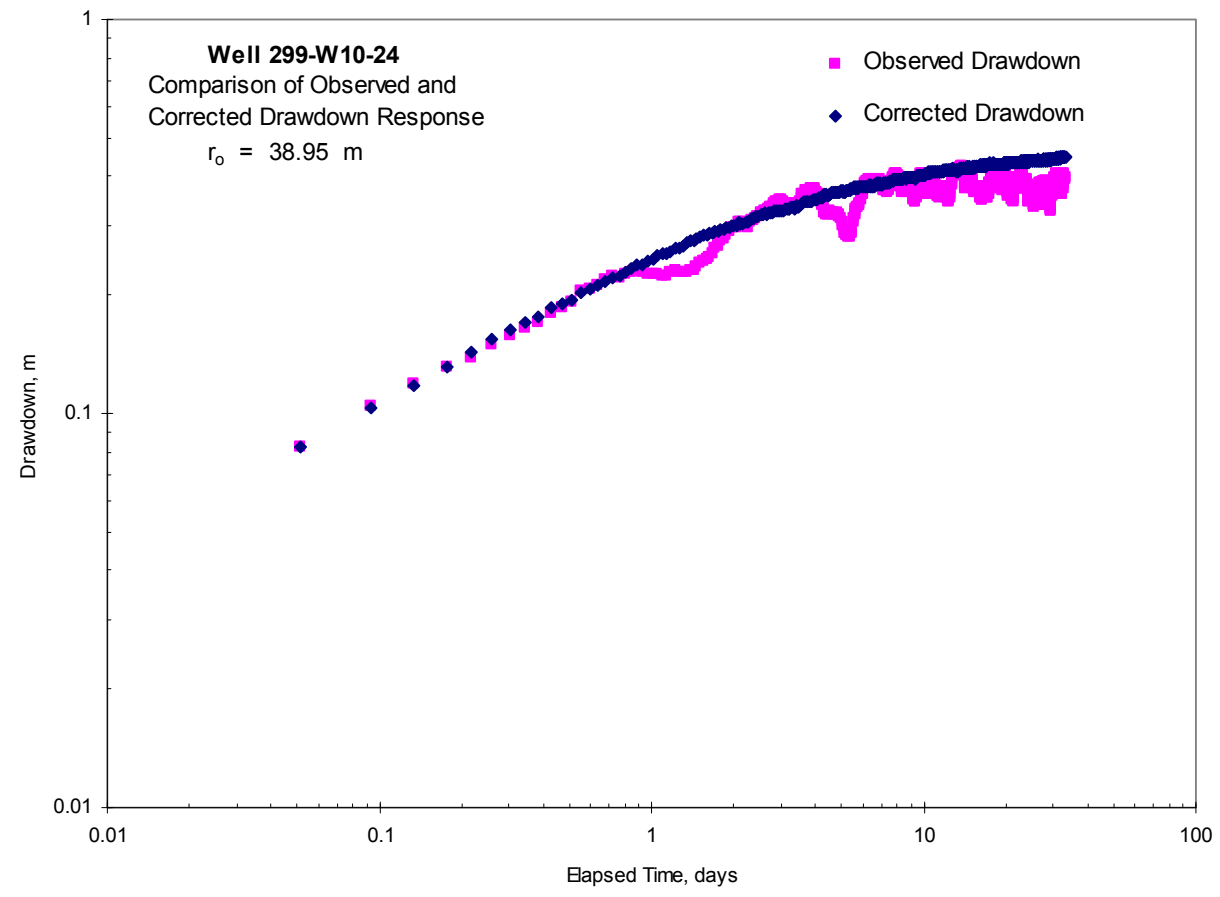

Figure D.2. Comparison of Observed and Barometric-Corrected Well Drawdown: Well 299-W10-24 


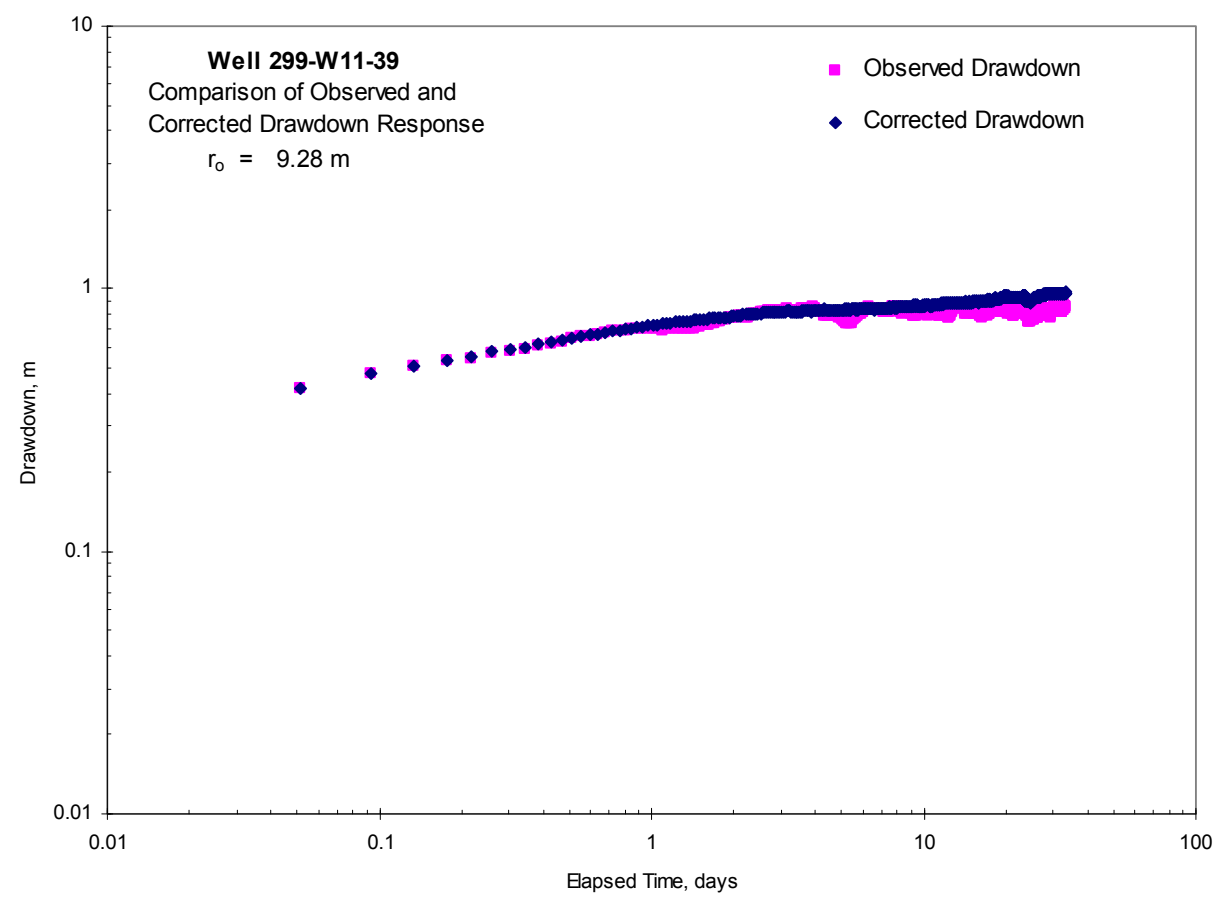

Figure D.3. Comparison of Observed and Barometric-Corrected Well Drawdown: Well 299-W11-39

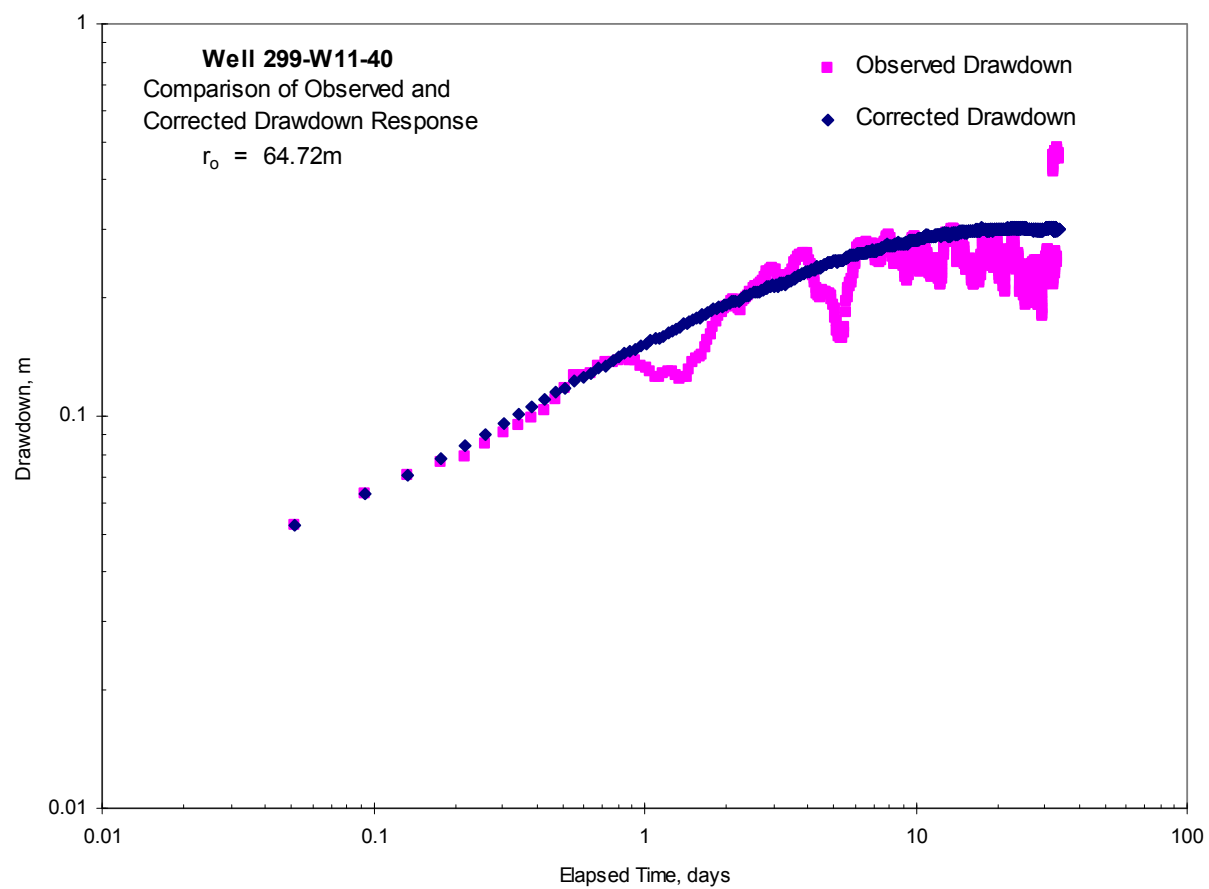

Figure D.4. Comparison of Observed and Barometric-Corrected Well Drawdown: Well 299-W11-40 


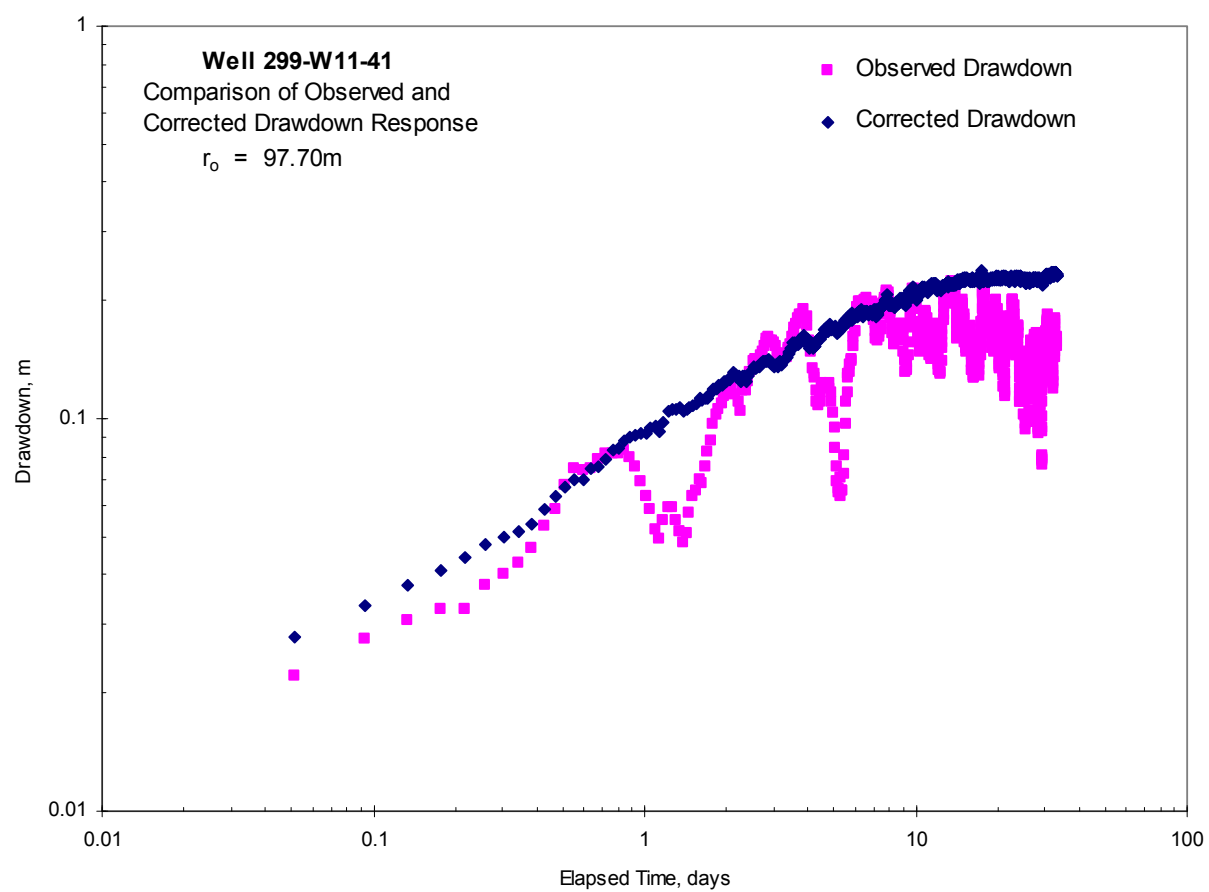

Figure D.5. Comparison of Observed and Barometric-Corrected Well Drawdown: Well 299-W11-41

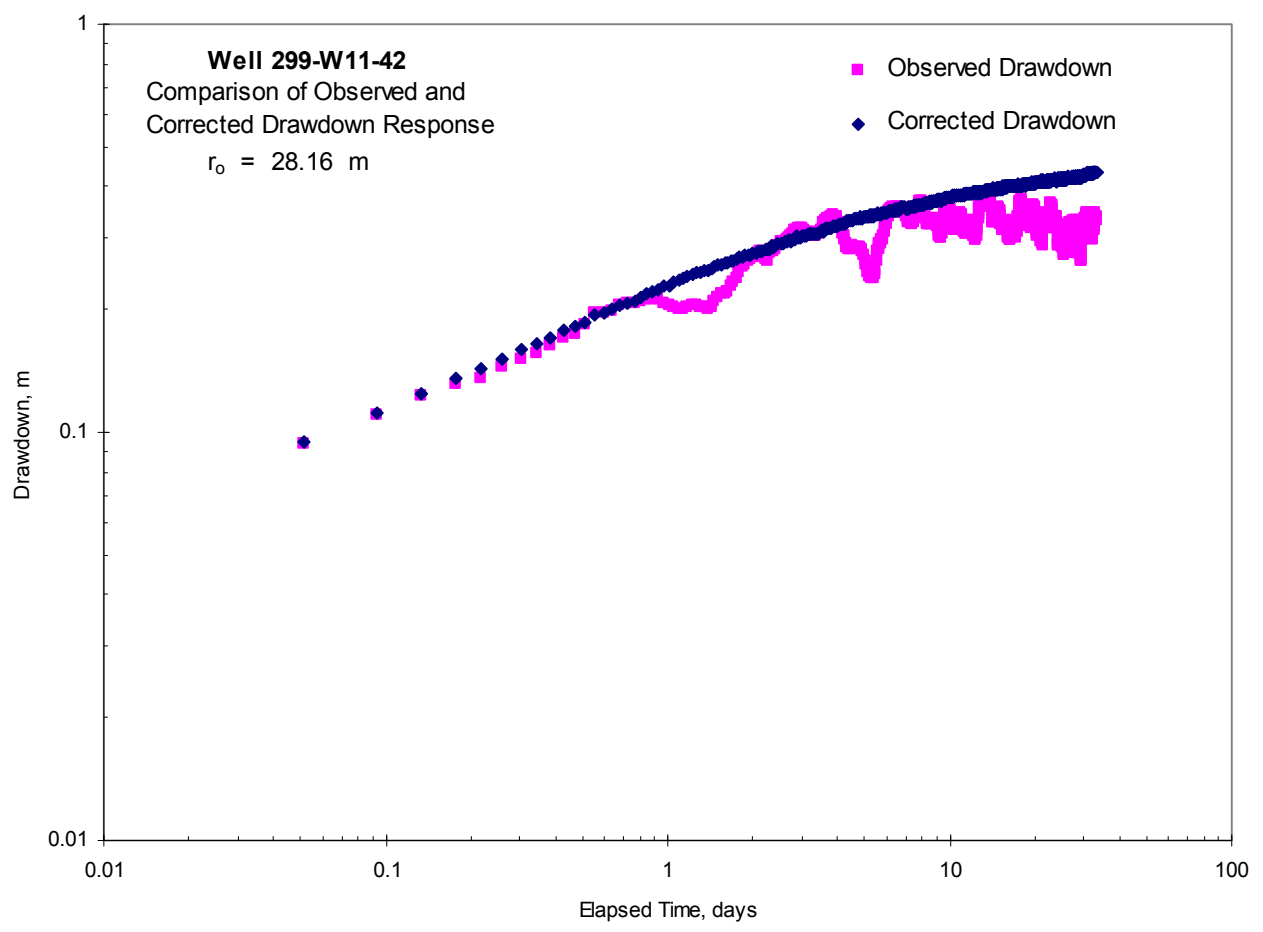

Figure D.6. Comparison of Observed and Barometric-Corrected Well Drawdown: Well 299-W11-42 


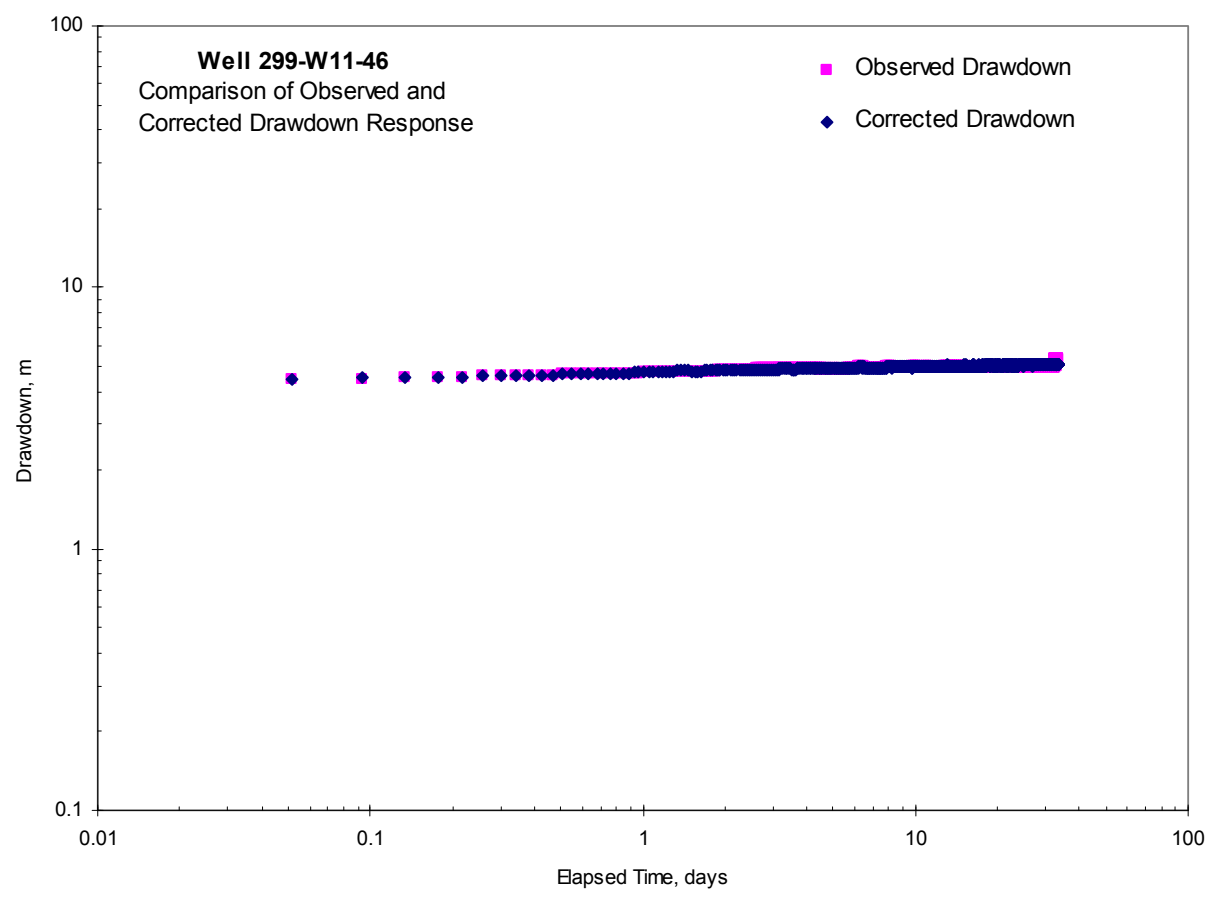

Figure D.7. Comparison of Observed and Barometric-Corrected Well Drawdown: Well 299-W11-46

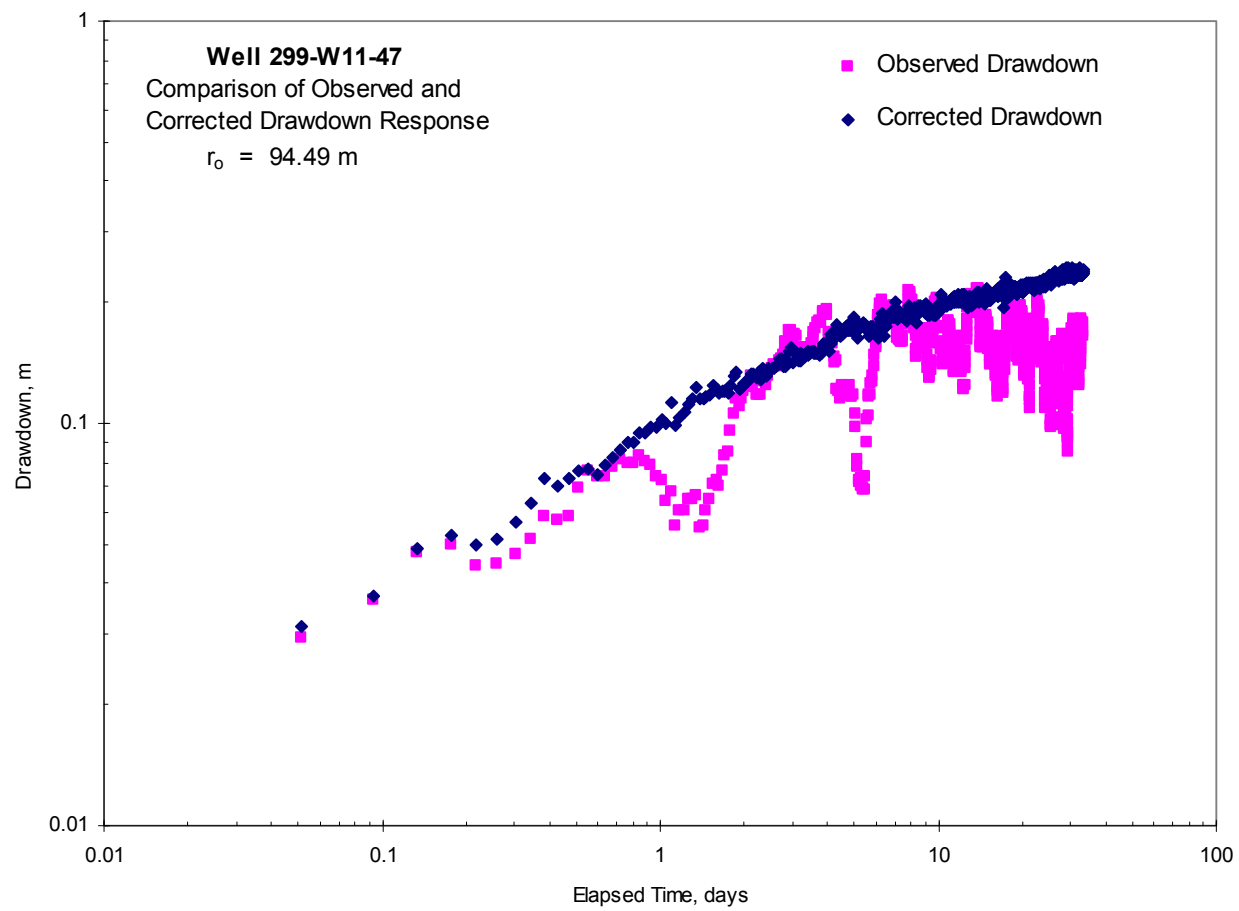

Figure D.8. Comparison of Observed and Barometric-Corrected Well Drawdown: Well 299-W11-47 


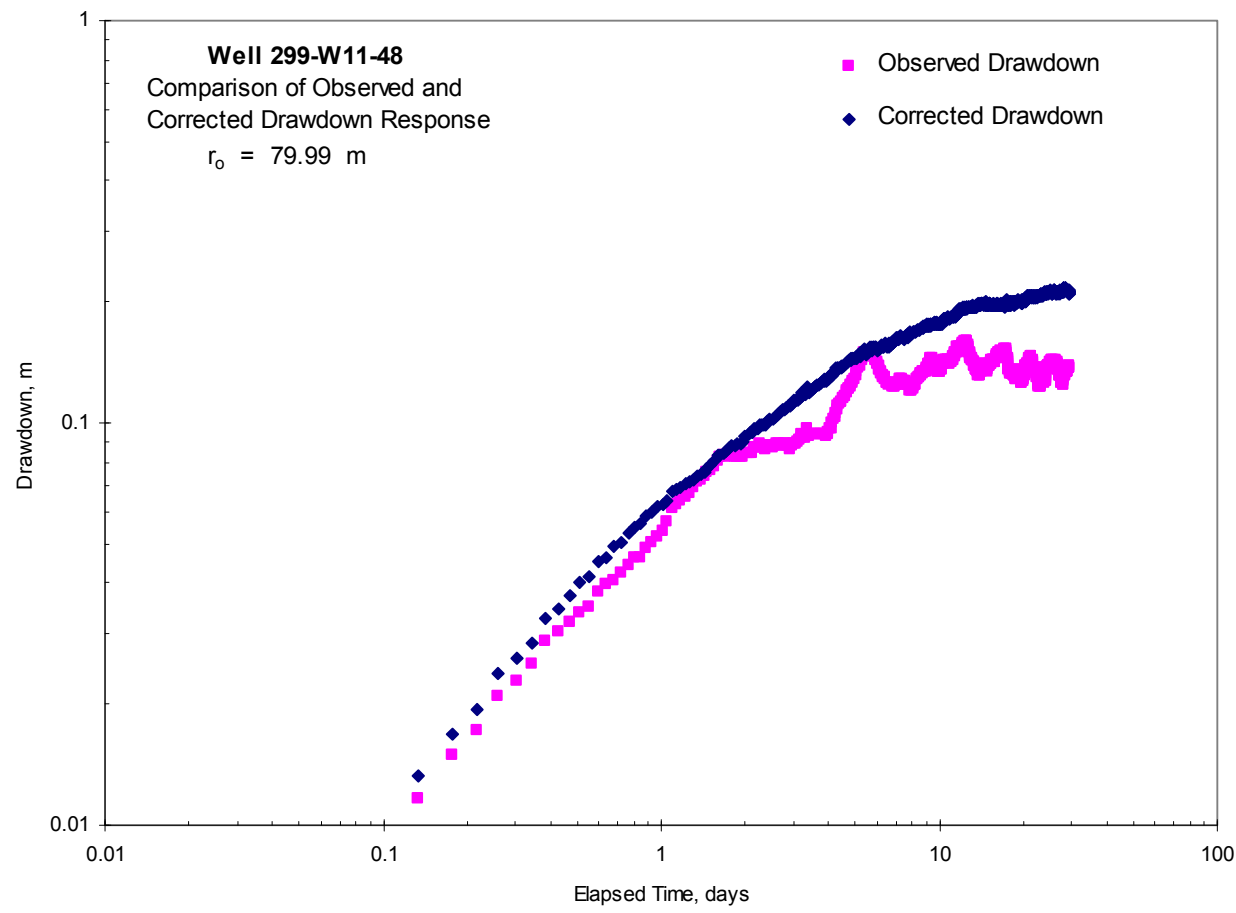

Figure D.9. Comparison of Observed and Barometric-Corrected Well Drawdown: Well 299-W11-48 
PNNL-17732

\section{Distribution}

No. of

Copies

OFFSITE

3 Vista Engineering 8203 W. Quinault

Building C, Suite 200

Kennewick, Washington 99336

Attn: Ken Moser

Wes Bratton

Craig Arola

1 S.S. Papadopulos \& Assoc., Inc. 7944 Wisconsin Avenue

Bethesda, MD, 20814

Tel: $3017188900 \times 258$

Fax: 3017188909

Cell: 5088159886

email: matt@sspa.com

Attn: Matt Tonkin (S.S. Papadopulos)

1 CH2M Hill Hanford Group, Inc.

Dave Myers

1 U.S. Department of Energy-Office of River

Protection

Bob Lober
No. of

Copies

ONSITE

$7 \quad$ Flour Hanford, Inc.

M. E. Byrnes E6-44

D. G. Horton E6-35

V. J. Rohay E6-44

L. C. Swanson E6-35

W. Elliott E6-44

D. B. Erb E6-35

R.S. Edrington E6-35

$4 \quad$ U.S. Department of Energy-Richland Operations

J. G. Morse A6-38

A. C. Tortoso A6-38

T.W. Fletcher A5-11

B. L. Charboneau A6-33

$5 \quad$ Pacific Northwest National Laboratory
F. A. Spane (2)
K6-96
T. J. Gilmore
K6-96
D. R. Newcomer K6-96
P. D. Thorne K6-96

Dist. 1 